\title{
Logaritmos e Função Logarítmica na Matemática Escolar Brasileira
}

\author{
Diogo Oliveira Soares
}

Dissertação apresentada ao Instituto de Matemática e Estatística da Universidade de São Paulo como requisito parcial para obtenção do título de Mestre em Ciências

Programa: Mestrado Profissional em Ensino de Matemática

Orientadora: $\operatorname{Prof}^{\mathrm{a}} \operatorname{Dr}^{\mathrm{a}}$ Circe Mary Silva da Silva Dynnikov

São Paulo, Março de 2017. 


\section{Logaritmos e Função Logarítmica na Matemática Escolar Brasileira}

Esta versão da dissertação contém as correções e alterações sugeridas pela Comissão Julgadora durante a defesa da versão original do trabalho, realizada no dia 29/03/2017. Uma cópia da versão original está disponível no Instituto de Matemática e Estatística da Universidade de São Paulo.

Comissão Julgadora:

- $\operatorname{Prof}^{\mathrm{a}} \operatorname{Dr}^{\mathrm{a}}$ Circe Mary Silva da Silva Dynnikov (orientadora) - IME-USP

- Prof. Dr. Henrique Marins de Carvalho - IF-SP

- Prof. Dr. Wagner Rodrigues Valente - UNIFESP 


\section{Agradecimentos}

Agradeço a Deus pela fé que tem me dado para seguir firme na caminhada dos estudos, do trabalho e da vida, podendo enfrentar as adversidades do dia-a-dia.

Agradeço a todos os meus familiares e amigos. Em especial: meus pais, Ednaldo e Nilza, meus tios, Damião e Elisa, minha irmã Daniele, minha prima Bruna e minha amiga Ana Olívia.

Agradeço a todos os meus professores, desde a pré-escola até o Mestrado. Em especial: prof. Dr. Henrique Marins de Carvalho, prof $^{a} \operatorname{Dr}^{a}$ Circe Mary Silva da Silva Dynnikov, prof. Dr. Antônio Carlos Brolezzi, prof ${ }^{a}$ Dr $^{a}$ Cristina Cerri e prof. Dr. Wagner Rodrigues Valente. 
"Os liuros são objetos transcendentes Mas podemos amá- los do amor táctil" (Caetano Veloso) 


\section{RESUMO}

\section{SOARES, D.O. Logaritmos e Função Logarítmica na Matemática Escolar Brasileira.}

2017. 98 f. Dissertação (Mestrado) - Instituto de Matemática e Estatística, Universidade de São Paulo, São Paulo, 2017.

Este trabalho tem o objetivo de verificar como o logaritmo e a função logarítmica são abordados nos livros didáticos de Matemática do século XIX ao XXI, indicando a inserção desses conteúdos na Matemática Escolar brasileira. Baseamo-nos, dentre outros autores, em Choppin (2004), Valente (1999, 2004, 2005 e 2008) e Bittencourt (2004 e 2008) para identificarmos o livro didático como fonte de pesquisa da Matemática Escolar, a partir de suas formas conceituais, de enfoque didático ou referente à organização do saber. A fim de verificar relações entre o histórico dos logaritmos e da função logarítmica na Matemática e na Matemática Escolar, apresentamos a ideia dos logaritmos de Napier como facilitadores de cálculos, interpretamos sua definição geométrica por meio de um sistema de equações diferenciais ordinárias e, assim, mostramos um breve histórico sobre a inserção do logaritmo como função no Cálculo Integral. Os livros didáticos de Matemática analisados foram publicados entre os anos de 1879 e 2013. Nesta análise, consideramos o modo como os autores abordam ou tratam a Matemática, os tipos de atividades que são propostas, os tipos de explicações, definições, exemplos, gráficos, exercícios, aplicações e problemas associados aos logaritmos e à função logarítmica. Os resultados apontam que no século XIX os logaritmos eram tratados nos livros didáticos, quase sempre, por meio da Aritmética. A partir da década de 1890, eles são abordados, tanto no campo aritmético, pela associação à teoria das progressões, como no campo algébrico, sendo expoentes numa equação ou função. A partir da década de 1930 até os dias de hoje verificamos uma predominância da concepção algébricofuncional dos logaritmos. Com base nas Orientações Curriculares para o Ensino Médio (2006), nos Parâmetros Curriculares Nacionais - Ensino Médio (PCN's - 2000), nos Parâmetros Curriculares Nacionais+ Ensino Médio (PCN's+ Ensino Médio - 2002), no Exame Nacional do Ensino Médio e em livros didáticos recentes, verificamos que os logaritmos e a função logarítmica se inserem, atualmente, na Matemática Escolar brasileira, pela sua associação às aplicações, como por exemplo, juros compostos, dinâmica populacional, desintegração radioativa, potencial hidrogeniônico, Escala Richter, Escala de Magnitude de Momento (MMS) e nível de intensidade sonora.

Palavras-chaves: Logaritmos; Função Logarítmica; Livros didáticos; Matemática Escolar. 


\begin{abstract}
SOARES, D.O. Logarithms and Logarithmic Function in Brazilian School Mathematics. 2017. 98 f. Dissertação (Mestrado) - Instituto de Matemática e Estatística, Universidade de São Paulo, São Paulo, 2017.

This work aims to verify how the logarithm and logarithmic function are approached in the textbooks of Mathematics from the 19th to the 21st century, indicating the insertion of these contents in Brazilian School Mathematics. We are based, among other authors, in Choppin (2004), Valente (1999, 2004, 2005 and 2008) and Bittencourt (2004 and 2008) to identify the didactic book as a research source of School Mathematics, from its conceptual forms, of didactic approach or referring to the organization of knowledge. In order to verify relations between the logarithmic and logarithmic functions in Mathematics and School Mathematics, we present the idea of the logarithms of Napier as facilitators of calculations, we interpret their geometric definition by means of a system of ordinary differential equations and we show a brief history about the insertion of the logarithm as a function in the Integral Calculus. The mathematical textbooks analyzed were published between the years 1879 and 2013. In this analysis, we consider how authors approach or treat mathematics, the types of activities that are proposed, the types of explanations, definitions, examples, graphs, exercises, applications and problems associated with logarithms and logarithmic function. The results show that in the 19th century, logarithms were treated in textbooks, almost always, through Arithmetic. From the 1890s, they are approached, both in the arithmetic field, by association with the theory of progressions, and in the algebraic field, being exponents in an equation or function. From the 1930s to the present day we have found a predominance of the algebraicfunctional conception of logarithms. Based on the Curriculum Guidelines for Secondary Education (2006), the National Curriculum Parameters - Secondary Education (PCN's 2000), the National Curriculum Parameters + High School (PCN's + High School - 2002), the National High School Examination and textbooks recent, we have verified that the logarithms and the logarithmic function are currently inserted in Brazilian School Mathematics, by their association to the applications, such as compound interest, population dynamics, radioactive disintegration, hydrogen ionic potential, Richter Scale, Momentum Magnitude Scale (MMS) and level of sound intensity.
\end{abstract}

Keywords: Logarithms; Logarithmic Function; Textbooks; School Mathematics. 


\section{SUMÁRIO}

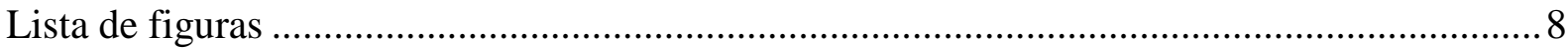

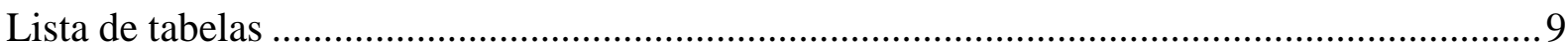

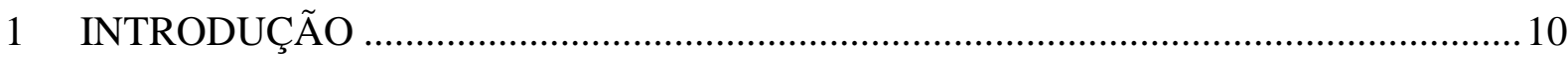

2 CONSIDERAÇÕES TEÓRICO - METODOLÓGICAS …........................................... 13

3 LOGARITMO E FUNÇÃO LOGARÍTMICA NA HISTÓRIA DA MATEMÁTICA.... 26

3.1 Introdução dos logaritmos na História da Matemática .......................................................26

3.2 Introdução da função logarítmica na História da Matemática........................................... 30

4 LOGARITMO E FUNÇÃO LOGARÍTMICA EM LIVROS DIDÁTICOS DE

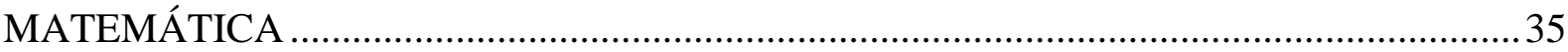

4.1 O logaritmo e a função logarítmica em livros didáticos de Matemática: da $2^{\mathrm{a}}$ metade do

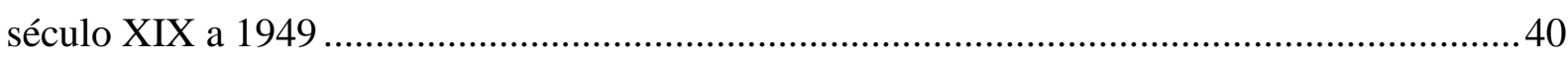

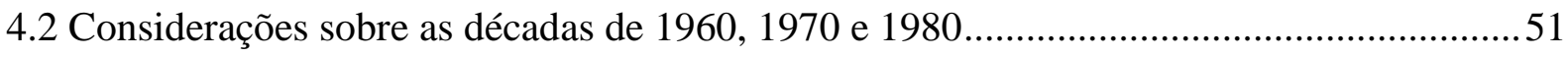

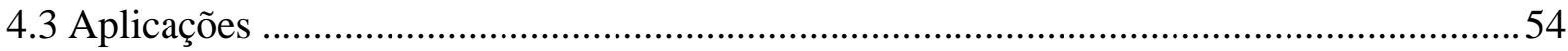

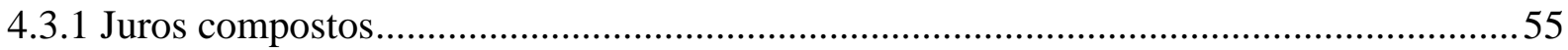

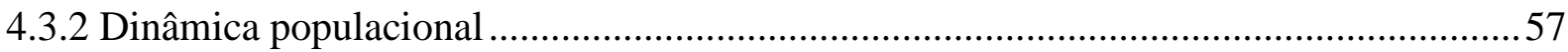

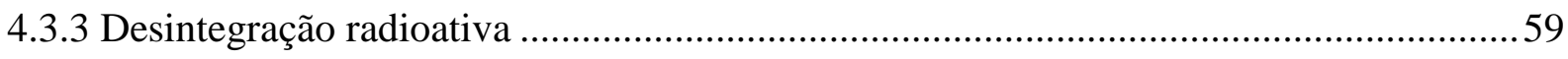

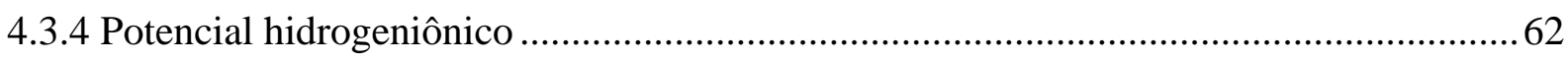

4.3.5 Escala Richter e Escala de Magnitude de Momento (MMS) ........................................63

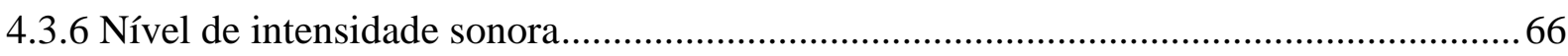

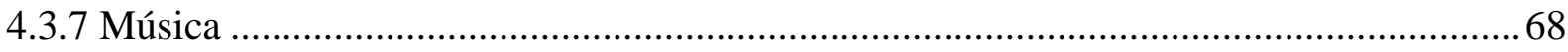

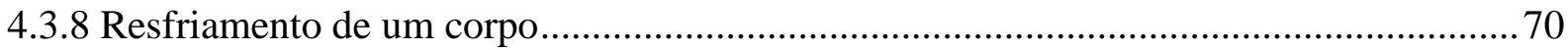

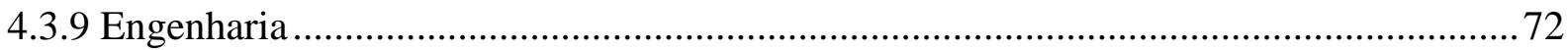

4.4 A concepção aritmética e algébrico-funcional em abordagens atuais .............................. 75

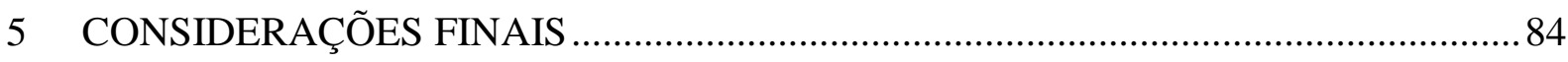

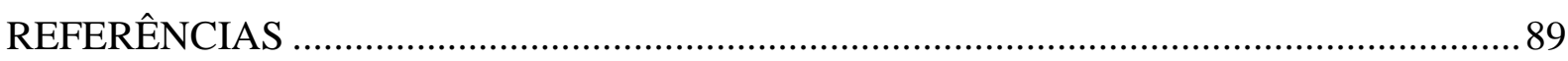




\section{Lista de figuras}

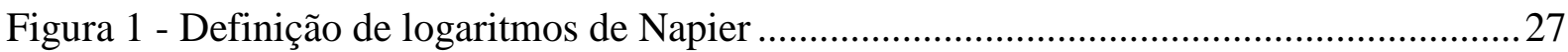

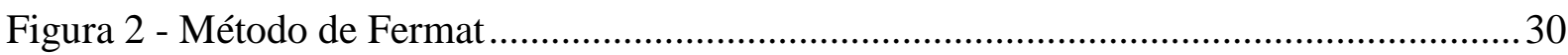

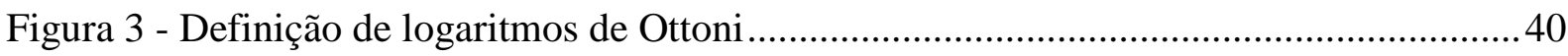

Figura 4 - Definição de logaritmos de Viana .................................................................... 41

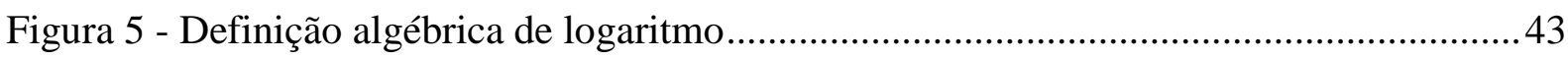

Figura 6 - Definição de função logarítmica de Matemática $2^{o}$ Ciclo - $2^{a}$ série ....................... 46

Figura 7 - Definição de logaritmo de Matemática $2^{o}$ Ciclo $-2^{a}$ série ...................................... 46

Figura 8 - Exercícios propostos em Matemática $2^{\circ}$ Ciclo $-2^{a}$ série …..................................... 47

Figura 9 - Definição de função logarítmica de Matemática Segunda Série - Curso Colegial

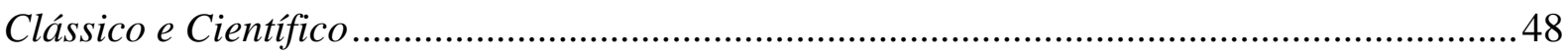

Figura 10 - Gráfico de função logarítmica e exponencial de Matemática Segunda Série -

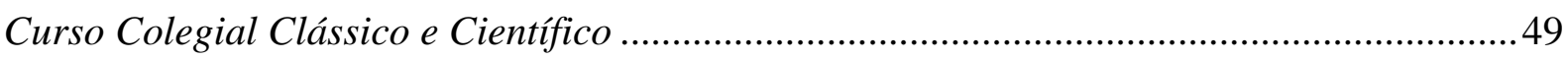

Figura 11 - Gráfico de função logarítmica em Aulas Práticas de Matemática - $2^{\circ}$ grau .........53

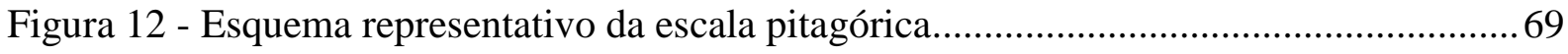

Figura 13 - Esquema representativo da escala temperada ou cromática ................................. 70

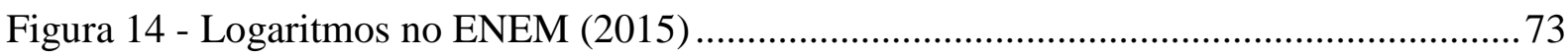

Figura 15 - Resolução de questão do ENEM (2015) ............................................................. 73

Figura 16 - Logaritmos e função logarítmica no Currículo do Estado de São Paulo ............... 75

Figura 17 - A função logarítmica no Caderno do aluno ......................................................... 77

Figura 18 - Relação entre a função logarítmica e a exponencial de Conexões com a

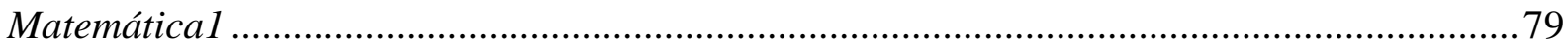

Figura 19 - Aplicações dos logaritmos de Conexões com a Matemática 1 .............................. 80 


\section{Lista de tabelas}

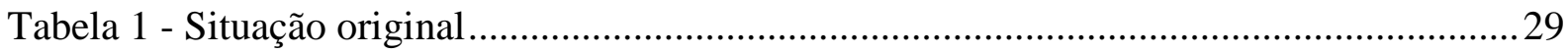

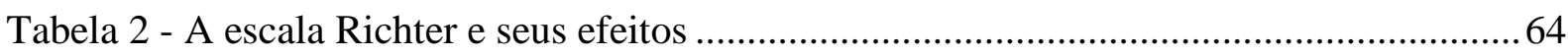

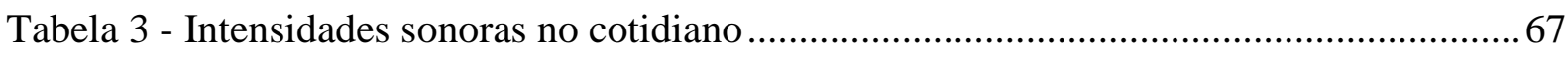

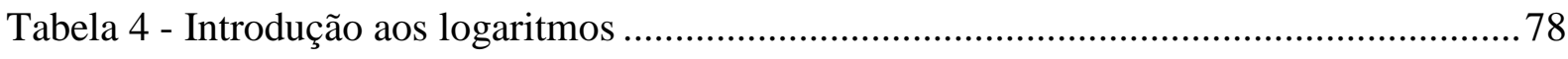

Tabela 5 - Síntese da inserção dos logaritmos e da função logarítmica na Matemática Escolar

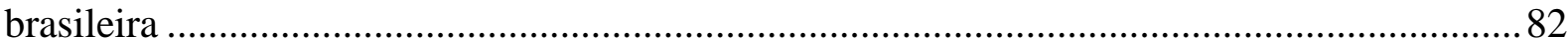

Tabela 6 - Síntese da inserção dos logaritmos e da função logarítmica na Matemática Escolar

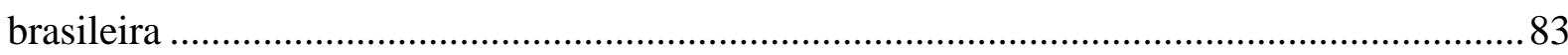




\section{INTRODUÇÃO}

Com o advento das calculadoras e o avanço da tecnologia, nota-se que o logaritmo não está associado somente à sua aplicação como facilitador de cálculos. Apesar de sua origem estar relacionada a fins aritméticos, há algum tempo os logaritmos ultrapassam esses limites.

Com base nas Orientações Curriculares para o Ensino Médio (2006), nos Parâmetros Curriculares Nacionais - Ensino Médio (PCN's - 2000), nos PCN's+ Ensino Médio (2002) e e no ENEM, acreditamos que, atualmente, a presença dos logaritmos no ensino e nas Propostas Curriculares se justifica principalmente pela aplicabilidade da função logarítmica, pois, assim como a sua inversa, a exponencial, ela está associada a modelos que descrevem matematicamente certos fenômenos de variação. Podemos citar alguns desses modelos, como problemas de juros compostos, estudo quantitativo da relação entre a altura e frequência dos sons emitidos por notas musicais, a alcalinidade de uma solução química, o estudo dos níveis de intensidade sonora, dentre outros.

Conforme as Orientações Curriculares para o Ensino Médio (2006), ao final do Ensino Médio, espera-se que, dentre outros propósitos da formação matemática na educação básica, os alunos saibam modelar fenômenos em outras áreas do conhecimento, percebam a Matemática como um conhecimento social e historicamente construído e saibam apreciar a importância da Matemática no desenvolvimento científico e tecnológico.

Segundo os PCN's+ Ensino Médio (2002), a evidência de linguagens, usadas em comum por diversas disciplinas científicas, permite ao aluno perceber sua universalidade e, consequentemente, distinguir especificidades desses usos. Exemplo disso é o logaritmo, pois, além de dar origem a funções matemáticas, conforme os PCN's+ Ensino Médio (2002), também é linguagem de representação em todas as ciências.

Assim, a pesquisa sobre a inserção do logaritmo e da função logarítmica como conteúdos da Matemática Escolar torna-se necessária, pois a partir disso poderá ser verificado porque é importante o ensino e a aprendizagem desses conteúdos, como eles se estabeleceram em relação às abordagens atuais e antigas dos livros didáticos que apresentam esses temas, quais fatos importantes implicaram nas mudanças e permanências desses conteúdos e de que

\footnotetext{
${ }^{1}$ Parâmetros Curriculares Nacionais+ Ensino Médio: Orientações Educacionais Complementares aos Parâmetros Curriculares Nacionais.
} 
forma a História da Matemática e as concepções verificadas na Matemática Escolar se associam.

Desse modo, este trabalho busca responder a questão de como o logaritmo e a função logarítmica são abordados nos livros didáticos de Matemática do século XIX ao XXI.

No decorrer desta pesquisa, foi possível aprofundar algumas ideias do Trabalho de Conclusão de Curso de Licenciatura em Matemática do Instituto Federal de São Paulo, elaborado em 2012 e intitulado Logaritmos: Napier versus Dante, no qual pudemos verificar o que permaneceu e o que mudou, tanto do ponto de vista matemático como didático, em relação à primeira obra sobre logaritmos, Mirifici Logarithmorum Canonis Descriptio, publicada em 1614, por John Napier (1550-1617), e em relação ao livro didático de Luiz Roberto Dante, Matemática: Contexto e Aplicações, de 1999.

No presente trabalho, procuramos dar ênfase à inserção do logaritmo e da função logarítmica na Matemática Escolar, a partir da análise de livros didáticos. Para desenvolver a pesquisa, dividimos o trabalho do seguinte modo:

- Considerações teórico-metodológicas, em que apresentamos os autores nos quais nos embasamos para desenvolver este trabalho, bem como mostramos a importância do livro didático não só como recurso didático, mas também como fonte de pesquisa da Matemática Escolar, evidenciando o modo pelo qual podemos desenvolver esta pesquisa e trabalhar com as diversas fontes.

- Logaritmo e Função logarítmica na História da Matemática, no qual apresentamos um breve esboço histórico sobre o logaritmo e a função logarítmica na Matemática, a fim de, nos capítulos posteriores, estabelecer relações entre esse histórico e a inserção de tais conteúdos na Matemática Escolar. Assim, mostramos a ideia dos logaritmos de Napier como facilitadores de cálculos, interpretamos sua definição geométrica por meio de um sistema de equações diferenciais ordinárias e apresentamos a inserção do logaritmo como função na História da Matemática, por meio do Cálculo Integral.

- Logaritmo e Função Logarítmica em livros didáticos de Matemática, em que mostramos uma análise da Matemática Escolar a partir das obras didáticas de 1879 até 2013, estudando a forma pela qual os autores abordam ou tratam a Matemática, por meio da associação dos logaritmos e da função logarítmica. Neste capítulo, primeiramente, expomos o 
tratamento do logaritmo e da função logarítmica em livros didáticos, a partir de 1879 até 1949. Em seguida, tecemos algumas considerações sobre as décadas de 1960, 1970 e 1980 . A partir das observações das Orientações Curriculares para o Ensino Médio (2006) e dos PCN's+ Ensino Médio (2002), apresentamos algumas aplicações de logaritmos e função logarítmica e o modo como elas aparecem no contexto da Matemática Escolar atual. Por fim, analisamos duas abordagens atuais nas quais predominam a concepção algébrico-funcional do logaritmo, porém, há uma tentativa de resgatar a concepção aritmética, por meio da história dos logaritmos.

- Considerações finais, em que apresentamos os resultados obtidos, levando em consideração aspectos que foram analisados e que servem como base para compreender de que modo o logaritmo e a função logarítmica são abordados nos livros didáticos de Matemática do século XIX ao XXI. A partir disso, procuramos mostrar como este trabalho pode contribuir para a formação do professor. 


\section{CONSIDERAÇÕES TEÓRICO - METODOLÓGICAS}

"Matemática Escolar é a expressão da própria Matemática no âmbito da escola, do meio escolar" (VALENTE, 2005, p. 23). Com essa ideia, podemos situar o gênero discursivo da Matemática Escolar a partir da práxis comunicativa que se instaura nos processos de ensino-aprendizagem da Matemática nos contextos escolares, práxis de alunos, professores, autores de livros didáticos, especialistas responsáveis pela proposição de programas de ensino e linhas de trabalho pedagógico, que, como sujeitos, interagem nessa esfera específica da convivência humana, que envolve não apenas as aulas de Matemática, como também a produção, a veiculação e a utilização de materiais de destinação didática e prescritiva para esses processos.

A partir dessa perspectiva, segundo Valente (1999, p. 20), temos “os livros didáticos como um lugar privilegiado da matemática escolar" e o

estudo dos livros didáticos, como fontes de pesquisa da cultura escolar, da
matemática escolar, precisa revelar como historicamente as múltiplas esferas não
escolares foram interferindo e sendo apropriadas pela escola para a sua
transformação em produto de sua cultura (VALENTE, 2004, p.81).

Como buscamos responder de que modo o logaritmo e a função logarítmica são abordados nos livros didáticos de Matemática do século XIX ao XXI, adotamos uma metodologia baseada na pesquisa bibliográfica e documental, visando compreender mudanças e permanências que permeiam o tema, tomando os livros didáticos de Matemática como as principais referências para este estudo.

Para Corrêa (2000), a utilização do livro didático como objeto e fonte de pesquisa enseja a investigação da circulação de ideias a respeito daquilo que a escola deveria ensinar, possibilitando também conhecer a concepção educativa que estaria permeando as propostas de formação dos sujeitos escolares, por meio das possíveis indagações a serem feitas em relação ao conteúdo ou discurso, considerando aspectos como temporalidade e espaço, vinculando-se, assim, à história das instituições escolares.

A fim de acompanhar a trajetória do Ensino de Matemática no Brasil e dos livros didáticos, é necessário situar os livros didáticos como fonte de pesquisa. Segundo Alonso et al (2012, p.2), “em tempos de História Cultural, os livros didáticos tornaram-se fontes de fundamental importância para a escrita do trajeto histórico de qualquer disciplina e, em especial, da disciplina Matemática”. 
Como este trabalho tem como principal fonte de pesquisa o livro didático, apoiamonos, dentre outros autores, em Choppin (2004), para identificar a importância do mesmo para o ensino:

\begin{abstract}
A concepção de um livro didático inscreve-se em um ambiente pedagógico específico e em um contexto regulador que, juntamente com o desenvolvimento dos sistemas nacionais ou regionais, é, na maioria das vezes, característico das produções escolares (edições estatais, procedimentos de aprovação prévia, liberdade de produção, etc) (CHOPPIN, 2004, p. 554).
\end{abstract}

Com isso, podemos verificar que o livro didático tem grande importância na educação escolar, pois sua utilização permite a ampliação do conhecimento, o que torna o livro não só um recurso didático, mas também uma fonte de pesquisa, uma vez que ele evidencia abordagens da época de sua publicação.

Um livro aberto pode ensejar múltiplas possibilidades de leituras, dependendo das intenções e motivações do leitor. O livro didático de matemática não foge à regra, podendo ser, por exemplo, uma das fontes privilegiadas de conhecimento da História da Educação Matemática. Entretanto, não faz mais de trinta anos que os livros didáticos conquistaram esse estatuto e se converteram em objeto de pesquisa (SILVA, 2015, p. 378).

No contexto escolar, no que se refere a recursos metodológicos, os livros didáticos se destacam e, muitas vezes, são utilizados pelos professores no processo de ensino e aprendizagem. Os livros didáticos podem ser considerados como difusores de circulação de ideias que auxiliam na construção de valores e conhecimentos os quais se pretende ensinar.

Embora o livro didático seja um material que contém muitas informações, ele não esgota todas as especificidades e necessidades encontradas em um determinado contexto escolar. Somente a sua utilização não é suficiente, faz-se necessário a busca por outras metodologias com o intuito de complementar a prática docente, bem como proporcionar aos alunos a possibilidade de participação na construção de seu aprendizado.

Entretanto, o livro didático não deixa de ser um parâmetro para se saber quais os conteúdos que eram propostos em determinada época e nos dias atuais, o que motivava e motiva a transmissão desses conteúdos e quais as permanências e mudanças observadas nos programas curriculares.

Acreditamos que esta pesquisa permite um avanço na compreensão de como o logaritmo e a função logarítmica se inserem na Matemática Escolar, pois o livro didático possibilita veicular os conteúdos explícitos ao processo de ensino-aprendizagem. 
O livro se caracteriza por si só em um objeto histórico, cultural, social, educativo e didático. Para Choppin (2004), estes elementos são expressos pelos autores de livros didáticos, ainda que seja indiretamente.

Contudo, em relação aos autores, acreditamos que não é possível, nesta pesquisa, atentarmo-nos apenas às questões que se referem ao que eles escrevem, "é necessário também prestar atenção àquilo que eles silenciam, pois se o livro didático é um espelho, pode ser também uma tela" (CHOPPIN, 2004, p. 557).

A produção didática, de meados do século XIX até os dias atuais, tem neste estudo o foco no ensino do logaritmo e da função logarítmica, e a análise será, principalmente, a partir das concepções de Choppin:

O livro didático não é um simples espelho: ele modifica a realidade para educar as novas gerações, fornecendo uma imagem deformada, esquematizada, modelada, frequentemente de forma favorável: as ações contrárias à moral são quase sempre punidas exemplarmente; os conflitos sociais, os atos delituosos ou a violência cotidiana são sistematicamente silenciados. E os historiadores se interessam justamente pela análise dessa ruptura entre a ficção e o real, ou seja, pelas intenções dos autores (CHOPPIN, 2004, p.557).

Com o crescimento do interesse pelo livro didático a partir da década de 60, o mercado editorial desses livros ultrapassa fronteiras por meio do impulso do acúmulo do capital e da escolarização em massa. Concomitantemente, no campo ideológico, aumenta a disputa conceitual entre educação como mercadoria e como formação sob a responsabilidade do Estado.

Com isso, segundo Choppin (2004), os livros didáticos assumem quatro funções essenciais, que resumimos a seguir, e que podem variar consideravelmente segundo o ambiente sociocultural, a época, as disciplinas, os níveis de ensino, os métodos e as formas de utilização:

1) Função referencial: o livro didático é a tradução dos programas de ensino, leis e decretos, constituindo o depositário de conhecimentos, técnicas ou habilidades a serem transmitidas às novas gerações.

2) Função instrumental: o livro didático propicia a aquisição de habilidades e a apropriação de competências, por meio de atividades que buscam a memorização dos conhecimentos. 
3) Função ideológica e cultural: o livro didático é instrumento privilegiado de construção de identidade, reconhecido como um símbolo da soberania nacional, assumindo um importante papel político.

4) Função documental: o livro didático, por meio de sua observação ou confrontação, pode desenvolver a criticidade do aluno. Essa função é encontrada em ambientes pedagógicos que privilegiam a autonomia do aluno.

Nesta pesquisa utilizaremos principalmente a função instrumental, por meio da qual pretendemos verificar como os logaritmos e a função logarítmica permeiam os livros, ou seja, como os resultados são apresentados e exemplificados, como os gráficos e os exercícios são usados e como são abordadas as definições e aplicações.

Atemo-nos também à função referencial, baseando-nos no Decreto nº 981 de 1890, que diz respeito à Reforma da Educação Brasileira, proposta por Benjamin Constant, bem como nos apoiamos no programa de ensino de 1915 extraído de Gussi (2011), no Decreto 19890 de 18 de abril de 1931, dentro da Reforma Francisco Campos, na Portaria Ministerial de 17 de março de 1936, sobre os programas propostos para o Curso Complementar, nos Parâmetros Curriculares Nacionais (2000), nos Parâmetros Curriculares Nacionais+ Ensino Médio (2002), nas Orientações Curriculares para o Ensino Médio (2006) e no Currículo do Estado de São Paulo (2011).

Segundo Valente (2008), a utilização de livros didáticos como fonte de pesquisa para a história da Matemática Escolar no Brasil pode se limitar pela busca de produções inovadoras que surgem como meios que conduzem uma nova visão para o ensino de Matemática. A busca, num determinado período histórico, por livros didáticos inovadores, representa uma condição necessária para a escrita da trajetória histórica de um determinado saber.

No entanto, segundo Valente (2008), essa condição não é suficiente, pois se levarmos em consideração que alguns livros, quando comparados com outros de mesma época, apresentam pouca variação na organização da sequência de capítulos, no conjunto de exemplos utilizados ou nos tipos de exercícios praticados, estamos diante do que Chervel (1990) denomina como fenômeno da vulgata escolar. 
Isso ocorre quando o pesquisador de uma determinada disciplina se depara com épocas em que a produção didática se mostra estável, sem muitas mudanças no que se refere principalmente aos conceitos ensinados.

Segundo Valente (2008, p.143), isso "nos leva pensar que a história da educação matemática se liga diretamente às transformações das vulgatas. Investigar como ocorreram essas transformações implicará investigar a própria história da educação matemática".

Com essas considerações, podemos inferir que os livros didáticos são elementos essenciais para a pesquisa histórica da Educação Matemática, assim como a ideia de vulgata é adequada ao tratamento didático e metodológico que os autores utilizam para abordar alguns conteúdos fixados nos livros didáticos.

Bittencourt (2008) explica que programas curriculares e livros didáticos se auxiliaram na elaboração dos conteúdos das disciplinas a serem utilizados pela educação formal. Com a consolidação das disciplinas escolares, a partir do século XIX, os programas de ensino passaram a preceder a elaboração dos livros.

Segundo Bittencourt (2008), o livro escolar era importante para organizar saberes dispersos, provenientes do mundo erudito, e que serviriam para preparar a formação de futuras gerações.

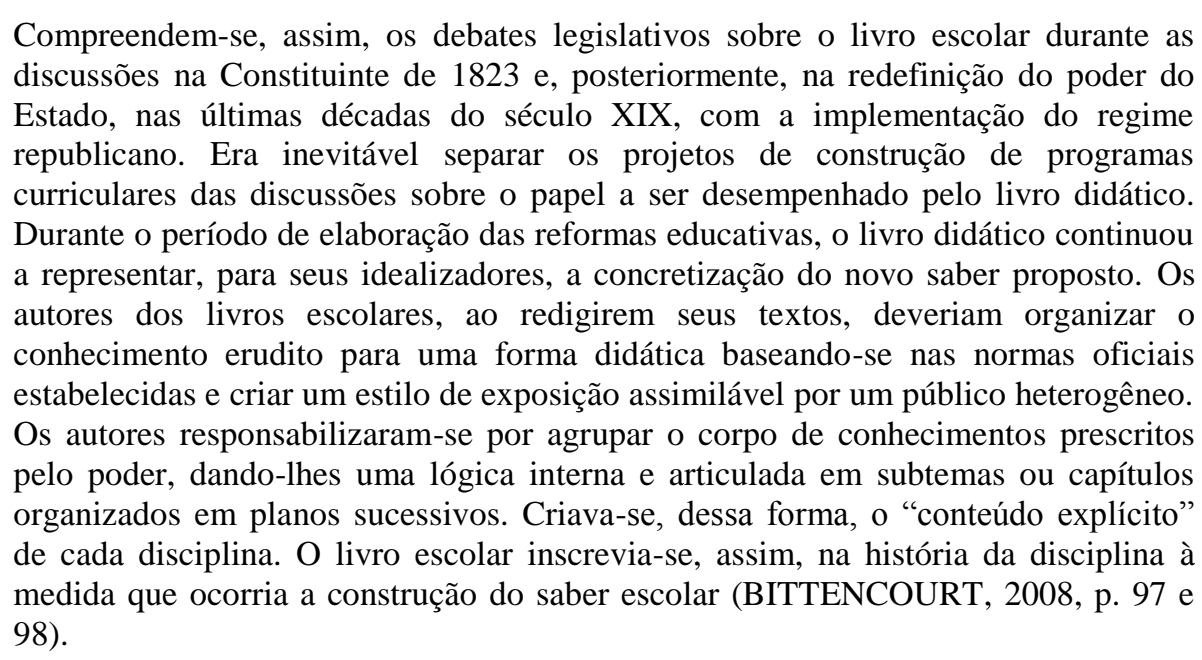

Então, a partir da construção deste saber escolar, o livro didático também serve como referência de conteúdo para alunos e professores, como representação das propostas curriculares oficiais e como mecanismo do processo de ensino-aprendizagem. 
Segundo Choppin (2004), atualmente o livro didático pode ser uma fonte de análise da História da Educação, assim como também se refere à necessidade de populações em criar ou resgatar uma identidade cultural, na qual ele exerce uma posição fundamental, como meio de produção social conduzido por uma gama de valores.

A pesquisa sobre livros didáticos deve, portanto, assumir múltiplas facetas. Logo, a "leitura de um livro é ato contraditório, e estudar seu uso é fundamental para o historiador compreender a dimensão desse objeto cultural” (BITTENCOURT, 2008, p. 15).

Entretanto, no caso deste trabalho, temos a faceta da Matemática. Temos como objeto de estudo o livro didático de Matemática, com todas as suas particularidades, propenso às influências sociais e políticas.

Choppin (2004) aponta que a pesquisa sobre livros didáticos, de modo geral, está baseada na análise científica do conteúdo, caracterizada por duas tendências: a crítica ideológica e cultural, bem como a análise epistemológica do que está contido no livro didático.

Em relação à crítica ideológica e cultural, Choppin (2004, p.556) considera que as análises "trazem respostas ou ao menos esclarecimentos às questões que a sociedade contemporânea coloca". Em contrapartida, a análise epistemológica tem por característica a fixação em uma disciplina determinada, que possui suas próprias finalidades, suas abordagens e metodologias específicas. Neste trabalho, atemo-nos principalmente à análise epistemológica, por tratarmos de livros didáticos de Matemática, considerando suas especificidades, abordagens e métodos adotados.

Segundo Valente (2008), a dependência de um curso de Matemática aos livros didáticos ocorreu desde as aulas iniciais que originaram a Matemática ensinada atualmente na Educação Básica. Isso significa que há uma relação direta entre os livros didáticos de Matemática e o desenvolvimento do ensino de Matemática no Brasil.

Atualmente, o livro didático de Matemática apresenta características distintas, por exemplo, em relação aos livros de cinquenta anos atrás, tanto no que se refere ao conteúdo quanto às metodologias e concepções adotadas. Considerando as quatro dimensões do livro didático, propostas por Bittencourt (2004) - produto cultural, mercadoria, suporte de conteúdos e método de ensino, veículo portador de valores - torna-se necessário compreender 
como elas se relacionaram ao longo de um dado período, isto é, estando conectadas essas quatro dimensões, temos como foco o entendimento de como elas se estabeleceram no período estudado, quais mudanças e permanências que elas acarretaram ao longo dos anos.

A definição e a classificação dos livros didáticos podem ser tarefas complicadas, pois eles assumem várias funções e apresentam distintas visões. Choppin (2004) aponta para a necessidade de se optar por uma perspectiva comparativa e histórica, a fim de superar a visão imediatista e idealizada dos livros didáticos.

Conforme Ossenbach e Sormoza (2001), Alain Choppin classifica os livros didáticos em duas categorias: os que são destinados somente ao uso escolar e os que adquirem essa dimensão pelo uso que a escola faz deles.

Portanto, podemos assumir que livros didáticos são aqueles que se utilizam na escola, mas com motivações e finalidades que vão além da instituição escolar, são compreendidos, segundo Ossenbach e Sormoza (2001), como instrumentos didáticos mediadores e reguladores entre um saber específico e os sujeitos participantes do processo educacional.

Assim, é possível afirmar que nos livros didáticos existe um conjunto de técnicas, pois, através dos textos, das figuras e dos exemplos, uma determinada temática é desenvolvida pelos autores.

Conforme Alonso et al (2012), Choppin aponta que, independentemente da época, do lugar e uso, o livro didático é um assunto que está relacionado a conflitos. Evidencia-se inicialmente como objeto de polêmica.

\begin{abstract}
Incessantes debates de opinião, violentas campanhas na imprensa e ruidosos pleitos marcam a história do manual na França e também em outros países, como no Japão. Segundo a natureza das queixas, é possível perceber como se mobilizam os atores do sistema educativo. Desse modo, na França, no final do século passado, o livro didático encontrava-se no centro da luta que travavam os partidários da laicidade e os da igreja católica. Numerosos livros considerados fanáticos foram então proibidos, tanto de um lado como de outro (ALONSO et al, 2012 p.5).
\end{abstract}

Porém, hoje, as mobilizações envolvendo livros didáticos são de modo diferente: entidades políticas contestam suposta falta de objetividade nos livros; pais e alunos reclamam dos preços; organizações sociais reivindicam a inserção e o respeito ao negro, à mulher, aos índios e a outras etnias nos livros didáticos etc.

O livro didático é assunto polêmico, pois gera posições radicais entre professores, alunos e pesquisadores dos problemas educacionais. Os principais consumidores de livros didáticos, professores e alunos, divergem na avaliação do papel exercido por ele na vida escolar. Para uma parcela de professores, o livro didático é considerado 
um obstáculo ao aprendizado, instrumento de trabalho a ser descartado em sala de aula. Para outros, ele é material fundamental ao qual o curso é totalmente subordinado. Na prática, o livro didático tem sido utilizado pelo professor, independentemente de seu uso em sala de aula, para preparação de "suas aulas" em todos os níveis da escolarização, quer para fazer o planejamento do ano letivo, quer para sistematizar os conteúdos escolares, ou simplesmente como referencial na elaboração de exercícios ou questionários (BITTENCOURT, 2008, p.13).

Com isso, Ossenbach e Sormoza (2001) inferem que os livros didáticos, como objetos de estudo, são herméticos, e isso implica um trabalho interdisciplinar. Como são produzidos com o objetivo de sua utilização nas escolas, como são parte da própria atividade escolar, como contêm diversas concepções pedagógicas, os livros didáticos são, antes de tudo, objetos das Ciências da Educação.

Logo, os conteúdos temáticos determinam a "tradução" de cada disciplina, bem como a "tradução" daquilo que o autor, as autoridades estatais, o editor ou a própria sociedade em geral acreditam que seja adequado transmitir a cada curso, modalidade ou idade.

A censura sobre o livro é constante, e a história está repleta de exemplos sobre as
medidas tomadas pelo poder para a destruição de obras "perigosas". O medo em
relação à palavra impressa, característica do poder instituído, demonstra aparente
contradição, considerando-se que, a partir do século XVII, o livro passou a assumir
papel de destaque na configuração da cultura ocidental enquanto se difundia a ideia
da construção de uma sociedade letrada, expressa com veemência pelos liberais do
século XVII (BITTENCOURT, 2008, p. 53).

Analisando desta forma, os livros didáticos devem ser vistos não só pelo que mostram, mas também pelo modo como mostram, assim como pelo que não mostram: o que está oculto pode ser tão importante como o que está evidente, pois o oculto e o evidente são parte do processo de elaboração, seleção, exclusão e hierarquização de valores e saberes.

Segundo Schubring (2003), em 1962, com a publicação do livro de Thomas Kuhn, “A estrutura das revoluções científicas", os livros didáticos entram em cena pela primeira vez, como objetos de pesquisa histórica. Em sua obra, Kuhn analisou-os, concedendo-lhes a separação entre "conhecimento escolar" e "conhecimento científico".

Schubring (2003) aponta que a análise isolada de um livro didático, avaliando sua estrutura interna, não pode ser considerada suficiente. Nenhum pesquisador ficará satisfeito somente com a descrição de um livro. Além disso, deverá analisar sua estrutura, suas concepções e metodologias adotadas, situando a obra e o autor no contexto do desenvolvimento da mesma. 
Vale ressaltar que é necessário admitir que muito pouco se conhece a respeito da constituição e do desenvolvimento da Matemática Escolar. Outro fator a ser considerado é que a falta de um padrão estabelecido para uma possível avaliação da Matemática Escolar torna a análise mais complexa, considerando a variabilidade da Matemática "ensinada", que passa por mudanças causadas por diferenças culturais e sociais. Logo, é inevitável analisar o livro didático como parte de uma composição social mais ampla, como o da produção do conhecimento pela comunidade científica em geral.

Ossenbach e Sormoza (2001) apontam que a utilização dos livros didáticos como fonte histórica adquiriu crescente relevância na medida em que, nos últimos anos, a pesquisa histórico-educativa foi se consolidando e contemplando novas temáticas, como as que incluem a análise do que acontece no interior das escolas e dos objetos e materiais nela utilizados.

Segundo esses pesquisadores, pode-se dizer que a grande maioria dos trabalhos sobre livros didáticos existentes, no âmbito da História da Educação, tem abordado prioritariamente a influência desses livros na criação das identidades nacionais e no imaginário coletivo.

Esses pesquisadores afirmam ainda que, embora o interesse pela análise de livros didáticos tenha crescido muito, a pesquisa propriamente dita encontra-se em seus momentos iniciais, restando ainda áreas inteiras para serem exploradas. Concluem também que, embora esses trabalhos estejam utilizando livros didáticos, seguem privilegiando alguns temas, assinalando direções sobre as quais será prioritário agir.

Segundo Ossenbach e Sormoza (2001), uma boa parte das pesquisas realizadas até o presente toma como objeto as matérias ou disciplinas humanísticas, históricas, de formação moral, religiosa ou cívica, em relação às práticas de homogeneização cultural e de criação de identidades coletivas. São menos frequentes os trabalhos que analisam o conjunto de disciplinas não humanísticas como a Matemática.

Alguns aspectos oferecem importantes possibilidades para o avanço desta análise, de acordo com Ossenbach e Sormoza (2001): o estudo das correntes pedagógicas nos livros didáticos das diferentes épocas; o estudo da forma como as correntes pedagógicas adaptaramse a determinadas intenções políticas ou, pelo contrário, o estudo das resistências oferecidas pela escola à introdução de novos enfoques pedagógicos. Nessa perspectiva, cabe grande diversidade de temas de estudo, sendo que alguns deles começam a ser objeto dos 
pesquisadores. Nesse tipo de pesquisa, cabe analisar especialmente as transformações que podem se produzir no caráter prescritivo dos livros didáticos.

Por meio de uma perspectiva histórica, Bittencourt (2008) discorre sobre o papel do livro didático como parte integrante da cultura escolar, explicando que o texto escolar era valorizado como depositário de um saber exclusivo. Com isso, a figura do velho, como detentor do conhecimento, foi desaparecendo, e a mãe deveria educar e estimular seus filhos aos estudos. Logo, o verdadeiro conhecimento seria adquirido pelo professor e, principalmente, pelos livros.

Esse saber "verdadeiro", entretanto, contido no livro didático correspondeu, ou corresponde até nossos dias, a um processo complexo de criação didática. Havia o problema da criação de uma linguagem acessível a alunos de idades variadas, jovens e crianças limitadoras de um saber produzido para outras finalidades, criado com certo rigor e método. No processo de criação didática do livro escolar deveria sempre ser levado em conta que se possuía um leitor intermediário encarregado de reelaborar o conhecimento contido no texto. O saber escolar para chegar à sala de aula passava por vários caminhos, enfrentando o poder do professor e sua capacidade de comunicação. Os livros escolares contaram com a interferência dos professores em vários níveis, incluindo a experiência didática da sala de aula, entendendo-se por que as autoridades foram obrigadas a preferir os docentes dentre os escritores da literatura escolar (BITTENCOURT, 2008, p. 190).

Com isso, segundo Bittencourt (2008), o livro didático, no decorrer do século XIX, torna-se uma ferramenta de trabalho essencial na sala de aula. Posteriormente, com o aprimoramento da fabricação do livro e o consumo crescente, por parte de alunos, aliados à permanência da má formação de professores, o livro didático se tornou um dos símbolos da cultura escolar.

Bittencourt (2008) explica que a diversidade de textos didáticos não exclui a ação do professor e do aluno, isso quer dizer que, pelo fato de ser manuseado por diversos leitores, o livro didático, isoladamente, não esgota todas as possibilidades do saber escolar. "O saber escolar contido no livro escolar, entretanto, passa, pela intervenção dos professores e alunos que podem transformar esse veículo ideológico em instrumento de trabalho, de socialização do saber sistematizado" (BITTENCOURT, 2008, p.221).

Conforme Claret (2002), o avanço das novas tecnologias como, por exemplo, a internet, que atinge parte significativa da população, faz com que alguns teóricos da comunicação de massa pensem em um futuro sem os livros tradicionais. Contudo, o autor defende a ideia de que o livro sempre pôde ser visto como símbolo cultural, sendo assim capaz de transmitir informação, sons, imagens, sentimentos e ideias através do espaço e do tempo. Com isso, o livro didático tem grande peso na produção editorial do Brasil. 
Livros escolares circulam aos milhões diariamente pelas mãos de professores e alunos. Editoras divulgam novos títulos e reeditam os mais vendidos, dando ao livro didático proeminência na indústria cultural. A literatura escolar é o produto de maior vendagem no quadro atual das editoras nacionais (BITTENCOURT, 2008 p. 13).

Para Lajolo (1996), isso causa uma contradição: enquanto, para alguns, é considerado insignificante para a literatura, por tratar de um texto "descartável", para outros, é valorizado pelas editoras, pois é vendável, devido ao apoio do sistema de ensino e ao auxílio do Estado.

Constata-se que nas províncias, depois Estados, foi possível a sobrevivência precária
da produção de obras didáticas em pequenas editoras ou tipografias, mas, nos
principais centros urbanos do centro-sul do País, a tendência foi o lento
desaparecimento de tais firmas que sucumbiram, paulatinamente, diante do domínio
de editoras que se constituíram em grandes empresas, transformando o livro didático
em uma das mercadorias mais rentáveis do setor à medida que ocorreu a expansão
educacional do País (BITTENCOURT, 2008, p. 80).

Atualmente essa ideia é reforçada pelo fato de que o governo federal brasileiro, desde 1996, por meio de uma equipe formada pelo MEC, avalia e emite pareceres $\left(\right.$ PNLD $^{2}$ e PNLEM $^{3}$ ) sobre os livros didáticos encaminhados pelas editoras, bem como compra e distribui os livros didáticos às escolas públicas de Ensino Fundamental e Médio.

Corrêa (2000) atribui a causa do estímulo do Estado sobre a produção editorial de livros escolares ao fato de que

[...] não se pode perder de vista a existência da política do livro didático visando à formação das massas populares com base em conhecimentos a que estas deveriam ou não ter acesso, o que significa não só o controle sobre os conteúdos escolares a serem ensinados e, de certo modo, o controle sobre as práticas escolares, como também sobre a produção desse tipo de livro [...] (CORRÊA, 2000, p.17).

Bittencourt (2008) aponta que o consumo do livro didático é praticamente obrigatório nas escolas e, com isso, o poder educacional e o setor privado estabelecem as formas de leitura, caracterizando a História da Educação Brasileira pela interferência empresarial e controle estatal.

O livro didático é, portanto, objeto da cultura escolar e fonte de pesquisa associado a "um conhecimento organizado e sistematizado com certo rigor e em condições de circular em meio a um público leitor heterogêneo cujo saber é fortemente construído pela intervenção das mídias" (BITTENCOURT, 2008, p. 221).

Embora tenhamos exposto a diversidade de olhares em relação ao livro didático como objeto e fonte de pesquisa, como parte integrante da cultura escolar e como recurso didático, concluímos este capítulo destacando os principais autores citados que apontam o modo pelo

\footnotetext{
${ }^{2}$ Programa Nacional do Livro Didático

${ }^{3}$ Programa Nacional do Livro do Ensino Médio
} 
qual o livro didático de Matemática pode ser analisado como referência para a pesquisa relacionada à Matemática Escolar.

Com base em Choppin (2004), Valente (1999, 2004, 2005 e 2008) e Bittencourt (2004 e 2008), acreditamos que, para este trabalho, a análise do discurso matemático escolar, a partir dos livros didáticos, propõe-se a identificar as formas conceituais, de enfoque didático ou referente à organização do saber que são comuns nas obras escolares e que têm configurado um discurso oficial para a disciplina de Matemática, a partir da qual se escrevem novas obras, assim como se organizam e se desenvolvem programas de ensino.

Ressaltamos que, nesta pesquisa, atemo-nos às funções instrumental e referencial do livro didático, segundo Choppin (2004), a fim de verificar e analisar o livro didático como "tradução" dos programas de ensino, constituindo o depositário de conhecimentos e habilidades, bem como instrumento que pode propiciar a aquisição de habilidades e a apropriação de competências.

Desse modo, destacamos a importância da ideia de vulgata de Chervel (1990), pela qual Valente (2008) indica no que consiste a investigação da própria História da Educação Matemática. O que nos permite afirmar que este trabalho pode contribuir para a História da Educação Matemática, pois a investigação sobre o modo pelo qual o logaritmo e a função logarítmica são abordados nos livros didáticos de Matemática se relaciona com as transformações das vulgatas.

Nesta pesquisa, analisamos os livros didáticos por meio da perspectiva comparativa e histórica, segundo Choppin (2004), pois também comparamos algumas abordagens, inseridas na Matemática Escolar brasileira, a partir do século XIX até o XXI, nas quais são apresentados os conceitos de logaritmos e função logarítmica. Isso nos permite compreender como os conceitos e as abordagens se modificam ou permanecem ao longo dos anos e o quanto isso influencia na inserção desses conteúdos na Matemática Escolar.

Como mencionamos anteriormente, Bittencourt (2008) afirma que o livro didático é um dos símbolos e objeto da cultura escolar. A partir dessa ideia, no capítulo 4, analisamos livros didáticos de Matemática, por meio de suas abordagens e metodologias adotadas, que permeiam sua complexidade e sua ação como produtores e divulgadores do conhecimento, como referência para a pesquisa relacionada à Matemática Escolar. 
Apresentamos no próximo capítulo um breve esboço histórico sobre a introdução dos logaritmos e da função logarítmica na Matemática, a fim de, posteriormente, estabelecer relações entre esse histórico e a inserção de tais conteúdos na Matemática Escolar, por meio da análise de livros didáticos. 


\section{LOGARITMO E FUNÇÃO LOGARÍTMICA NA HISTÓRIA DA MATEMÁTICA}

Neste capítulo, apresentamos a ideia dos logaritmos de Napier e interpretamos sua definição geométrica por meio de um sistema de equações diferenciais ordinárias. Em seguida, mostramos a inserção do logaritmo como função no Cálculo Integral, caracterizando a introdução da função logarítmica na História da Matemática.

\subsection{Introdução dos logaritmos na História da Matemática}

Pelo seu interesse por certos aspectos da Matemática, o jovem escocês John Napier (1550 - 1617) se inquietou por algum tempo com as sequências de potências sucessivas de um dado número encontradas em Arithmetica Integra de Michael Stifel (1487-1567) e em algumas obras de Arquimedes.

Segundo Boyer (1996), ao mesmo tempo em que isso acontecia, havia na época uma grande necessidade de realizar cálculos extensos relacionados à Astronomia e Navegação, devido às mudanças que ocorreram nos séculos XVI e XVII, marcados pelo desenvolvimento científico verificado no Renascimento. Tais cálculos poderiam ser recorridos à trigonometria, através do uso da prostaférese, que relaciona produtos com somas ou subtrações.

Foi assim que, então, Napier começou a pensar num sistema em que somas e subtrações corresponderiam a multiplicações e divisões, respectivamente, através do uso de uma sequência de potências que pudesse atender melhor do que a prostaférese as necessidades de cálculo da época.

Tendo em vista seu uso, principalmente na Astronomia, Napier pôs-se a pensar aproximadamente durante vinte anos numa tábua calculadora com o auxílio de uma relação entre os senos de alguns ângulos e seus "números artificiais", que posteriormente receberiam o nome de logaritmos.

Através de uma situação cinemática, que apresentamos a seguir, era notável que essa relação associava os termos de uma progressão geométrica decrescente aos termos de uma progressão aritmética crescente. Além disso, era possível usar interpolação e preencher lacunas entre os termos na correspondência estabelecida, evitando erros grosseiros que às vezes apareciam com a ferramenta da trigonometria. 
Conforme Boyer (1996), Napier definiu os logaritmos da seguinte forma: considere um segmento de reta $A B$ e uma semirreta $C E$ (Figura 1). Supõe-se que um ponto P parte de $A$ e se move ao longo de $\mathrm{AB}\left(\mathrm{AB}=10^{7}\right)$ com velocidade variável, decrescendo em proporção com sua distância a B. Concomitantemente ao movimento de $\mathrm{P}$, supõe-se que um ponto $\mathrm{Q}$ parte de $\mathrm{C}$ e se move ao longo de $\mathrm{CE}$, com velocidade constante igual à velocidade inicial de $\mathrm{P}$, que Napier determinou como $V_{P(0)}=10^{7}$. Assim, ele definiu CQ como o logaritmo da distância PB.

Figura 1 - Definição de logaritmos de Napier

a)

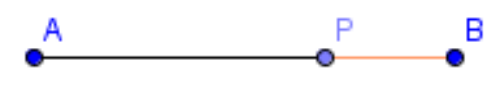

b)

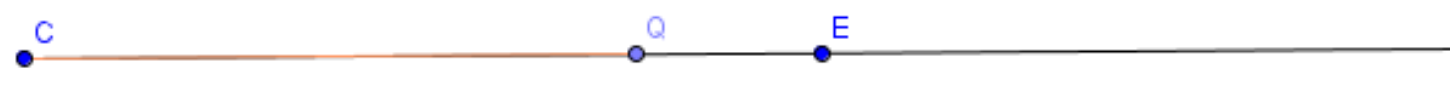

Fonte: Soares, 2012, p. 36

Na linguagem matemática moderna, interpretamos a definição de Napier do seguinte modo: considerando $\mathrm{PB}=\mathrm{x}$ e $\mathrm{CQ}=\mathrm{y}$, como $V_{P(0)}=10^{7}$ e $\mathrm{AB}=10^{7}$, a definição geométrica acima pode ser representada pelo sistema de equações diferenciais abaixo:

$$
\left\{\begin{array}{l}
\frac{d x}{d t}=-\alpha x \\
\frac{d y}{d t}=10^{7}
\end{array}\right.
$$

Em que $\alpha$ é um número real positivo, $\frac{d x}{d t}$ é a velocidade instantânea do ponto $\mathrm{P}$ em $\mathrm{AB}$ $\mathrm{e} \frac{d y}{d t}$ é a velocidade instantânea do ponto Q em CE.

Por conveniência, tomamos $\alpha=1$, de tal forma que:

$$
\left\{\begin{array} { l } 
{ \frac { d x } { d t } = - x } \\
{ \frac { d y } { d t } = 1 0 ^ { 7 } }
\end{array} \Leftrightarrow \left\{\begin{array}{l}
\frac{d t}{d x}=-\frac{1}{x} \\
\frac{d y}{d t}=10^{7}
\end{array}\right.\right.
$$

Pela regra da cadeia, temos:

$$
\frac{d y}{d x}=\frac{d y}{d t} \frac{d t}{d x}=-\frac{10^{7}}{x} \Leftrightarrow \frac{d y}{10^{7}}=-\frac{d x}{x} \Rightarrow
$$




$$
\begin{gathered}
\Rightarrow \int \frac{d y}{10^{7}}=-\int \frac{d x}{x} \Rightarrow y \cdot 10^{-7}=-\ln x+k \Rightarrow y=(-\ln x+k) \cdot 10^{7}, \\
x>0, \text { em que } \ln x=\int_{1}^{x} \frac{d t}{t} .
\end{gathered}
$$

Considerando a definição de Napier, obtemos, de acordo com a teoria de Equações Diferenciais Ordinárias, um problema de valor inicial, de tal forma que:

Para $y=0 \Rightarrow x=10^{7}$, pois quando a distância entre C e Q é nula, a distância entre $\mathrm{P}$ e $\mathrm{B}$ é igual à medida do segmento $\mathrm{AB}$. Assim, obtemos:

$$
0=\left(-\ln 10^{7}+k\right) \cdot 10^{7} \Leftrightarrow k=\ln 10^{7} .
$$

Então, $y=\left(-\ln x+\ln 10^{7}\right) \cdot 10^{7}=\left(\ln \frac{10^{7}}{x}\right) \cdot 10^{7}=\left[\log _{\frac{1}{e}}\left(x 10^{-7}\right)\right] \cdot 10^{7}$.

Como podemos ver, a base desse sistema de logaritmos é $\frac{1}{e}$, porém, no início do século XVII, não se sabia da existência do número "e". No caso de Napier, a fim de que os números que representam a medida do segmento CQ estivessem bem próximos, era necessário tomar a base do logaritmo muito próximo de 1. Na realidade, segundo Boyer (1996, p.214), "Napier não pensou numa base para seu sistema, mas suas tabelas eram compiladas por multiplicações repetidas, equivalentes a potências de 0,9999999".

Pode-se dizer, então, que Napier teria escolhido o número $1-10^{-7}$ como base do seu sistema de logaritmos (ou 0,9999999) e, para evitar casas decimais, ele multiplicou cada potência por $10^{7}$. Assim, se $N=10^{7}\left(1-10^{-7}\right)^{L}$, então, L é o "logaritmo" de Napier do número $\mathrm{N}$, ou ainda,

$$
\log N=L \Leftrightarrow N=10^{7}\left(1-10^{-7}\right)^{L}
$$

Através dessa definição, nota-se que, de fato, Napier elegeu o valor ${ }^{4} 10^{7}$ para a medida do segmento $\mathrm{AB}$, pois quando $L=0 \Rightarrow N=10^{7}$. Notemos que $\mathrm{L}=0$ significa que a medida do segmento CQ é nula, e nesse caso o ponto $\mathrm{P}$ ainda não partiu do ponto $\mathrm{A}$, logo,

\footnotetext{
${ }^{4}$ Conforme Miguel e Miorim (2002): Este número, 107 , Napier atribuía à medida do raio de uma circunferência e ao longo do qual eram determinados outros segmentos menores representativos dos senos de certos ângulos.
} 
$P B=A B=10^{7}$, conforme a dedução feita anteriormente no sistema de equações diferenciais.

Segundo Miguel e Miorim (2002), pela definição apresentada, temos que P descreve um movimento retilíneo uniformemente variado enquanto $Q$ descreve um movimento uniforme. Além disso, vimos que Napier considerava o comprimento do segmento AB igual a $10^{7}$. Logo, podemos inferir que o coeficiente de desaceleração na velocidade do ponto $\mathrm{P}$ era de $\left(1-10^{-7}\right)$ e os intervalos de tempos considerados, a fim de tornarem discretos os movimentos contínuos dos pontos $\mathrm{P}$ e Q, eram de $10^{-7}$. Desse modo, a tabela 1 apresenta a situação original considerada por Napier, em que:

$t_{i} \rightarrow$ valores dos tempos

$V_{Q} \rightarrow$ valores das velocidades do ponto Q nesses diferentes tempos

$C Q \rightarrow$ valores das distâncias percorridas pelo ponto $\mathrm{Q}$ nesses diferentes tempos

$A P \rightarrow$ valores das distâncias percorridas pelo ponto $\mathrm{P}$ nesses diferentes tempos

$V_{P} \rightarrow$ valores das velocidades do ponto $\mathrm{P}$ nesses diferentes tempos

$P B \rightarrow$ valores das distâncias que restam a ser percorridas pelo ponto $\mathrm{P}$ nesses diferentes tempos.

Tabela 1 - Situação original

\begin{tabular}{|c|c|c|c|c|c|}
\hline$t_{i}$ & $V_{Q}$ & $C Q$ & $A P$ & $V_{P}$ & $P B$ \\
\hline$t_{0}=0$ & $10^{7}$ & 0 & 0 & $10^{7}$ & $10^{7}$ \\
\hline$t_{1}=1$ & $10^{7}$ & 1 & $\left(1-10^{-7}\right)$ & $10^{7}\left(1-10^{-7}\right)$ & $10^{7}\left(1-10^{-7}\right)$ \\
\hline$t_{2}=2$ & $10^{7}$ & 2 & $2\left(1-10^{-7}\right)$ & $10^{7}\left(1-10^{-7}\right)^{2}$ & $10^{7}\left(1-10^{-7}\right)^{2}$ \\
\hline$t_{3}=3$ & $10^{7}$ & 3 & $3\left(1-10^{-7}\right)$ & $10^{7}\left(1-10^{-7}\right)^{3}$ & $10^{7}\left(1-10^{-7}\right)^{3}$ \\
\hline$t_{4}=4$ & $10^{7}$ & 4 & $4\left(1-10^{-7}\right)$ & $10^{7}\left(1-10^{-7}\right)^{4}$ & $10^{7}\left(1-10^{-7}\right)^{4}$ \\
\hline$t_{5}=5$ & $10^{7}$ & 5 & $5\left(1-10^{-7}\right)$ & $10^{7}\left(1-10^{-7}\right)^{5}$ & $10^{7}\left(1-10^{-7}\right)^{5}$ \\
\hline
\end{tabular}

Fonte: Adaptado de Miguel e Miorim, 2002, p. 38

Portanto, de acordo com a definição de Napier, os logaritmos de cada uma das distâncias que aparecem na última coluna da tabela 1 seriam iguais às respectivas distâncias que aparecem na terceira coluna: $\log 10^{7}=0, \log 10^{7}\left(1-10^{-7}\right)=1, \log 10^{7}(1-$ $\left.10^{-7}\right)^{2}=2$, e assim por diante. Com isso, é possível verificar que Napier associava números 
sequenciados aritmeticamente (os logaritmos) a números sequenciados geometricamente. Segundo Miguel e Miorim (2002), isso caracteriza a concepção aritmética dos logaritmos, quando eles estão associados à teoria das progressões.

Mesmo que Napier tenha concebido os logaritmos simplesmente para fins aritméticos, o estudo dos logaritmos não ficou restrito a essa finalidade. Vejamos, então, um esboço histórico da introdução do logaritmo como função na História da Matemática.

\subsection{Introdução da função logarítmica na História da Matemática}

Segundo Maor (2008), em torno de 1640, trinta anos antes de Isaac Newton (16431727) e Gottfried Wilhelm Leibniz (1646-1716) estabelecerem a fórmula da área sob a curva $y=x^{n}$ como parte de seu Cálculo Integral, Pierre de Fermat (1607-1665) já conseguia a fórmula da área $A=\frac{a^{n+1}}{n+1}$, para a curva $y=x^{n}, \operatorname{com} n>0$, entre os pontos $x=0$ e $x=a$, no eixo $x$. Posteriormente, com pequenas mudanças no seu método, ele também demonstrou que a fórmula também vale para valores negativos atribuídos a $n$.

Porém, para a curva $y=x^{-1}$, temos $\mathrm{n}=-1$ que resulta em $A=\frac{a^{n+1}}{n+1}=\frac{a^{0}}{0}$, que não existe, pois o 0 aparece no denominador. A partir desse problema, percebe-se a inserção dos logaritmos no estudo do Cálculo:

As tábuas de Napier e Briggs e seus seguidores revolucionaram a arte do cálculo numérico. No entanto, a importância dos logaritmos no desenvolvimento histórico do Cálculo surge a partir da descoberta publicada em 1647 pelo jesuíta belga Gregorius de Saint Vincent, que implica numa conexão surpreendente entre a função logarítmica natural e a hipérbole retangular xy=1 (EDWARDS, 1979, p.154, tradução nossa).

A figura 2 ilustra o método de Fermat aplicado à hipérbole $y=\frac{1}{x}$ :

Figura 2 - Método de Fermat

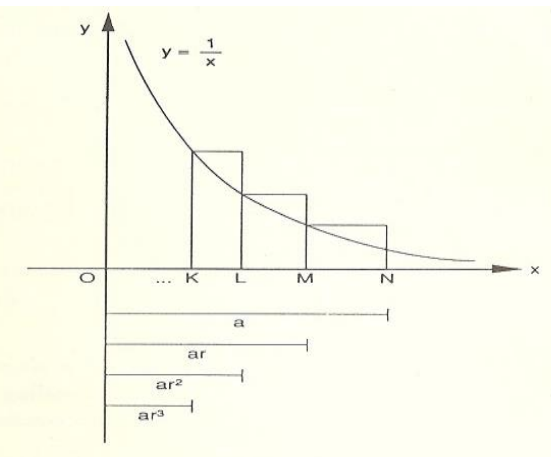

\begin{tabular}{|c|c|c|}
\hline base & altura & área \\
\hline$a(1-r)$ & $1 / a$ & $(1-r)$ \\
\hline$a r(1-r)$ & $1 / a r$ & $(1-r)$ \\
\hline$a r^{2}(1-r)$ & $1 / a r^{2}$ & $(1-r)$ \\
\hline$a r^{3}(1-r)$ & $1 / a r^{3}$ & $(1-r)$ \\
\hline$\cdots$ & $\cdots$. & $\cdots \cdots$ \\
\hline
\end{tabular}

Fonte: Soares, 2012, p.68 
Observando a figura 2, conforme Maor (2008), Gregorius de Saint Vicent (1584-1667) notou que, para $n=-1$, enquanto as bases dos retângulos formam uma progressão geométrica, os retângulos usados na aproximação da área sob a hipérbole possuem áreas todas iguais.

Para calcular as bases desses retângulos, tomemos como exemplo os retângulos de base MN e LM. Pela figura 2, temos:

$$
M N=a-a r=a(1-r)
$$

Do mesmo modo, temos que $L M=a r-a r^{2}=\operatorname{ar}(1-r)$. Assim, obtemos as bases $a r^{2}(1-r), a r^{3}(1-r), a r^{4}(1-r), \ldots$ dos retângulos da figura 2 .

Começando em $\mathrm{N}$ e trabalhando no sentido inverso, para que esses intervalos formem uma progressão geométrica decrescente, temos $\mathrm{ON}=\mathrm{a}, \mathrm{OM}=\mathrm{ar}, \mathrm{OL}=a r^{2}$, e assim por diante, em que $\mathrm{r}$ é menor que 1. Assim, as alturas (ordenadas) da curva nesses pontos são $a^{-1},(a r)^{-1},\left(a r^{2}\right)^{-1}, \ldots$

Isso significa que, conforme a distância, em relação ao zero, cresce geometricamente no eixo das abscissas, as áreas correspondentes crescem em incrementos iguais, ou seja, aritmeticamente, e isso continua sendo verdade mesmo se passarmos ao limite quando $r \rightarrow 1$, isto é, quando fazemos a transição dos retângulos discretos para a hipérbole contínua. Portanto, a relação entre a área e a distância tem a mesma característica da tábua de logaritmos de Napier e é logarítmica. Desse modo, um dos alunos de Saint Vicent, Afonso Anta de Sarasa (1618 - 1667), escreveu essa relação explicitamente, registrando uma das primeiras ocasiões em que se fez uso de uma função logarítmica, quando, até então, os logaritmos eram considerados principalmente uma ferramenta de cálculo.

Como consequência do trabalho de Gregorius de Saint Vicente e Sarasa, parece ter
sido realmente conhecido, na década de 1660 , que a área determinada por um
intervalo, sob a hipérbole $y=\frac{1}{x}$, equivale ao logaritmo da razão entre as
extremidades do intervalo (EDWARDS, 1979, p.164, tradução nossa).

Se denotarmos por $A(t)$ a área sob a hipérbole, a partir de um ponto de referência fixo $x>0$ (por conveniência geralmente escolhemos $x=1$ ) até um ponto variável $x=t>1$, teremos $A(t)=\log t$, e assim o mistério da quadratura da hipérbole estava próximo de ser desvendado. Porém, uma questão permanecia aberta: "Qual será a base desse logaritmo que determina a área sob a hipérbole numericamente?" 
Mais tarde, com o aprimoramento desses estudos, Newton e Leibniz puderam mostrar que Saint Vicent estava certo, isto é, a relação entre a distância e a área é realmente logarítmica e, além disso, concluíram que a base procurada é o número $e$, em que $e=$ $=\lim _{x \rightarrow \infty}\left(1+\frac{1}{x}\right)^{x}$. Assim, a fórmula $\int_{1}^{x} \frac{1}{t} d t=\ln x$ resolveu o "caso perdido".

A partir de então, os logaritmos tornam-se uma ferramenta útil ao Cálculo Diferencial e Integral e, além disso, observamos a aplicabilidade do logaritmo como função, o que não era evidente em 1614 quando Napier publicou a primeira obra sobre logaritmos.

Segundo Miguel e Miorim (2002), foi William Gardiner, no seu livro Tables of Logarithms (1742), quem forneceu a primeira exposição sistemática dos logaritmos concebidos como expoentes. Assim, desde o momento em que os logaritmos foram originalmente concebidos por Napier até a elaboração explícita de uma concepção estritamente algébrica dos mesmos como expoentes, transcorreram cerca de 140 anos.

Embora possa parecer óbvia e natural aos leitores da atualidade, a ligação entre logaritmos e equação ou função exponencial demandou, historicamente, tempo e esforço para ser estabelecida.

Na primeira metade do século XVIII, o próprio conceito de função estava apenas no início de seu processo de desenvolvimento. Segundo Boyer (1996, p. 306), em 1748, Leonhard Euler (1707-1783), em seu Introductio in analysin infinitorum, "define função de uma quantidade variável como qualquer expressão analítica formada daquela quantidade variável e de números ou quantidades constantes”.

Nesta mesma obra, Euler propôs uma classificação das funções em funções algébricas e funções transcendentes. Nesta última categoria, ele inseriu as funções exponenciais, as logarítmicas e outras, sem nome, que haviam surgido no campo do Cálculo Integral.

\footnotetext{
As seções do Introductio mais influentes, no entanto, lidam com as funções exponencial, logarítmica e trigonométrica, por isso é que Euler introduziu as notações e conceitos que tornaram obsoletas todas as discussões de tais funções em textos anteriores. Todos os tratamentos modernos dessas funções, de algum modo, derivaram daquelas de Euler. Assim, Euler definiu funções exponenciais como potências nas quais os expoentes são variáveis e então - e isso está em primeiro - os logaritmos em termos dessas. Isto é, se $a^{z}=y$, Euler definiu $z$ como o logaritmo de $y$ na base $a$. As propriedades básicas da função logarítmica são, então, derivadas da exponencial (KATZ, 1998, p.568, tradução nossa).
} 
Quando Euler escreveu $a^{z}=y$, em que z é uma variável, ele concebeu os logaritmos em termos de função. Ele definiu função logarítmica a partir da função exponencial e, portanto, houve mais uma contribuição na maneira de abordar os logaritmos.

Durante os séculos XVII e XVIII, com o estudo das funções transcendentes o
logaritmo se tornou um conceito importante para esclarecer as ferramentas
algébricas da análise e dar-lhes consistência (ROQUE, 2012, p. 438).

Segundo Roque (2012), acreditava-se que o logaritmo de qualquer número negativo era um número real e igual ao logaritmo de seu valor absoluto. Equivocadamente, deduzia-se isso da seguinte forma:

$$
\begin{gathered}
(-x)^{2}=x^{2} \Rightarrow \log (-x)^{2}=\log x^{2} \Rightarrow \\
\Rightarrow 2 \cdot \log (-x)=2 \cdot \log (x) \Rightarrow \log (-x)=\log (x) .
\end{gathered}
$$

Assim, um número e seu oposto deveriam possuir o mesmo logaritmo. Entretanto, Euler mostrou uma contradição neste resultado e, segundo Roque (2012), podemos entender seu argumento usando a notação atual: "Euler já sabia que $e^{i . \pi}=\cos \pi+i$. $\operatorname{sen} \pi$, ou seja, $e^{i \pi}=-1$. Logo, $\ln (-1)=\pi . i$ e os logaritmos de números negativos devem ser imaginários, e não reais" (ROQUE, 2012, p. 440).

Em sua obra, Introductio in analysin infinitorum, Euler (1748) conceitua a ideia de base de um logaritmo, demonstra algumas propriedades de logaritmo, como a da potência e da soma, e explica como calcular o logaritmo de um número usando a mudança de base, bem como a tábua de logaritmos decimais. Neste último caso, ele exemplifica como se faz para obter o logaritmo de um número por meio de aproximações.

No decorrer deste livro, Euler (1748) mostra que, se um determinado número b não pode ser expresso como uma potência de outro número $a$, então $\log _{a} b$ é irracional. Ainda assim, nesta mesma obra, no Capítulo VII - Du Développement dês Quantités exponentielles e logarithmiques en Séries, é introduzido o conceito do número "e", através do estudo de séries de funções logarítmicas e pelo uso de propriedades de logaritmos. Neste capítulo, o autor afirma que os logaritmos, cuja base é o número "e", são denominados como naturais ou hiperbólicos, pois representam a quadratura da hipérbole.

Portanto, com a percepção de que os logaritmos poderiam, não só facilitar cálculos, mas também expressar analítica e quantitativamente a variação de duas grandezas interdependentes, sua concepção torna-se, além de aritmética, também algébrico-funcional, 
segundo Miguel e Miorim (2002), pois o logaritmo é, a partir de então, visto como uma equação e como uma função.

Esta concepção algébrico-funcional dos logaritmos é a predominante no contexto da Matemática Escolar atual no Brasil, porém, nem sempre foi assim. Verifiquemos isso no próximo capítulo, a partir da análise do tratamento do logaritmo e da função logarítmica em livros didáticos de Matemática. 


\section{LOGARITMO E FUNÇÃo LOGARÍTMICA EM LIVROS DIDÁTICOS DE MATEMÁTICA}

Neste capítulo, buscamos a compreensão de como o logaritmo e a função logarítmica são abordados nos livros didáticos de Matemática do século XIX ao XXI, indicando a inserção desses conteúdos na Matemática Escolar brasileira. De modo geral, postulamos uma análise da Matemática Escolar a partir das obras didáticas, estudando a forma com a qual os autores abordam ou tratam a Matemática, o sentido dos argumentos, os tipos de atividades ou situações que são propostas, os tipos de explicações, definições, exemplos, aplicações e problemas associados aos logaritmos e à função logarítmica.

O critério de seleção dos livros adotados para esta pesquisa consistiu em escolher aqueles que, geralmente, foram reeditados ou que há indícios de seu uso, o que pode indicar a consolidação de sua abordagem em uma determinada época e caracterizar uma vulgata. Além disso, buscamos livros em consonância com documentos oficiais de cada período estudado, assim como selecionamos autores, desde a $2^{\text {a }}$ metade do século XIX até os dias atuais, em que há registros de suas contribuições para o Ensino de Matemática no Brasil.

Assim, foi importante, para o critério de escolha de livros mais antigos, por exemplo, do século XIX, a recomendação de seu uso por parte de escolas, como as militares e o Colégio Pedro II, e as indicações de órgãos como o Ministério da Instrução Pública. Para os livros didáticos recentes, selecionamos principalmente os que foram aprovados pelo PNLEM, bem como os que contemplam as diretrizes dos PCN's + ou das Matrizes Curriculares de Referência para o Sistema Nacional de Avaliação de Educação Básica (SAEB).

Os livros pesquisados foram: Elementos de Algebra (4ª edição), de Ottoni (1879), Elementos de Arithmetica ( $7^{\mathrm{a}}$ edição), de Ottoni (1886), Elementos de Arithmetica (13 ${ }^{\mathrm{a}}$ edição), de Viana (1910), Curso de Matemática II - Algebra (2 edição), de Aarão Reis [189? $]^{5}$, Elementos de Álgebra (5 edição), de Perez y Marin (1923), Matemática $2^{o}$ Ciclo $-1^{a}, 2^{a} e$ $3^{a}$ séries, de Cunha et al (1944 e 1959), Matemática Segunda Série - Curso Colegial Clássico e Científico (2 $2^{\mathrm{a}}$ edição), de Almeida et al (1949), Matemática para os Cursos Clássico e Científico - $1^{o}$ ano (12 ${ }^{\mathrm{a}}$ edição), de Carvalho (1957), Matemática Curso Colegial Moderno volume 1 e 2 (2 $2^{\text {a }}$ edição), de Barbosa, Netto e Rocha (1967 e 1968), Matemática na Escola Renovada - $1^{a}$ série do $2^{o}$ grau (3a edição), de Góes e Netto (1973), Matemática

\footnotetext{
${ }^{5}$ Não há registro do ano de publicação deste livro. Acreditamos que este livro seja da década de 1890, pois o Curso Elementar de Mathemática - Arithmetica (2a edição), de Aarão e Lucano Reis, é de 1892.
} 
Aplicada 1 - $2^{\circ}$ Grau, de Imenes, Jakubovic e Trotta (1979), Aulas Práticas de Matemática $2^{o}$ grau. Vol. 1, de Bongiovanni et al (1988), Matemática: Contexto e Aplicações $\left(1^{\mathrm{a}}\right.$ e $4^{\mathrm{a}}$ edições), de Dante (1999 e 2007), Matemática (1 $1^{\text {a }}$ edição), de Paiva (1999), Matemática: Ciência e Aplicações ( $2^{\mathrm{a}}$ edição), de Almeida et al (2004), Matemática: volume único (4 ${ }^{\mathrm{a}}$ edição), de Degenszajn et al (2007), Matemática: uma ciência para a vida 1, de Furtado e Rosso Jr. (2011) e Conexões com a Matemática 1, organizado pela Editora Moderna (2013).

Apresentamos, então, algumas considerações que indicam a importância dos livros didáticos citados e de alguns de seus autores no que se refere à Matemática Escolar brasileira.

Segundo Lorenz e Vechia (2016), João José Luiz Viana, Cristiano Benedito Ottoni e Aarão Reis são autores de livros didáticos adotados nos programas de ensino do Colégio Pedro II no século XIX.

Valente (1999, p. 131) explica que Ottoni foi um autor que transitou do ensinotécnico-militar para os currículos de formação clássico-literária e "se trata de um personagem fundamental para a organização e estruturação da Matemática Escolar no Brasil, durante quase meio século". Logo, suas obras foram de fundamental importância.

C. Ottoni não ambicionava auferir ganhos com seus compêndios, mas tamanho foi o
sucesso de suas obras que relata, em suas memórias, a venda de seis mil exemplares
de Aritmética em duas edições, cinco mil e seiscentos exemplares de Álgebra em
duas edições e sete mil exemplares de Geometria em três edições. Ao final de sua
"Autobiografia", em notas de correção ou acrescentando informações relevantes ao
seu texto, declara a venda de nove mil exemplares de Álgebra e outros nove mil de
Geometria (LANCILOTTI e LUIZ, 2014, p. 26).

Lancilotti e Luiz (2014) destacam ainda que as obras didáticas de Ottoni serviram de base para outros autores de livros de Matemática, como José de Abreu Medeiros e Jeronymo Pereira de Lima Campos.

Segundo Valente (1999, p. 160), “João José Luiz Viana foi bacharel em Matemática pela Escola Central e, ainda, professor do curso de preparatórios da Escola Naval. Seus Elementos de Aritmética tiveram primeira edição em 1883".

Conforme Bortoli (2016), a escrita do livro didático de Perez y Marin (1923) foi elaborada com base nos programas de ensino do Ginásio Nacional no início do século XX.

Segundo Ribeiro e Valente (2007), os autores da coleção Matemática $1^{a}$, $2^{a}$ e $3^{a}$ séries - $2^{o}$ ciclo (1944 e 1959), em grande parte, marcaram a sua participação no processo de constituição da disciplina de Matemática no primeiro ciclo do Ensino Secundário Brasileiro 
em duas reformas educacionais, Reforma Francisco Campos e Capanema. Além disso, participaram ativamente nas reuniões no Ministério da Educação e Cultura, no Colégio Pedro II, e outros eventos nos quais eram discutidos programas e metodologias de ensino de Matemática.

Matemática Segunda Série - Curso Colegial Clássico e Científico (1949) é um livro didático elaborado por autores como, por exemplo, Omar Catunda e Benedito Castrucci, que foram professores da USP e atuaram por muitos anos na formação de professores de Matemática.

Omar Catunda, além de exercer outros cargos, foi professor de Análise Matemática e Superior na Faculdade de Filosofia, Ciências e Letras da USP (FFCL-USP). Segundo Silva (2000, p. 11), ele "criticava o ensino apoiado apenas na transmissão de regras e fórmulas, em que o aluno era obrigado a aprender processos práticos como quem aprende a usar uma ferramenta que nunca mais usará".

Catunda também criticava a relação entre o ensino secundário e a Álgebra, que para ele:

\begin{abstract}
levava os alunos apenas a conhecimentos limitados na prática de um algoritmo, tornando-os incapazes de resolver um problema de construção ou imaginar uma configuração espacial. Por causa dessas limitações, sugeria que o ensino da Álgebra deveria ser retardado o mais possível, dando espaço ao desenvolvimento de um pensamento aritmético e geométrico (SILVA, 2000, p. 11).
\end{abstract}

Conforme Duarte (2007), ele era um matemático que buscava compatibilizar aspectos educacionais com a pesquisa científica, com reflexos para a cultura geral da população, o que evidencia sua aproximação com a formação de professores.

Segundo Duarte, Oliveira e Pinto (2010), Benedito Castrucci se licenciou em Física e Matemática, em 1939, pela Universidade de São Paulo. Em 1942, assumiu o cargo de Professor da Cadeira de Geometria Analítica, Projetiva e Descritiva. Com a desvinculação da Seção de Matemática da Faculdade de Filosofia e a consequente criação do Instituto de Matemática e Estatística da Universidade de São Paulo, após a Reforma Universitária, Castrucci transferiu-se para o referido Instituto, iniciando assim outra trajetória, sempre marcada por muita dedicação.

Na área de ensino e de pesquisa, conforme Duarte, Oliveira e Pinto (2010), Castrucci participou das mais diversas instituições científicas em sua especialização, assim como 
contribuiu para as vertentes acadêmico-administrativas da Universidade. Integrou, em 1978, o Conselho de Ensino, Pesquisa e Extensão de Serviços à Comunidade (CEPE).

Conforme Ribeiro (2010), Thales Mello Carvalho é um dos autores de livros didáticos de Matemática que mais foram consultados, tanto por alunos como por professores, na atual Escola Estadual São Paulo, entre os anos de 1942 e 1961. Em seu livro, Matemática para os Cursos Clássico e Científico - $1^{\circ}$ ano, de 1957, o autor ressalta que a obra segue os programas oficiais vigentes na época.

Segundo Silva (2008), a coleção Matemática - Curso Colegial Moderno (1967 e 1968), escrito por Scipione Di Pierro Netto, Luiz Mauro Rocha e Ruy Madsen Barbosa, estava em consonância com as Sugestões para um roteiro de Programa para a cadeira de Matemática, propostas pelo Grupo de Estudos do Ensino de Matemática (GEEM) ${ }^{6}$, em 1962, no IV Congresso em Belém, que foram publicadas posteriormente no Diário Oficial do Estado de São Paulo no ano de 1965.

Na apresentação do livro Matemática - Curso Colegial Moderno (1967), percebe-se uma tentativa de elaborar um material que auxiliasse os professores no ensino dos conceitos modernos para os conteúdos da Matemática, colaborando para uma transformação nas práticas pedagógicas do Ensino de Matemática, conforme Silva (2008).

A abordagem da coleção Matemática na Escola Renovada, de Célia Contin Góes e Scipione di Pierro Netto (1973), está fundamentada nas ideias do Movimento da Matemática Moderna.

Além de sua importância como autor de livros didáticos para colégio nas décadas de 1960 e 1970, segundo Britto (2008), Scipione Di Pierro Netto, um dos autores de Matemática na Escola Renovada, foi professor de Matemática e educador brasileiro. Ele fundou a editora Scipione e foi professor universitário da PUC-SP e da FE-USP.

Conforme Silva (2009), a coleção Matemática Aplicada, de Imenes, Jakubovic e Trotta, destinada ao ensino secundário e publicada em 1979, tem como parâmetro as propostas para o ensino de Matemática, vigentes na década de 1970, mas esta coleção também

\footnotetext{
${ }^{6}$ Segundo Lima (2006), o GEEM foi criado em 1961, com sede na Universidade Mackenzie em São Paulo, e teve como presidente o professor Osvaldo Sangiorgi. Esse grupo foi o primeiro a atuar em São Paulo e contou com a participação de professores universitários, secundários e primários, provavelmente com a intenção de disseminar o Movimento da Matemática Moderna entre professores de todos os níveis de ensino.
} 
foi reeditada na década de 1980. A metodologia adotada por estes autores busca apresentar os conteúdos, por meio de um problema. Em seguida, os conteúdos são desenvolvidos, não se restringindo ao problema proposto inicialmente. Por fim, para que possa ser resolvido, o problema inicial é retomado.

O livro Aulas Práticas de Matemática - $2^{\circ}$ grau (1988) possui uma abordagem prática e restrita a assuntos essenciais, cujos exercícios ajustam-se de modo a permitir total aproveitamento dessa coleção. No próprio livro, os autores explicam que se trata de uma obra didática que atende às reais necessidades do ensino de $2^{\circ}$ grau.

Segundo o que consta em seu Currículo Lattes, apresentado pelo Conselho Nacional de Desenvolvimento Científico e Tecnológico ( $\mathrm{CNPq}$ ), Vincenzo Bongiovanni, um dos autores de Aulas Práticas de Matemática - $2^{\circ}$ grau (1988), além de possuir uma boa formação em Engenharia, Matemática e Ensino de Matemática, tem experiência na área de Matemática, com ênfase em Educação Matemática, atuando principalmente nas áreas de geometria, novas tecnologias, formação de professores e História da Matemática.

Matemática, de Manoel Paiva (1999), está de acordo com a 2a edição das Matrizes Curriculares de Referência para o Sistema Nacional de Avaliação de Educação Básica (SAEB), segundo o que consta no próprio livro do autor.

As coleções de Dante (1999 e 2007), Almeida et al (2004) e Degenszajn et al (2007), bem como o livro Conexões com a Matemática 1 (2013) foram todos aprovados pelo PNLEM, conforme os próprios autores indicam em suas obras didáticas.

Segundo o que consta no livro Matemática: uma ciência para a vida, 1 , de Furtado e Rosso Jr. (2011), esta obra foi organizada e escrita com o intuito de auxiliar os professores e motivar os alunos ao aprendizado, assim como contempla as diretrizes dos PCN's+ em todos os conteúdos de Matemática, normalmente abordados e trabalhados no Ensino Médio.

Para tratarmos das aplicações dos logaritmos e da função logarítmica na seção 4.3, mostramo-las não só em livros didáticos, mas também como elas aparecem no Exame Nacional do Ensino Médio (ENEM), dada a importância deste exame para o ensino brasileiro nos dias atuais.

Nas seções 4.3 e 4.4 também mostramos um pouco sobre a abordagem do Caderno do Aluno da $1^{\mathrm{a}}$ série do Ensino Médio (2014), que não se trata de um livro didático, mas é um 
material de apoio fornecido aos alunos da Rede Estadual de Ensino do Estado de São Paulo e, portanto, segue a Proposta Curricular do Estado.

\subsection{O logaritmo e a função logarítmica em livros didáticos de Matemática: da $2^{\mathrm{a}}$} metade do século XIX a 1949

Conforme Miguel e Miorim (2002), a análise dos programas oficiais brasileiros de ensino de Matemática para o curso secundário, a partir da segunda metade do século XIX até 1912, evidencia a teoria dos logaritmos presente quase sempre no campo da Aritmética, com uma abordagem que tinha o objetivo de conceber os logaritmos simplesmente como facilitadores de cálculos extensos. A figura 3 mostra uma definição de logaritmos de Ottoni (1886):

Figura 3 - Definição de logaritmos de Ottoni

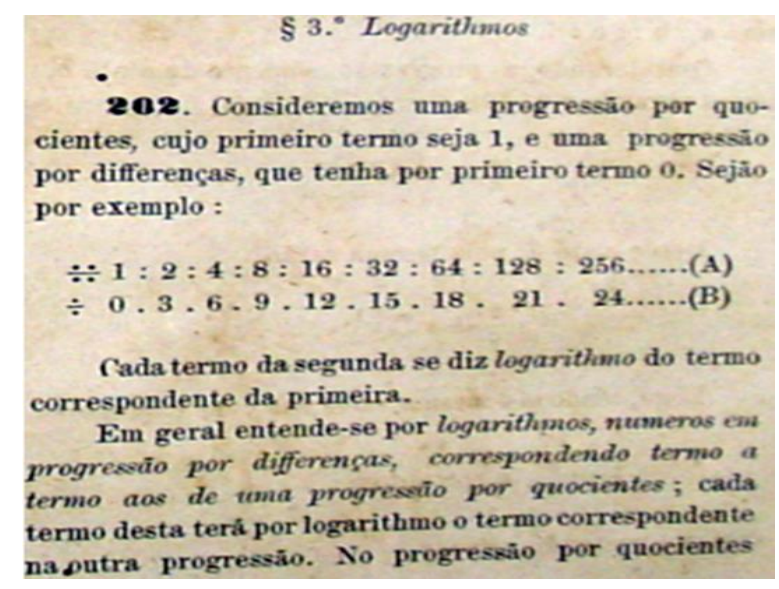

Fonte: Ottoni, 1886 p. 233

No livro de Ottoni, intitulado Elementos de Arithmetica (1886), constata-se que o autor incluiu os logaritmos como números em progressões, situando-os, desse modo, no campo da Aritmética.

Viana (1910) introduz o capítulo sobre logaritmos a partir da ideia de que há uma operação pela qual se pode transformar a multiplicação e divisão em soma e subtração, bem como a potência e a extração de raiz em multiplicação e divisão. $\mathrm{O}$ autor explica que a teoria dos logaritmos surgiu dessa ideia e, por isso, "é considerada uma das mais grandiosas concepções do espírito humano" (VIANA, 1910, p.238). A figura 4 mostra a definição de logaritmos de Viana (1910): 
Figura 4 - Definição de logaritmos de Viana

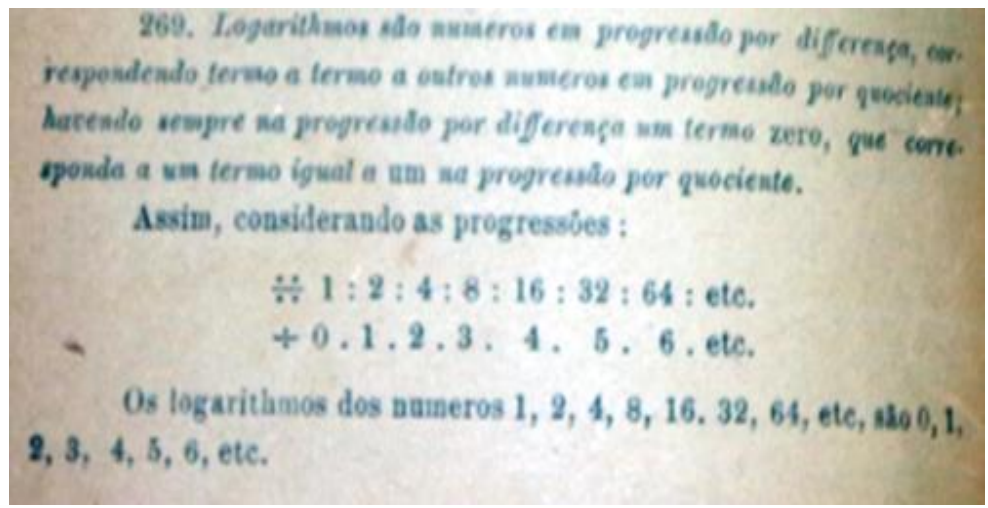

Fonte: Viana, 1910 p. 238

Por meio das definições de Ottoni (1886) e Viana (1910), notamos os logaritmos associados à teoria das progressões. Além disso, os logaritmos são sequenciados aritmeticamente e estão em correspondência biunívoca com outros números sequenciados geometricamente.

Essa ideia caracteriza a concepção aritmética dos logaritmos, segundo Miguel e Miorim (2002), pois, a partir da associação à teoria das progressões, os logaritmos são considerados números e o estudo de números e das propriedades que os regem constitui objeto da Aritmética.

Como mencionado anteriormente, na segunda metade do século XIX até 1912, os livros didáticos de Matemática quase sempre apresentavam os logaritmos no campo da Aritmética, mas é possível encontrar a abordagem dos logaritmos em alguns livros de Álgebra desse período.

Exemplo disso está em Elementos de Algebra de Ottoni (1879), no qual, após discutir a relação entre $x$ e $y$ na equação $a^{x}=y$, o autor define o logaritmo como expoente, o que não ocorre nos livros de Aritmética: "chama-se logaritmos de um número o expoente a que é necessário elevar um número invariável para formar o proposto” (OTTONI, 1879, p. 201).

Neste livro, Ottoni demonstra algebricamente algumas propriedades, aprofunda o uso de tábuas de logaritmo e usa os logaritmos para resolução de equações exponenciais, que são importantes na aplicação dos logaritmos em problemas de juros compostos.

As questões de juros compostos também muito se simplificão com o emprego dos logaritmos; e, principalmente, quando a incógnita é o tempo em que certo capital venceu juros. A fórmula dos juros compostos deduzida na Arithmetica é 


$$
C=c\left(\frac{100+i}{100}\right)^{t}
$$

representando $\mathrm{c}$ o capital empregado, $\mathrm{i}$ a taxa, $\mathrm{t}$ o numero de annos ou de mezes, $\mathrm{C}$ a quantia produzida afinal, ou a somma do capital com os juros e juros de juros (OTTONI, 1879, p. 209).

Em virtude da Reforma da Educação Brasileira proposta por Benjamin Constant, no dia 8 de novembro de 1890, foi sancionado o Decreto $\mathrm{n}^{\circ}$ 981, o qual insere oficialmente os logaritmos entre os tópicos algébricos e aritméticos. Em relação ao estudo de Aritmética e noções de Álgebra, o decreto estabelece, entre outros conteúdos:

Theoria geral da numeração. Theoria das seis operações fundamentaes, primeiro em relação aos numeros inteiros e depois em relação ás fracções ordinarias e decimaes. Noções das progressões por differença e por quociente. Theoria elementar dos logarithmos e uso das taboas. Arithmetica social: juros simples e compostos; capitalisação, amortizações, etc (BRASIL, 1890, p.24).

A partir de então, segundo Miguel e Miorim (2002), de 1893 a 1912, o tema logaritmos passaria a ser tratado tanto no campo da Aritmética quanto no da Álgebra. Nesse período, antes de apresentar a Teoria dos Logaritmos em seu livro, Curso de Matemática II Algebra, Aarão Reis [189-?] definia formação, por meio de uma ideia semelhante à que se apresenta, atualmente, sobre função nos livros didáticos:

A impossibilidade de determinar, por meio de medidas diretas, a maior parte das
grandezas, obrigou o espírito humano a procurar determinal-as indiretamente, isto é,
umas por meio de outras pelas relações precizas que entre elas existem. E, essas
relações precizas, que existem entre as grandezas, ligando-as umas as outras,
determinam as diversas FORMAÇÕES, cujo estúdo constitúe a ciencia matemática.
Assim, por exemplo, no fenômeno da quéda de um corpo, a altura e o tempo da
quéda estam intimamente ligados entre si, de modo que uma é formação do outro, e
vice-versa, podendo este ser determinado indiretamente por meio daquela, e vice-
versa (REIS, [189-?], p. 1, grifos do autor).

Em seguida, Reis [189-?] explica que o símbolo matemático da formação é $y=f(x)$ e que a "quantidade, a que se podem dar arbitráriamente valores, quaisquer, toma a dezignação de variável independente; e a outra, cujos valores rezultam dos atribuídos áquela toma a dezignação de variável correlativa dependente" (REIS, [189-?], p. 2, grifos do autor). Desse modo, Aarão Reis [189-?] já abordava o uso da função logarítmica, porém, ele a denominava como formação logarítmica:

LOGARITMO de um número é o termo duma progressão ARITMÉTICA, começando por 0 , correspondente a esse mesmo numero considerado como termo de outra progressão GEOMÉTRICA, começando por 1.

Do exposto decorre que:

1. $\left.{ }^{\circ}\right)$ - Os logaritmos deduzem-se também da formação exponencial, constituindo uma nova formação - a logarítmica - inversa da primeira; isto é, de:

deduz-se que:

$$
a^{x}=y
$$$$
x=\log _{a} y
$$

2. ${ }^{\circ}$ - Há identidade perfeita entre os logaritmos aritméticos e os logaritmos algébricos (REIS, [189-?], p. 185, grifos do autor). 
A partir da observação da abordagem de Reis [189-?], notamos que no final do século XIX, o logaritmo já era apresentado como expoente numa equação ou função, o que caracteriza o uso da concepção algébrico-funcional. Porém, isso não descaracteriza a associação dos logaritmos à concepção aritmética neste período, pois o autor associa os logaritmos à teoria das progressões para definir a formação logarítmica.

A partir de 1915, segundo Miguel e Miorim (2002), os programas oficiais situam o tema logaritmos exclusivamente no terreno da Álgebra. Gussi (2011) apresenta, por exemplo, o programa de ensino de 1915 do Colégio Pedro II, no qual verificamos a presença dos logaritmos somente no campo da Álgebra. Dentre os conteúdos algébricos desse programa temos:

Definições preliminares, Expressões algébricas, Operações algébricas (inclusive sobre as frações algébricas), Equações do $1^{\circ}$ e 2 graus e uma incógnita. Resolução. Sistema de equações do $1^{\circ}$ grau (formado por qualquer número de equações e com o mesmo número de incógnitas); e do $2^{\circ}$ grau (formado por duas equações a duas incógnitas), Progressões, Logaritmo, Matemática comercial (juros compostos, anuidades) (GUSSI, 2011, p.91).

Em 1923, em seu livro didático, Elementos de Álgebra, Perez y Marin já definia a função logarítmica como a inversa da exponencial, conforme a figura 5, a partir do que ele se referia como definição algébrica do logaritmo, que, segundo o autor, é o logaritmo como expoente. Ainda assim, Perez y Marin explica que os logaritmos aritméticos são os mesmos que os logaritmos algébricos, pois, por meio de uma tabela, ele mostra que os números em progressão aritmética são os expoentes dos números em progressão geométrica.

Figura 5 - Definição algébrica de logaritmo

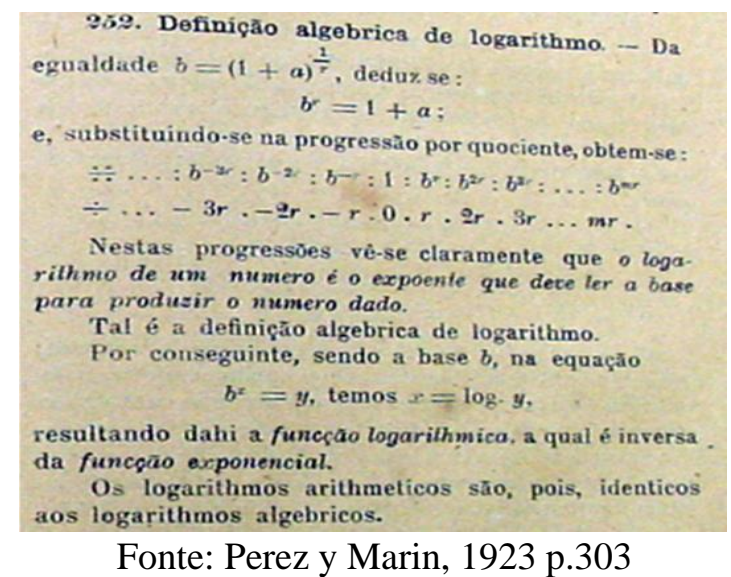

Porém, Perez y Marin não explora exercícios sobre função logarítmica. Somente explica quando a função é crescente ou decrescente, mas não há representação gráfica, pois no 
capítulo Teoria dos Logaritmos, no qual é abordada a função logarítmica, o autor dá mais ênfase às propriedades e tábuas de logaritmos.

A partir de 1929, é introduzido oficialmente o tópico Função Exponencial, o qual será vinculado à Função Logarítmica, no Programa de Matemática para o Curso Fundamental, apresentado no decreto 19890, de 18 de abril de 1931, dentro da Reforma Francisco Campos, que teve influência do matemático alemão Félix Klein (1849 - 1925).

De acordo com Gomes (2012) e Ambrósio et al (2003), o matemático alemão Félix Klein (1849 - 1925) presidiu uma comissão internacional, criada em 1908 no quarto congresso internacional de Matemática. Essa comissão foi criada para tratar de questões de ensino e teve como intuito estabelecer um estudo sobre o ensino secundário da Matemática em diversos países, bem como o Brasil.

Assim, isso se constituiu como um primeiro movimento internacional para modernizar o ensino.

No Brasil, o maior adepto das ideias modernizadoras foi o professor catedrático de Matemática do Colégio Pedro II, Euclides Roxo (1890-1950), que liderou a proposição de uma mudança radical nos programas de ensino da instituição, aprovada por sua congregação em 1928. A característica mais evidente dessa proposta era a unificação das antigas disciplinas de Aritmética, Álgebra, Geometria e Trigonometria, que eram ensinadas por docentes distintos e faziam uso de livros diferentes, em uma nova disciplina chamada Matemática (GOMES, 2012, p.19).

Conforme Gomes (2012), as ideias modernizadoras foram concretizadas em 1931, por meio da já citada reforma Francisco Campos no Governo Getúlio Vargas. Um dos pontos principais da nova proposta de ensino da época se refere à importância do conceito de função, cujo tema deveria ser tratado, num primeiro momento, intuitivamente e, depois, seria desenvolvido gradativamente ao longo das séries até ser aprimorado na quinta série, quando, ao aluno, seriam apresentadas as noções básicas do Cálculo Diferencial e Integral, como limite, derivada e integral.

Isso mostra o quanto Félix Klein influenciou o ensino de Matemática desse período no Brasil, pois, segundo o matemático alemão,

Nós, os chamados reformadores, queremos colocar, no centro do ensino, o conceito de função, como conceito da Matemática dos dois últimos séculos, que desempenha o papel fundamental em qualquer campo em que há noções de Matemática. Desejamos que o aluno comece a se familiarizar o mais rápido possível com este conceito, sempre sobre a base do constante emprego dos métodos gráficos, da representação de qualquer lei no plano das variáveis $(x, y)$, que hoje se utiliza em todas as aplicações da Matemática pelo caráter que se evidencia (KLEIN, [19--?], p.5, tradução nossa). 
Nos programas propostos para o Curso Complementar, apresentados através da Portaria Ministerial de 17 de março de 1936, segundo Miguel e Miorim (2002), o estudo das funções exponencial e logarítmica está associado ao Cálculo Diferencial e Integral e à Geometria Analítica.

Dentre os diversos conteúdos matemáticos apresentados na $1^{\mathrm{a}}$ série do Curso Complementar, segundo a Portaria Ministerial de 17 de março de 1936, temos:

16. Theoria do plano e da linha recta; problemas.

17. Esphera. Superficies do $2^{\circ}$ gráo; suas equações reduzidas

18. Funcções. Evoluções do conceito de funcção;-ponto de

vista actual. Continuidade. Classificação das funcções; pontos de vista que podem ser adoptados. Estudo elementar das funções exponencial e logarithimica. Funções circulares, directas e inversas.

19. Derivadas e differenciaes das funcções de uma variavel; definições, notações e interpretação geometrica.

20. Funcções de mais de uma variavel. Derivadas e differenciaes parciaes. Differencial total.

21. Derivadas e differenciaes sucessivas (BRASIL, 1936, p.5801).

Assim, a concepção algébrico-funcional dos logaritmos, neste momento, focada no estudo da função logarítmica como inversa da função exponencial, torna-se parte integrante de todos os programas do que é o equivalente ao nosso Ensino Médio atual. Vejamos dois livros da década de 1940 que se enquadravam nos programas em que se priorizava o estudo da função logarítmica como inversa da função exponencial.

No livro Matemática $2^{o}$ Ciclo $-2^{a}$ série de Cunha et al (1944), notamos que as progressões aritméticas e geométricas são abordadas antes da função exponencial e da logarítmica, que por sua vez são vistas antes da teoria dos logaritmos, o que não ocorre a partir da década de 1980.

Conforme a figura 6, ao introduzirem o tema função logarítmica, estes autores reforçam a ideia de função inversa e mostram que, analisando a função exponencial $y=a^{x}$, podemos concluir que há uma correspondência biunívoca entre $x$ e $y$, o que leva à definição de função logarítmica. 
Figura 6 - Definição de função logarítmica de Matemática $2^{o}$ Ciclo $-2^{a}$ série

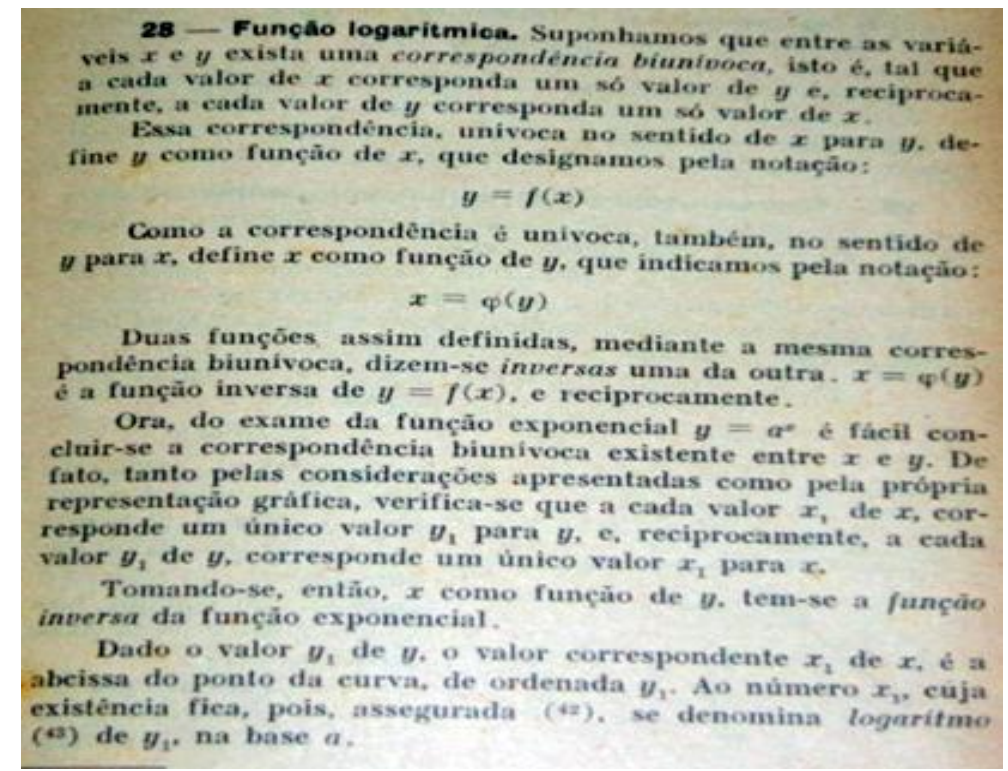

Fonte: Cunha et al, 1944, p. 49

Após esta definição, que evidencia a função logarítmica como inversa da exponencial, os autores exploram a representação gráfica das duas funções para abordar geometricamente conceitos da função logarítmica, como seu crescimento, decrescimento e sua simetria com a sua inversa, a exponencial.

Após abordarem o tema função logarítmica, os autores apresentam a teoria dos logaritmos, com a finalidade de defini-los e explorar suas propriedades, o que não é possível ser realizado somente com o estudo da função logarítmica. A figura 7 mostra a definição de logaritmo de Matemática $2^{o}$ Ciclo $-2^{a}$ série:

Figura 7 - Definição de logaritmo de Matemática $2^{o}$ Ciclo $-2^{a}$ série

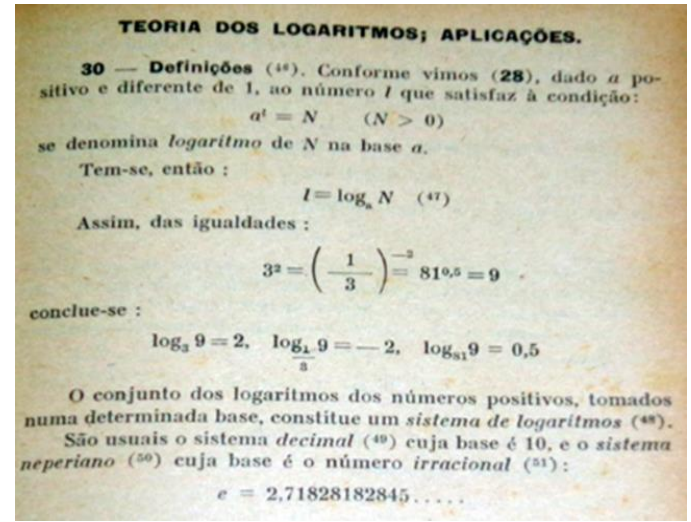

Fonte: Cunha et al, 1944, p. 51 
Na definição apresentada, os logaritmos são caracterizados como expoentes. Logo, as propriedades de potenciação são usadas em exemplos que permitem a dedução de propriedades de logaritmo.

Neste livro, os autores não propõem exercícios sobre função logarítmica. No capítulo sobre logaritmos, em geral, os exercícios são direcionados às aplicações de mantissa e característica, ao uso da definição, com a finalidade de deduzir em que base estão os logaritmos de determinados números, e ao emprego das propriedades. A figura 8 mostra alguns exercícios propostos em Matemática $2^{\circ}$ Ciclo $-2^{a}$ série:

Figura 8 - Exercícios propostos em Matemática $2^{o}$ Ciclo $-2^{a}$ série

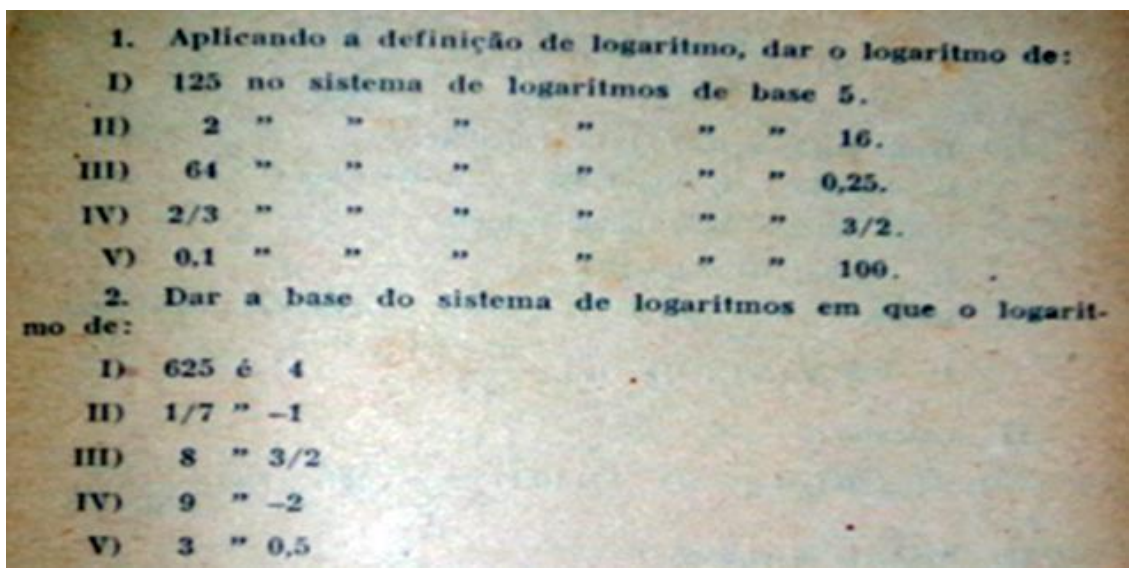

Fonte: Cunha et al, 1944, p. 69

Isso mostra um livro didático que busca apresentar conceitos de função logarítmica, mas não tem a pretensão de aprofundá-los, pois as ideias relacionadas ao tema não são enfatizadas por meio de exercícios que poderiam ensejar eventuais discussões acerca de domínio, imagem, gráfico e continuidade da função logarítmica.

Observemos agora outro livro da mesma época, de Almeida et al (1949), que mantém a ordem dos temas, apresentando as progressões aritméticas e geométricas antes dos logaritmos, assim como abordando a função logarítmica antes da teoria dos logaritmos.

Antes de definirem a função logarítmica, estes autores definem o logaritmo como expoente, como podemos ver:

Logaritmo de um número (19) - Sabemos (apêndice, pág. 435, nº 38), que, dados os números a e $\mathrm{b}$, ambos positivos e o primeiro diferente de 1 , existe sempre um único número real c tal que

$$
a^{c}=b \text {. }
$$

O número c é o que se chama logaritmo de b na base a. Designamos o logaritmo c de b, na base a, pelo símbolo 
e escrevemos então,

$$
c=\log _{a} b
$$

Em resumo:

O logaritmo, numa certa base (sempre positiva e diferente de 1) de um número positivo, é o expoente que se deve dar à base para se obter o número (ALMEIDA et al, 1949, p. 64, grifos dos autores).

A partir desta concepção de logaritmo, Almeida et al (1949) definem a função logarítmica, como mostra a figura 9:

Figura 9 - Definição de função logarítmica de Matemática Segunda Série - Curso Colegial Clássico e Científico

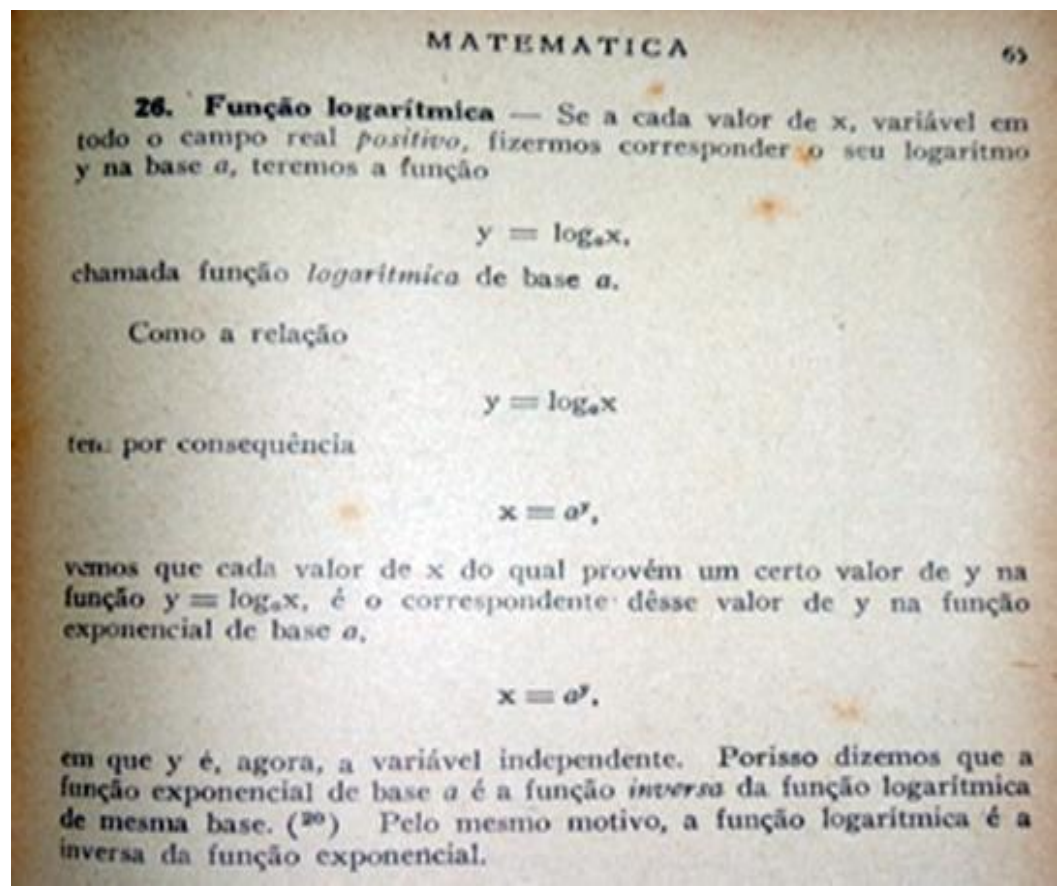

Fonte: Almeida et al, 1949 p. 65

Notamos que nesta definição os autores buscam associar a função logarítmica à exponencial para, em seguida, recorrer à representação gráfica e explorar conceitos de simetria, crescimento, decrescimento e continuidade. A figura 10 mostra alguns gráficos de função logarítmica e exponencial, extraídos de Almeida et al (1949), que evidenciam a simetria dessas funções em relação à reta $y=x$ : 
Figura 10 - Gráfico de função logarítmica e exponencial de Matemática Segunda Série -

\section{Curso Colegial Clássico e Científico}

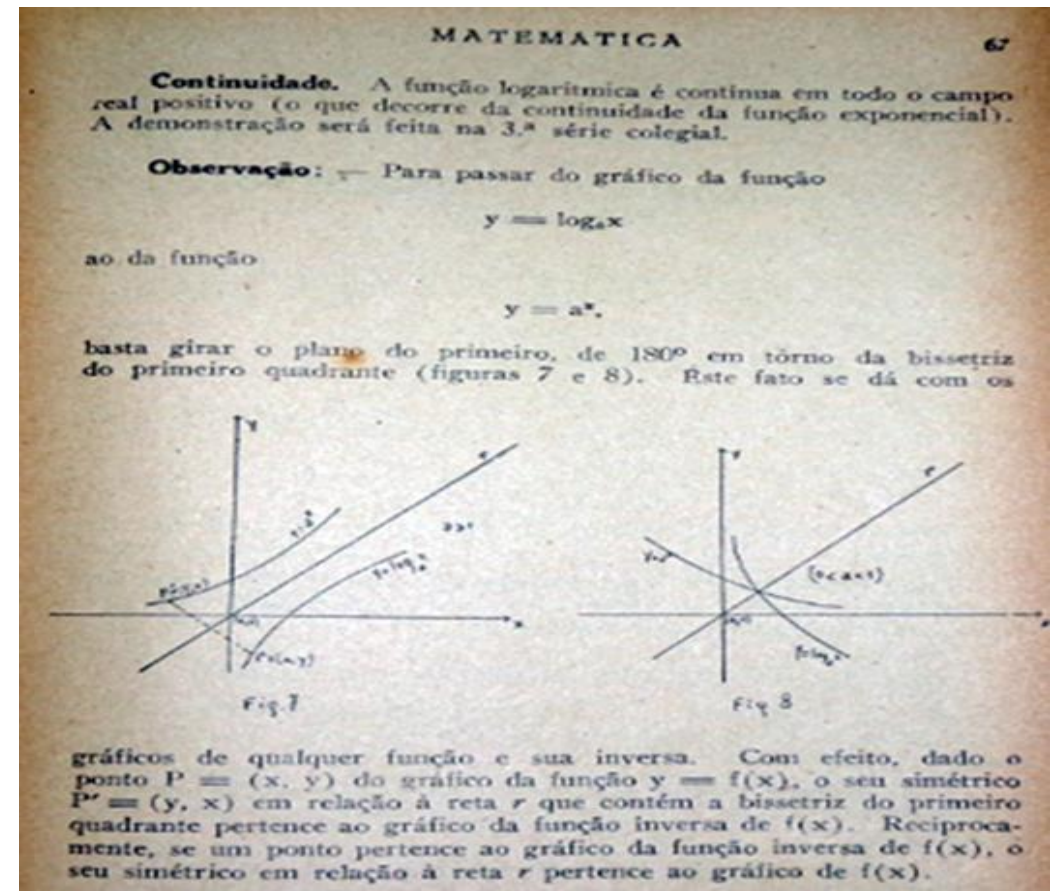

Fonte: Almeida et al, 1949 p. 67

Em Matemática Segunda Série - Curso Colegial Clássico e Científico (1949), também não há exercícios sobre função logarítmica. No capítulo Teoria dos Logaritmos - Aplicações, posterior ao capítulo Função Logarítmica, os autores abordam exercícios sobre logaritmos, mas não fazem nenhuma conexão com função logarítmica.

Em geral, os exemplos e exercícios do Capítulo Teoria dos Logaritmos - Aplicações buscam abordar aplicações de propriedades de logaritmos, propriedades de característica e mantissa e o uso de tábuas de logaritmos.

Uso das tábuas (29) - Ha dois problemas fundamentais que devemos resolver para a aplicação dos logaritmos nos cálculos numéricos. São os seguintes:

1..$\left.^{\circ}\right)$ Determinar o logaritmo de um número dado.

$\left.2^{\circ}{ }^{\circ}\right)$ Determinar o número que tem um logaritmo dado (ALMEIDA et al, 1949, p. 82, grifos dos autores).

Apesar de Almeida et al (1949) apresentarem a função logarítmica, os aspectos utilitários dos logaritmos, abordados por estes autores, ainda permaneciam relacionados às aplicações de cálculos numéricos que não necessitavam dos conceitos estudados no capítulo Função Logarítmica. Não se verifica, portanto, a aplicabilidade da função logarítmica nesta abordagem. 
Ao observarmos estas duas abordagens da década de 1940, podemos afirmar que Cunha et al (1944) definem a função exponencial, mostram sua continuidade e determinam a função logarítmica como a inversa da exponencial, caracterizando a bijetividade das duas funções, segundo os autores, por meio do exame da função exponencial e pela sua própria representação gráfica. Estes autores tratam da representação gráfica da função logarítmica, enfatizando a simetria entre os gráficos da função exponencial e logarítmica.

Seguindo esta abordagem, porém, com algumas diferenças no modo de expor o tema função logarítmica, Almeida et al (1949), primeiramente, definem o logaritmo como expoente e, em seguida, definem a função logarítmica, ressaltando que ela e a exponencial são inversas uma da outra. Desse modo, os autores mostram a representação gráfica da função logarítmica, explorando a ideia da simetria e de quando ela é crescente ou decrescente.

É possível notar, que, tanto Cunha et al, (1944), como Almeida et al (1949), são exemplos de autores de livros didáticos, publicados depois da reforma Francisco Campos, que tratam da Teoria dos Logaritmos, desde suas propriedades até as tábuas de logaritmos, depois da conceitualização da função logarítmica. Porém, essa abordagem não se manteve a partir da década de 1980.

Nesta seção, vimos que da $2^{a}$ metade do século XIX até 1912, os logaritmos eram tratados pelos livros didáticos quase sempre no campo da Aritmética, associados à teoria das progressões e caracterizados, portanto, pela concepção aritmética. Porém, com a Reforma da Educação Brasileira proposta por Benjamin Constant, a partir da década de 1890 os logaritmos apareceram oficialmente tanto no campo da Aritmética como no campo da Álgebra.

A partir de então, temos indícios da inserção da função logarítmica na Matemática Escolar, pois Reis [189-?], por exemplo, já tratava da função logarítmica, denominando-a como a formação logarítmica, a inversa da formação exponencial.

Em 1915, os logaritmos são situados exclusivamente no terreno da Álgebra e, em 1929, o tópico Função Exponencial é introduzido nos programas oficiais. Com a Reforma Francisco Campos, em 1931, há a vinculação entre os tópicos Função Logarítmica e Função Exponencial. 
Pela associação das funções exponencial e logarítmica ao Cálculo Diferencial e Integral e à Geometria Analítica, verificada a partir dos Programas Propostos para o Curso Complementar, em 1936, fica caracterizada a predominância da concepção algébricofuncional dos logaritmos, focada no logaritmo como expoente numa equação e na função logarítmica como inversa da função exponencial, o que permanece até os dias de hoje.

Algumas coleções da década de 1950, como por exemplo, de Carvalho (1957) e de Cunha et al (1959), não apresentam mudanças significativas, no que se refere ao logaritmo e à função logarítmica, em relação às abordagens que analisamos da década de 1940.

Vejamos algumas considerações sobre as décadas de 1960, 1970 e 1980, nas quais prevaleceu o domínio da concepção algébrico-funcional, consolidando o que verificamos na análise dos livros da década de 1940, mas também mostrando pequenas alterações no que se refere ao tratamento do logaritmo e da função logarítmica em livros didáticos de Matemática.

\subsection{Considerações sobre as décadas de 1960, 1970 e 1980}

A partir da segunda metade da década de 1960, por influência do Movimento da Matemática Moderna, de inspiração bourbakista, a concepção algébrico-funcional do logaritmo, visto tanto como operação inversa da potenciação quanto como função inversa da exponencial, passa a ser tratada com mais formalismo e numa mesma série.

Além disso, as funções exponencial e logarítmica não mais aparecem diretamente conectadas nem com a teoria das progressões e nem com noções de Geometria Analítica e de Cálculo Diferencial e Integral, mas passam a ser tratadas como um assunto da Matemática Secundária, no contexto das funções.

Com isso, ao contrário do que analisamos em relação aos livros da década de 1940, em Matemática Curso Colegial Moderno volume 1, por exemplo, de Barbosa, Netto e Rocha (1967), encontramos alguns exercícios sobre função logarítmica, cuja finalidade é fixar a ideia de domínio de função logarítmica, aprimorar o conceito de função inversa e estimular a construção de gráficos, por meio do uso de papel quadriculado ou milimetrado. Porém, nesta abordagem, ainda não se associava as aplicações à função logarítmica, assim como ocorria em anos anteriores.

Dadas as funções: $y=\log _{3} x$ e $y=\log _{4} x$, para que valores de $x$ as imagens da primeira são maiores do que as da segunda?

Usando papel quadriculado ou milimetrado, construir os gráficos cartesianos das funções: 

1) $y=\log _{2} x$
3) $y=\left|\log _{2} x\right|$
2) $\log _{1 / 2} x$
4) $y=\log _{10} x$

(BARBOSA, NETTO e ROCHA, 1967, p. 145).

As funções: $y=\log _{e}\left(x+\sqrt{x^{2}+1}\right)$ e $x=\frac{e^{y}-e^{-y}}{2}$ onde $e$ é o número de EulerNeper (cujo valor é aproximadamente 2,718) são inversas entre si?

NOTA: $\log =\log$ aritmo de base 10 .

Se $y=\log \left(x^{2}-7 x+6\right)$, qual o domínio desta função?

Qual o domínio da função $f(x)=\log _{2}\left(2-x^{2}\right)$ ?

Qual o domínio da função $f(x)=\log (\log x)$ ?

Qual o domínio da função $\log _{2}\left[\log _{2}\left(\log _{2} x\right)\right]$ ? (BARBOSA, NETTO e ROCHA, 1967, p. 147).

Segundo Silva (2009), a década de 1970 é marcada por um período de transição entre o abandono do Movimento da Matemática Moderna e a criação da Educação Matemática como campo de pesquisa. Contudo, algumas coleções, como por exemplo, de Góes e Netto (1973) e de Imenes, Jabucovic e Trotta (1979) têm a mesma característica da década de 1960, em relação à abordagem do logaritmo e da função logarítmica, cujos conteúdos são apresentados, de modo geral, sob a concepção algébrico-funcional e sem a associação da função logarítmica às aplicações.

A partir de meados da década de 1980, as críticas ao Movimento da Matemática Moderna se intensificam e novas tendências vêm a se configurar na Educação Matemática brasileira. Logo, o ensino de logaritmos passa por uma redefinição.

Neste período,

A Proposta Curricular para o ensino de matemática $-2^{\circ}$ grau - do Estado de São Paulo, por exemplo, insere os logaritmos em um grande tema denominado Potências e Expoentes, dentro de uma abordagem pedagógica bastante diferenciada em relação aos programas e livros didáticos de períodos anteriores (MIGUEL e MIORIM, 2002, p.97).

Segundo Miguel e Miorim (2002), o logaritmo aparece, então, como um sub-tópico da função exponencial intitulado: problema inverso determinação de expoentes (ou logaritmos). No entanto, a concepção algébrico-funcional de logaritmo como função inversa da função exponencial continua dominante. Em tal abordagem, também continuam prevalecendo algumas características da década de 1960, tais como a desvinculação dos logaritmos da teoria das progressões e do ensino de Cálculo Diferencial e Integral, tema este que não é mais incluído entre os recomendados para o Ensino Médio.

Na coleção de Bongiovanni et al (1988), verificamos uma mudança, em relação às décadas passadas, na ordem dos temas a serem abordados antes e depois da função 
logarítmica. Assim, além de outros temas como, por exemplo, conjuntos e funções, temos neste livro:

- Unidade 6 - Equação Exponencial

- Unidade 7 - Função Exponencial

- Unidade 8 - Logaritmo

- Unidade 9 - Função Logarítmica

- Unidade 10 - Progressões Aritméticas

- Unidade 11 - Progressões Geométricas

Porém, neste mesmo volume, há também um contraponto, em relação à análise de Miguel e Miorim (2002), no que se refere ao domínio da concepção algébrico-funcional de logaritmo como função inversa da função exponencial, no período da década de 1980. Após abordarem os temas equação exponencial, função exponencial e logaritmo, todos em unidades separadas, os autores exploram a ideia da função logarítmica, sem mencionar a função exponencial, utilizando a função $f(x)=\log _{2} x$ como exemplo a ser discutido por meio de gráfico e tabela, como mostra a figura 11:

Figura 11 - Gráfico de função logarítmica em Aulas Práticas de Matemática - $2^{o}$ grau

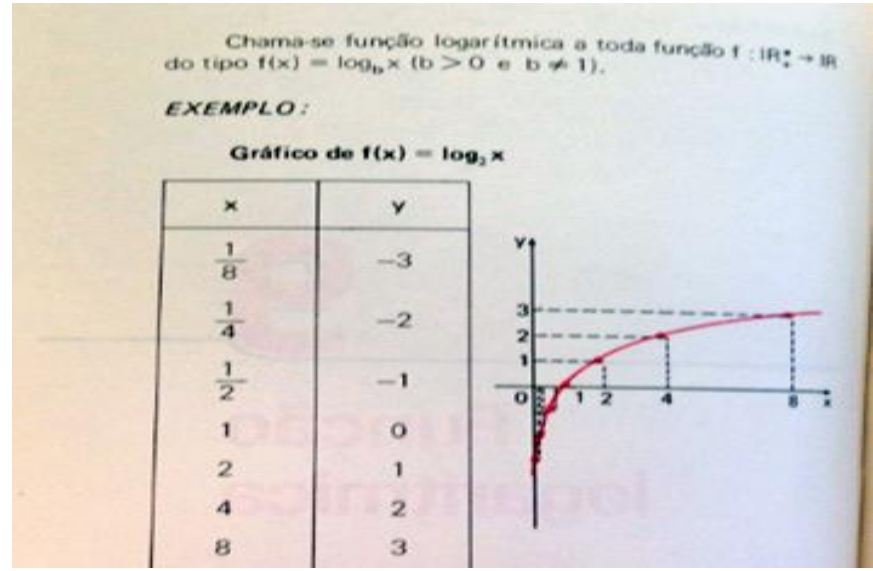

Fonte: Bongiovanni et al, 1988 p.174

Os autores mostram, através de exemplos e exercícios, quando que a função logarítmica é crescente ou decrescente, a fim de apresentar o sub-tópico inequações logarítmicas e encerrar a unidade com exercícios que, em geral, buscam aprimorar conceitos sobre função logarítmica, como imagem e domínio. 
Vejamos agora, na seção 4.3, algumas aplicações de logaritmo e função logarítmica, pois nelas consiste o principal motivo pelo qual esses conteúdos se inserem na Matemática Escolar brasileira atual, segundo o que podemos verificar em documentos oficiais, como por exemplo, as Orientações Curriculares para o Ensino Médio (2006) e os PCN's+ Ensino Médio (2002).

Em seguida, na seção 4.4, apresentamos duas abordagens atuais, nas quais se verifica uma tentativa de resgatar a concepção aritmética, mas prevalece o domínio da concepção algébrico-funcional, que tem caracterizado os logaritmos nos livros didáticos de Matemática, desde a década de 1930, a partir da Reforma Francisco Campos, em 1931, e dos Programas Propostos para o Curso Complementar, em 1936.

\subsection{Aplicações}

Como mostram as Orientações Curriculares para o Ensino Médio (2006), há hoje uma preocupação maior em relacionar a função logarítmica e exponencial às aplicações, com o intuito de tornar mais interessante o ensino desses tópicos.

É pertinente discutir o alcance do modelo linear na descrição de fenômenos de crescimento, para então introduzir o modelo de crescimento/decrescimento exponencial $\left(f(x)=a^{x}\right)$. É interessante discutirem as características desses dois modelos, pois enquanto o primeiro garante um crescimento à taxa constante, o segundo apresenta uma taxa de variação que depende do valor da função em cada instante. Situações reais de crescimento populacional podem bem ilustrar o modelo exponencial. Dentre as aplicações da Matemática, tem-se o interessante tópico de Matemática Financeira como um assunto a ser tratado quando do estudo da função exponencial - juros e correção monetária fazem uso desse modelo. Nos problemas de aplicação em geral, é preciso resolver uma equação exponencial, e isso pede o uso da função inversa - a função logaritmo. $O$ trabalho de resolver equações exponenciais é pertinente quando associado a algum problema de aplicação em outras áreas de conhecimento, como Química, Biologia, Matemática Financeira, etc. Procedimentos de resolução de equações sem que haja um propósito maior devem ser evitados. Não se recomenda neste nível de ensino um estudo exaustivo dos logaritmos (BRASIL, 2006, págs. 74 e 75).

Essa ideia de não se recomendar um estudo exaustivo dos logaritmos, a fim de enfatizar suas aplicações, também é ressaltada, pelos PCN's+ Ensino Médio (2002), na abordagem dos Temas estruturadores do ensino de Matemática:

É importante evitar detalhamentos ou nomenclaturas excessivos. Por exemplo, se o único caso de funções inversas que os alunos verão no ensino médio forem as funções exponencial e logaritmo, não há necessidade de todo o estudo sobre funções injetoras, sobrejetoras e inversíveis, assim como se o foco do estudo estiver na análise de gráficos e nas aplicações da função logarítmica, podemos questionar por que estudar cologaritmos, característica e mantissa (BRASIL, 2002, p.120). 
A partir destas observações das Orientações Curriculares para o Ensino Médio (2006) e dos PCN's+ Ensino Médio (2002), notamos que na orientação oficial atual há um distanciamento da Matemática Moderna, em que o formalismo prevalecia sobre as aplicações.

Apresentamos, então, algumas aplicações de logaritmos e função logarítmica e o modo como elas aparecem no contexto da Matemática Escolar, por meio de livros didáticos e do Caderno do Aluno (2014). Abordamos também algumas aplicações verificadas no Exame Nacional do Ensino Médio (ENEM), pois, além de servir como instrumento de acesso ao Ensino Superior, segundo o que consta em seu Edital (2016), este exame tem como eixos cognitivos o domínio de linguagens, a compreensão de fenômenos, a resolução de situaçãoproblema, a construção de argumentos e a elaboração de propostas. Com isso, acreditamos que se tornam importantes as considerações sobre a maneira como o ENEM apresenta as questões relacionadas às aplicações de logaritmo e função logarítmica.

\subsubsection{Juros compostos}

Considere o caso de um capital $C_{0}$ aplicado por um período de tempo $t$, que rendeu ao investidor o capital inicial acrescido de juros $\mathrm{J}$. Chamamos de montante $\mathrm{M}$ a soma $C_{0}+\mathrm{J}$ e $\beta$, a taxa de juros, isto é, $\beta=\frac{J}{C_{0}}$.

Um capital inicial $C_{0}$, aplicado no regime de juros compostos de taxa $\beta$, em $n$ períodos de tempo, transforma-se em um montante igual a $C_{0}(1+\beta)^{n}$.

De fato, após um período de tempo, o montante torna-se igual a $C_{0}+C_{0} . \beta=$ $=C_{0}(1+\beta)$. Decorridos 2 períodos de tempo, o montante é dado por:

$$
C_{o}(1+\beta)+C_{o}(1+\beta) \cdot \beta=C_{0}(1+\beta) \cdot(1+\beta)=C_{0}(1+\beta)^{2} .
$$

Assim, em $\mathrm{n}$ períodos de tempo o capital obtido é dado por: $C_{0}(1+\beta)^{n}$. Considerando uma fração $\frac{1}{n}$ do período de tempo, o capital aplicado à mesma taxa de juros, $\frac{\beta \cdot C_{0}}{n}$, renderia, então, o montante do período, que seria de $C_{0}+\frac{\beta \cdot C_{0}}{n}=C_{0}\left(1+\frac{\beta}{n}\right)$. Em mais $\frac{1}{n}$ do período de tempo, o montante resultante seria:

$$
C_{0}\left(1+\frac{\beta}{n}\right)+C_{0}\left(1+\frac{\beta}{n}\right) \frac{\beta}{n}=C_{O}\left(1+\frac{\beta}{n}\right)^{2}
$$

Assim, após $n$ períodos de tempo, o montante obtido se tornaria igual a: 


$$
C_{0}\left(1+\frac{\beta}{n}\right)^{n}
$$

Sendo $M(t)=C_{0}(1+\beta)^{t}$, para obter o tempo necessário $t$ que um capital inicial $C_{0}$ atinja o valor $M(t)$, podemos usar logaritmos:

$$
\begin{aligned}
M(t)=C_{0}(1+\beta)^{t} & \Rightarrow \log [M(t)]=\log \left[C_{0}(1+\beta)^{t}\right] \Rightarrow t \cdot \log C_{0}(1+\beta)= \\
& =\log [M(t)] \Rightarrow t=\frac{\log [M(t)]}{\log C_{0}(1+\beta)} .
\end{aligned}
$$

Se o investidor puder ter os juros incorporados ao capital a cada instante, após $n$ períodos de tempo, o montante recebido seria de $\lim _{n \rightarrow \infty} C_{0}\left(1+\frac{\beta}{n}\right)^{n}=C_{0} \cdot e^{\beta}$.

Quando a taxa de juros é dada, por exemplo, em anos, sendo $i \%$ ao ano e $\beta=\frac{i}{100}$, tem-se que um capital inicial $C_{0}$, aplicado a essa taxa, depois de $t$ anos, será dado por:

$$
\lim _{n \rightarrow \infty} C_{0}\left(1+\frac{\beta \cdot t}{n}\right)^{n}=C_{0} e^{\beta \cdot t}
$$

No livro didático de Degenszajn et al (2007), por exemplo, os juros compostos são uma motivação para o estudo dos logaritmos, pois os problemas envolvendo juros compostos são usados como introdução para o subcapítulo Logaritmos, assim como para o subcapítulo Função Logarítmica.

Na introdução do subcapítulo Logaritmos, Degenszajn et al (2007, p. 103) propõem o seguinte problema: "Um caminhão custa hoje R\$ 100 000,00 e sofre uma desvalorização de $10 \%$ por ano de uso. Depois de quanto tempo de uso o valor do veículo será igual a $\mathrm{R} \$ 20$ 000,00?"

A partir desse problema, os autores mostram que o valor do veículo, em reais, decresce a cada ano, de acordo com a sequência, na qual $x$ indica o número de anos de uso: 100 000; (0,9). 100 000; $(0,9)^{2} .100000 ;(0,9)^{3} .100000 ; \ldots ;(0,9)^{x} .100000$.

Para responder o problema, é necessário, então, resolver a equação $(0,9)^{x}=0,2$, cuja solução depende do uso dos logaritmos, pois, nesse caso, segundo Degenszajn et al (2007, p. 103), "não conseguimos reduzir todas as potências à mesma base". 
A partir dessa motivação, propiciada pelo problema de juros compostos, neste subcapítulo Logaritmos, os autores definem o logaritmo e, posteriormente, abordam as consequências da definição, propriedades e outras aplicações, como o potencial hidrogeniônico.

Na introdução do subcapítulo Função Logarítmica, Degenszajn et al (2007, p. 115) propõem o seguinte problema: “Cássio está depositando suas economias em uma caderneta de poupança especial, que rende $1 \%$ ao mês. Por quantos meses ele deverá deixar o dinheiro na conta para que seu valor dobre?".

Denominando $c$ como o valor inicial depositado por Cássio, os autores mostram que ao final de $n$ meses de aplicação, seu saldo na poupança será de $(1,01)^{n} c$. Degenszajn et al (2007) mostram que, se quiséssemos descobrir em quantos meses deverá dobrar o saldo inicial de Cássio, devemos aplicar os logaritmos, de tal forma que: $n=\log _{1,01} 2$, que é aproximadamente 70 meses.

Aproveitando essa ideia, Degenszajn et al (2007, p. 115) perguntam: "E se quiséssemos que o capital inicial fosse multiplicado por $x$ ?”. Com isso, os autores mostram que, a partir desse problema, obteríamos um caso particular da função logarítmica $(f(x)=$ $\left.=\log _{1,01} x\right)$.

Em seguida, esses autores definem a função logarítmica, exploram sua representação gráfica e mostram a aplicação da função logarítmica na escala Richter.

O livro didático de Degenszajn et al (2007) é, portanto, um exemplo de abordagem que mostra a aplicabilidade dos logaritmos e da função logarítmica na resolução de problemas que envolvem juros compostos, caracterizando o uso de ferramentas matemáticas em situações cotidianas.

\subsubsection{Dinâmica populacional}

Conforme Zill (2011), Thomas Malthus, em 1798, foi quem concebeu uma das primeiras tentativas de modelagem do crescimento populacional humano. $\mathrm{O}$ modelo malthusiano pressupõe que a taxa, segundo a qual a população de um país cresce em um determinado instante, é proporcional à população total do país naquele instante. 
“Apesar de um pouco equivocado e muito criticado em alguns conceitos, este modelo possui relevância devido à sua contribuição para a evolução dos modelos, haja vista que serviu de base para muitos outros” (LEITE e MAGALHÃES, 2012, p.351).

Partindo da hipótese de Malthus, quanto mais pessoas houver em um instante t, mais pessoas existirão no futuro. Na linguagem matemática, considerando $\mathrm{P}(\mathrm{t})$ como a população total no instante t, a hipótese do modelo malthusiano pode ser expressa por:

$$
\text { 1) } \frac{d P}{d t}=k \cdot P, k>0
$$

Disso, decorre que: $\frac{d P}{P}=k d t \Rightarrow \int \frac{d P}{P}=\int k d t \Rightarrow \ln P=k t+b$, em que $b$ é uma constante. Da última igualdade, temos:

$$
P(t)=e^{k t+b}=e^{k t} \cdot e^{b}
$$

Denotando a população inicial $P(0)$ como $P_{0}$, temos:

$$
P(0)=e^{0} \cdot e^{b}=e^{b}=P_{0} \Rightarrow P(t)=P_{0} \cdot e^{k t}
$$

Esse modelo simples, embora não leve em conta muitos fatores que podem influenciar a população humana tanto em seu crescimento quanto em seu declínio (imigração e emigração, por exemplo), não obstante mostrou-se razoavelmente preciso na previsão da população dos Estados Unidos entre os anos de 1790 e 1860 (ZILL, 2011, p. 21).

Zill (2011) explica que é raro encontrar populações que crescem a uma taxa conforme o modelo de Malthus, contudo, o modelo malthusiano é ainda usado para modelar o crescimento de pequenas populações em um intervalo de tempo consideravelmente curto, como, por exemplo, crescimento de bactérias em uma placa de Petri.

No livro didático de Almeida et al (2004), encontramos um exercício do capítulo Logaritmos, extraído do vestibular da Universidade Federal do Ceará (UF-CE), que trata da dinâmica populacional entre duas cidades:

(UF-CE) Suponha que o crescimento populacional de duas cidades, A e B, seja descrito pela equação: $P(t)=P_{0} e^{k t}$, em que:

$P_{0}$ é a população no início da observação; $k$ é a taxa de crescimento populacional na forma decimal; $t$ é o tempo medido em anos; $e$ é a base do logaritmo natural; $P(t)$ é a população $t$ anos após o início da observação. Se no início de nossa observação a população da cidade $\mathrm{A}$ é o quíntuplo da população da cidade $\mathrm{B}$, e se a taxa de crescimento populacional de A permanecer em $2 \%$ ao ano e a de B em $10 \%$ ao ano, em quantos anos, aproximadamente, as duas cidades possuirão o mesmo número de habitantes? Considere $\ln 5=1,6$ (ALMEIDA et al, 2004, p. 235). 
Para resolver o exercício é necessário o uso da definição e de propriedade do logaritmo. Seja $P_{A}(t)$ a população da cidade $\mathrm{A}, P_{B}(t)$ a população da cidade B e $P_{0}$ a população inicial de B.

Pelas hipóteses do enunciado, temos:

$$
P_{A}(t)=5 \cdot P_{0} \cdot e^{0,02 t} \text { e } P_{B}(t)=P_{0} \cdot e^{0,1 t}
$$

Com base na pergunta, devemos ter:

$$
\begin{gathered}
P_{A}(t)=P_{B}(t) \Rightarrow 5 \cdot P_{0} \cdot e^{0,02 t}=P_{0} \cdot e^{0,1 t} \Rightarrow 5 \cdot e^{0,02 t}=e^{0,1 t} \Rightarrow e^{0,08 t}=5 \Rightarrow \ln e^{0,08 t}= \\
=\ln 5 \Rightarrow 0,08 t=1,6 \Rightarrow t=20 \text { anos. }
\end{gathered}
$$

Este tipo de exercício pode ilustrar o uso dos logaritmos aplicado à dinâmica populacional, proporcionando uma relação importante entre a Matemática e a Geografia, a partir da ideia de estimativa de populações.

\subsubsection{Desintegração radioativa}

Conforme Lima (2009), os átomos de substâncias radioativas como, por exemplo, o urânio e o rádio tendem naturalmente a se desintegrarem emitindo partículas e se transformando em uma substância não radioativa. Assim, com o passar do tempo, a quantidade de material existente neste corpo se desintegra de maneira proporcional à massa da substância original.

Considerando $M(t)$ a massa da substância no instante t, podemos, então, supor que:

$$
\text { 2) } \frac{d M}{d t}=-k \cdot M, k>0 \text {. }
$$

Obtemos, assim, uma equação análoga à equação 1) do crescimento populacional. Disso, decorre que:

$$
M(t)=M_{0} \cdot e^{-k t} \text {, em que } M_{0} \text { é a massa da substância no instante } t=0 \text {. }
$$

Para calcular a meia-vida da substância, que é o tempo $\left(t_{1 / 2}\right)$ que ela leva para desintegrar metade da sua massa radioativa, devemos considerar: $M\left(t_{1 / 2}\right)=\frac{M_{0}}{2}$. Logo, 


$$
\begin{gathered}
M_{0} \cdot e^{-k \cdot t_{1 / 2}}=\frac{M_{0}}{2} \Rightarrow e^{-k \cdot t_{1 / 2}}=\frac{1}{2} \Rightarrow \\
\Rightarrow \ln e^{-k \cdot t_{1 / 2}}=\ln \frac{1}{2} \Rightarrow-k \cdot t_{1 / 2}=\ln \frac{1}{2} \Rightarrow \\
\Rightarrow t_{1 / 2}=-\frac{1}{k} \cdot \ln \frac{1}{2} \Rightarrow t_{1 / 2}=\frac{\ln 2}{k} .
\end{gathered}
$$

Assim, a meia-vida pode ser dada por $t_{1 / 2}=\frac{\ln 2}{k}$, desde que se conheça a taxa $(k)$ de desintegração, que varia entre as substâncias.

No capítulo Logaritmo e Função Logarítmica da coleção de Dante (2007), é possível encontrar exercícios sobre desintegração radioativa. Em um deles Dante (2007, p. 250) pede para mostrar a fórmula $t_{1 / 2}=\frac{\ln 2}{k}$ : "Mostre que uma substância radioativa que decai exponencialmente de acordo com a fórmula $m(t)=m_{0} e^{-k t}$ tem meia-vida igual a $\frac{\ln 2}{k}$, .

Em outro exercício, Dante (2007, p. 239, grifos do autor) pergunta: "Em quantos anos $500 \mathrm{~g}$ de uma substância radioativa, que se desintegra a uma taxa de $3 \%$ ao ano, se reduzirão a $100 \mathrm{~g}$ ? Use $Q=Q_{0} \cdot e^{-r t}$, em que $\boldsymbol{Q}$ é a massa da substância, $\mathbf{r}$ é a taxa e $\mathbf{t}$ é o tempo em anos".

Para responder a pergunta deste exercício é necessário resolver a equação exponencial $100=500 \cdot e^{-0,03 t}$. Para isso, o autor mostra que é necessário o uso do logaritmo natural e de propriedade de logaritmo, assim como ele usa uma aproximação para o valor de $\ln 5$ :

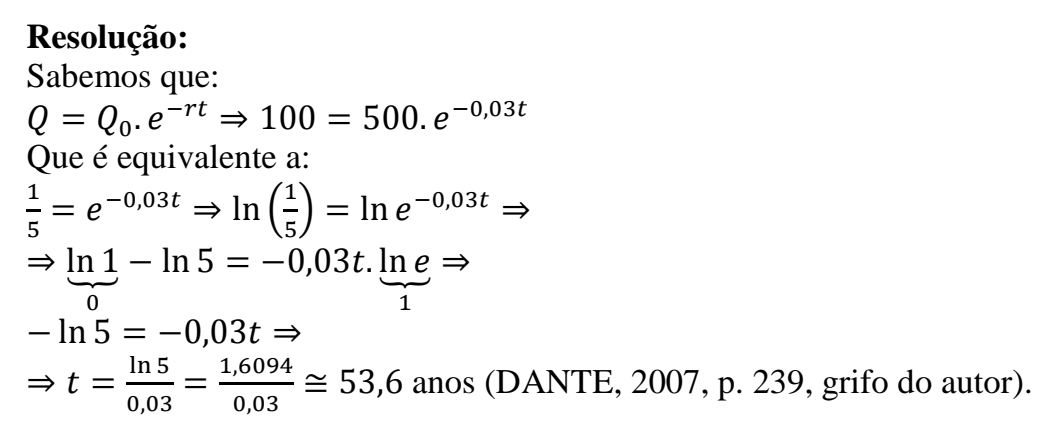

Por meio da ideia deste exercício, Dante (2007, p. 252) explora outros exercícios a partir da fórmula $Q=Q_{0} \cdot e^{-r t}$, na qual $Q$ é a massa da substância, r é a taxa e t é o tempo em anos: "Uma substância radioativa se desintegra a uma taxa de 8\% ao ano. Em quantos anos $50 \mathrm{~g}$ dessa substância se reduzirão a 5 g?" 
Com isso, notamos que Dante (2007) é um autor de livro didático que ilustra a aplicabilidade dos logaritmos em exercícios sobre desintegração radioativa, integrando o estudo da Matemática com a Química.

No ENEM (2013), há uma questão sobre desintegração radioativa na qual se pergunta sobre a redução relativa à massa inicial do césio-137:

\footnotetext{
Em setembro de 1987, Goiânia foi palco do maior acidente radioativo ocorrido no Brasil, quando uma amostra de césio-137, removida de um aparelho de radioterapia abandonado, foi manipulada inadvertidamente por parte da população. A meia-vida de um material radioativo é o tempo necessário para que a massa desse material se reduza à metade. A meia-vida do césio-137 é 30 anos e a quantidade restante de massa de um material radioativo, após $t$ anos, é calculada pela expressão $M(t)=$ A. $(2,7)^{k t}$, onde A é a massa inicial e k é uma constante negativa.

Considere 0,3 como aproximação para $\log _{10} 2$.

Qual o tempo necessário, em anos, para que uma quantidade de massa do césio-137 se reduza a $10 \%$ da quantidade inicial? (BRASIL, 2013, p.27).
}

Pelo enunciado temos que o tempo $\left(t_{1 / 2}\right)$ que a massa do césio-137 leva para desintegrar metade da sua massa radioativa é de 30 anos, logo:

$$
\begin{gathered}
A \cdot(2,7)^{30 k}=\frac{A}{2} \Rightarrow(2,7)^{30 k}=\frac{1}{2} \Rightarrow \log (2,7)^{30 k}=\log 2^{-1} \Rightarrow \\
\Rightarrow 30 k \cdot \log (2,7)=-0,3 \Rightarrow k=-\frac{0,3}{30 \cdot \log (2,7)}=-\frac{0,01}{\log (2,7)}
\end{gathered}
$$

Para que a massa do césio-137 se reduza a 10\% da quantidade inicial, devemos ter:

$$
\begin{gathered}
A .(2,7)^{k t}=0,1 A \Rightarrow(2,7)^{k t}=0,1(3) . \text { Como } k=-\frac{0,01}{\log (2,7)}, \text { então: } \\
\log 2,7=-\frac{0,01}{k} \Leftrightarrow 10^{-\frac{0,01}{k}}=2,7 \Rightarrow \\
\Rightarrow\left(10^{-\frac{0,01}{k}}\right)^{k t}=2,7^{k t} \Rightarrow 10^{-0,01 t}=2,7^{k t}
\end{gathered}
$$

Pela equação 3), temos:

$$
10^{-0,01 t}=0,1=10^{-1} \Leftrightarrow-0,01 t=-1 \Rightarrow t=\frac{1}{0,01}=100 \text { anos. }
$$

Nesta questão do ENEM (2013) que apresentamos, notamos que se trata de uma aplicação da Matemática na Química, evidenciando a importância dos logaritmos, por meio do uso de propriedades de logaritmo e da função exponencial $M(t)=A \cdot(2,7)^{k t}$. 


\subsubsection{Potencial hidrogeniônico}

Os logaritmos também são usados na representação do potencial hidrogeniônico, ou simplesmente pH. Segundo Motoki (2016), esse conceito, que relaciona logaritmos, foi criado pelo químico dinamarquês S. P. L. Sorensen, para representar a concentração do íon hidrogênio $\left[H^{+}\right]$, com a finalidade de medir a acidez de uma solução usada na fabricação de cerveja.

$\mathrm{O}$ pH indica a quantidade aproximada de íons $H^{+}$que se encontram livres no líquido, indicando a concentração (quantidade por unidade de volume) de tais íons. A escala de pH é logarítmica e determina-se o valor do $\mathrm{pH}$ de uma solução aquosa a partir da concentração de íons de $H^{+}$presentes nela: $p H=-\log \left[H^{+}\right]$. O pH de uma solução varia de 0 a 14 , sendo que:

- $\quad p H<7 \Rightarrow$ soluções ácidas.

- $p H>7 \Rightarrow$ soluções básicas.

- $p H=7 \Rightarrow$ soluções neutras.

Após explicar sucintamente sobre o significado de potencial hidrogeniônico, Furtado e Rosso Jr. (2011) exploram um exercício resolvido sobre $\mathrm{pH}$, utilizando propriedades operatórias de logaritmos:

Para classificar uma substância como ácida, básica ou neutra, os químicos utilizam um índice conhecido como $\mathrm{pH}$, que é dado por:

$$
p H=-\log \left[H^{+}\right]
$$

em que $\left[H^{+}\right]$é a concentração de íons hidrogênio em mols por litro. Estime o pH de cada uma das substâncias:

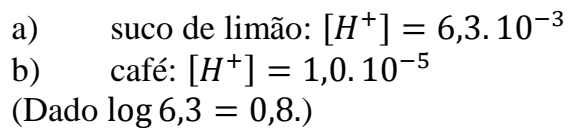

Resolução

a) $\quad p H=-\log \left[H^{+}\right]=-\log \left(6,3 \cdot 10^{-3}\right)=-\left(\log 6,3+\log 10^{-3}\right)=$ $=-(\log 6,3-3 \cdot \log 10)=-(0,8-3)=2,2$

b) $\quad p H=-\log \left[H^{+}\right]=-\log \left(1,0.10^{-5}\right)=-\left(\log 1+\log 10^{-5}\right)=$ $=-(\log 1-5 \cdot \log 10)=-(-5)=5($ FURTADO e ROSSO JR., 2011, p. 275, grifo dos autores).

A partir da ideia deste exercício, os autores propõem que seja calculado o $\mathrm{pH}$ de uma substância que tem $\left[H^{+}\right]=5,4 \cdot 10^{-6}$ mols/litro, usando $\log 2=0,30$ e $\log 3=0,48$. 
Assim como o livro de Dante (2007) ilustra a ideia da desintegração radioativa, o livro didático de Furtado e Rosso Jr. (2011) também é exemplo de abordagem que estabelece relações entre a Matemática e a Química, por meio da aplicabilidade dos logaritmos no cálculo do $\mathrm{pH}$.

\subsubsection{Escala Richter e Escala de Magnitude de Momento (MMS)}

Conforme Motoki (2016), Roballo (2014) e Pinheiro (2013), em 1935 os abalos sísmicos já eram registrados por sismógrafos e, utilizando-os em seus estudos ao sul da Califórnia, Charles Francis Richter e Beno Gutenberg colheram dados para criação de um sistema que calculasse a magnitude das ondas obtidas. Do trabalho de Richter e Gutenberg surgiu uma escala que recebeu o nome de apenas um dos seus criadores e utiliza logaritmos de base 10 para ser composta. A sistemática utilizada foi definir um abalo padrão para o cálculo dos demais, obtidos através do logaritmo decimal do quociente entre o registro de um novo abalo e o padrão adotado. Assim, temos que todos os registros desta escala nada mais são que um expoente para a potência de 10 que indica o quociente entre o abalo real e o abalo padrão.

A Escala Richter, também conhecida como Escala de Magnitude Local $\left(M_{l}\right)$, atribui um número único para quantificar o nível de energia liberada por um sismo. Pelo fato de ser uma escala logarítmica de base 10, um terremoto que mede 5 na Escala Richter tem uma amplitude sísmica 10 vezes maior do que uma que mede 4.

Uma das fórmulas utilizada nesta escala é: $M_{l}=\log \frac{A}{A_{0}}=\log A-\log A_{0}$, em que $M_{l}$ é a magnitude local, $A$ é a amplitude máxima medida no sismógrafo e $A_{0}$ é uma amplitude de referência.

A fórmula proposta por Richter pode ser escrita de várias formas distintas, dependendo das variáveis escolhidas para a sua composição. Outra fórmula utilizada nesta

escala é: $M_{l}=\frac{2}{3} \cdot \log \left(\frac{E}{E_{0}}\right)$, em que $E$ é a energia liberada pelo terremoto, em $\mathrm{kWh}$, e $E_{0}=$ $=7 \times 10^{-3} \mathrm{kWh}$.

Na seção Matemática e Geologia do capítulo Função Logarítmica do livro didático de Degenszajn et al (2007), os autores citam um terremoto de 9 graus, na escala Richter, que foi registrado na costa da ilha de Sumatra, na Indonésia, no dia 26 de dezembro de 2004. Eles 
explicam a origem da escala Richter, mostrando que ela serve para avaliar a magnitude de um terremoto, conforme a energia liberada sob a forma de ondas, medida pelos sismógrafos. A tabela 2, extraída de Degenszajn et al (2007), mostra a escala Richter e seus efeitos:

Tabela 2 - A escala Richter e seus efeitos

\begin{tabular}{|c|c|}
\hline 0 a 1,9 & Tremor detectado apenas por um sismógrafo. \\
\hline 2 a 2,9 & Oscilações de objetos suspensos. \\
\hline 3 a 3,9 & Vibração parecida com a da passagem de um caminhão \\
\hline 4 a 4,9 & Vidros quebrados, queda de pequenos objetos. \\
\hline 5 a 5,9 & Móveis são deslocados, fendas nas paredes. \\
\hline 6 a 6,9 & Danos nas construções, destruição das casas mais frágeis. \\
\hline 7 a 7,9 & Danos maiores, fissuras no subsolo, canos se rompem. \\
\hline 8 a 8,9 & Pontes destruídas, maioria das construções desaba. \\
\hline 9 ou mais & Destruição quase total das construções, tremor de terra visível a olho nu. \\
\hline
\end{tabular}

Fonte: Degenszajn et al, 2007, p.120

Após apresentarem a fórmula utilizada pela escala Richter $\left(M=\log A-\log A_{0}\right)$ e deduzir a fórmula $M_{1}-M_{2}=\log \left(\frac{A_{1}}{A_{2}}\right)$, que relaciona as magnitudes $\left(M_{1} \mathrm{e} M_{2}\right)$ de dois terremotos em função da amplitude das ondas geradas, os autores comparam o terremoto de 2004 da Indonésia com outro que ocorreu em João Câmara (Rio Grande do Norte) e atingiu 5 graus na escala Richter.

É possível comparar, usando a expressão obtida, as amplitudes das ondas geradas por esse terremoto e pelo terremoto que causou as tsunamis na Ásia (9 graus): João Câmara: $M_{1}=5$ e Tsunami: $M_{2}=9$.

$$
\begin{gathered}
M_{1}-M_{2}=\log \left(\frac{A_{1}}{A_{2}}\right) \Rightarrow 5-9=\log \left(\frac{A_{1}}{A_{2}}\right) \Rightarrow-4=\log \left(\frac{A_{1}}{A_{2}}\right) \\
10^{-4}=\frac{A_{1}}{A_{2}} \Rightarrow \frac{1}{10000}=\frac{A_{1}}{A_{2}} \Rightarrow A_{2}=10000 A_{1}
\end{gathered}
$$

Isto é, as ondas do terremoto que causou a devastação na Ásia são 10000 vezes mais amplas que as do terremoto em João Câmara (DEGENSZAJN et al, 2007, págs. 120 e 121).

Esta abordagem mostra a importância da função logarítmica $M_{l}=\log \frac{A}{A_{0}}$, bem como a aplicabilidade do logaritmo na comparação de diferentes graus na escala Richter, o que permite ter uma ideia da razão pela qual há efeitos diferentes correspondentes a cada número obtido na escala. 
Esta ideia também foi proposta no ENEM (2016), por meio de um problema que questiona sobre a relação entre as energias liberadas pelos terremotos do Japão, em 2011, e da China, em 2013:

Em 2011, um terremoto de magnitude 9,0 na escala Richter causou um devastador tsunami no Japão, provocando um alerta na usina nuclear de Fukushima. Em 2013, outro terremoto, de magnitude 7,0 na mesma escala, sacudiu Sichuan (sudoeste da China), deixando centenas de mortos e milhares de feridos. A magnitude de um terremoto na escala Richter pode ser calculada por

$$
M=\frac{2}{3} \log \left(\frac{E}{E_{0}}\right)
$$

sendo $\mathrm{E}$ a energia, em $\mathrm{kWh}$, liberada pelo terremoto e $E_{0}$ uma constante real positiva. Considere que $E_{1}$ e $E_{2}$ representam as energias liberadas nos terremotos ocorridos no Japão e na China, respectivamente. Disponível em: www.terra.com.br. Acesso em: 15 ago. 2013 (adaptado).

Qual a relação entre $E_{1}$ e $E_{2}$ ? (BRASIL, 2016, p.31).

Pelo enunciado e considerando a mesma ideia de Degenszajn et al (2007), temos que:

$$
\frac{2}{3} \cdot \log \left(\frac{E_{1}}{E_{2}}\right)=9-7=2 \Rightarrow \log \left(\frac{E_{1}}{E_{2}}\right)=3 \Leftrightarrow \frac{E_{1}}{E_{2}}=10^{3} \Leftrightarrow E_{1}=10^{3} \cdot E_{2}
$$

Esse cálculo, envolvendo logaritmos, mostra que a energia liberada no terremoto do Japão, em 2011, é 1000 vezes maior que a energia liberada no terremoto da China, em 2013.

Ainda hoje, é comum o uso da Escala Richter, porém, ela já foi substituída pela Escala de Magnitude de Momento (MMS), pois, segundo Roballo (2014), ela é mais precisa que a Escala Richter.

Conforme Pinheiro (2013), a MMS foi criada em 1975 por Thomas C. Haks e Hiroo Kanamori. Embora as fórmulas da Escala Richter e da MMS sejam diferentes, esta manteve os valores de magnitude definidos pela Richter e é usada para estimar as magnitudes de todos os grandes terremotos modernos.

O símbolo da Escala de Magnitude de Momento é $M_{w}$, em que $w$ significa trabalho mecânico realizado. $M_{w}$ é um número adimensional definido por:

$$
M_{w}=\frac{2}{3} \log \left(M_{0}\right)-10,7
$$

$M_{0}$ é o momento sísmico em dina.centímetro $\left(10^{-7} N . m\right)$. Nesta escala, a magnitude é baseada no momento do terremoto, que é igual à resistência da Terra multiplicada pela quantidade média de deslocamento da falha e o tamanho da área que se deslocou. 
Na MMS, devido à sua formulação, um terremoto é cerca de trinta vezes mais potente para cada grau de diferença. A magnitude 5, por exemplo, é 30 vezes superior que a magnitude 4, ao passo que a magnitude 6 é 900 vezes superior a uma magnitude 4, e assim por diante.

No ENEM (2011) há uma questão sobre a MMS, na qual é necessário aplicar a definição de logaritmos para resolvê-la. A função $M_{w}=\frac{2}{3} \log \left(M_{0}\right)-10,7$ é dada e se pergunta qual foi o momento sísmico $M_{0}$, em dina $\cdot \mathrm{cm}$, do terremoto de Kobe no Japão, ocorrido no dia 17 de janeiro de 1995, cuja magnitude foi de $M_{w}=7,3$.

Para resolver, substituímos $M_{w}=7,3$ na fórmula dada, de tal forma que:

$$
\begin{aligned}
& 7,3=\frac{2}{3} \log \left(M_{0}\right)-10,7 \Rightarrow \frac{2}{3} \log \left(M_{0}\right)=18 \Rightarrow \\
& \Rightarrow \log \left(M_{0}\right)=\frac{18.3}{2}=27 \Rightarrow M_{0}=10^{27} \text { dina.cm. }
\end{aligned}
$$

Verificamos que tanto o ENEM (2011) quanto o ENEM (2016) mostram aplicações da Matemática em relação às escalas Richter e MMS, por meio dos logaritmos, evidenciando o caráter interdisciplinar deste Exame, avaliando a competência que envolve variáveis técnicocientíficas e usando situação-problema cuja modelagem envolve representações algébricas.

\subsubsection{Nível de intensidade sonora}

O nível de intensidade sonora, $\beta$, medido em decibéis $(\mathrm{dB})$, em homenagem a Alexander Graham Bell (1847-1922), é definido em escala logarítmica, segundo Roballo (2014), pelo fato de que o ser humano, possui a particularidade de que sua sensibilidade varia linearmente enquanto que o estímulo respectivo varia exponencialmente. Isso significa que o ouvido só percebe variações de intensidade como lineares, se as amplitudes variarem exponencialmente.

O nível de intensidade sonora $\beta$ é dado por: $\beta=10 . \log \left(\frac{I}{I_{0}}\right) . I$ e $I_{0}$ são intensidades sonoras, em $\left(W / m^{2}\right)$. Normalmente se escolhe $I_{0}=10^{-12} W / m^{2}$, que é a mínima intensidade sonora audível para um ser humano. 


$$
\text { Para } I=I_{0}=10^{-12} \mathrm{~W} / \mathrm{m}^{2} \Rightarrow \beta=10 \cdot \log \left(\frac{10^{-12}}{10^{-12}}\right)=10 \cdot \log (1)=0 \quad \mathrm{~dB}, \quad \text { o } \quad \text { que }
$$
corresponde ao menor nível de intensidade do som na faixa audível humana. Logo, se tomarmos valores de $I$ menores que $10^{-12} \mathrm{~W} / \mathrm{m}^{2}$, teremos $\beta<0 \mathrm{~dB}$, indicando níveis de intensidade sonora abaixo da faixa audível humana.

A tabela 3, extraída do Caderno do Aluno (2014), mostra as intensidades sonoras correspondentes a algumas situações cotidianas:

Tabela 3 - Intensidades sonoras no cotidiano

\begin{tabular}{|c|c|c|c|c|}
\hline Tipo de som & $\begin{array}{c}\text { Intensidade } \\
\left(\mathrm{watt} / \mathrm{m}^{2}\right)\end{array}$ & $\begin{array}{c}\text { Números } \\
\text { proporcionais }\end{array}$ & Medida em bel & Medida em decibel \\
\hline $\begin{array}{c}\text { Som fracamente } \\
\text { audível }\end{array}$ & $10^{-12}$ & 1 & 0 & 0 \\
\hline $\begin{array}{c}\text { Ruído das folhas de } \\
\text { uma árvore }\end{array}$ & $10^{-11}$ & 10 & 1 & 20 \\
\hline Sussurro humano & $10^{-10}$ & $10^{2}$ & 6 & 70 \\
\hline Conversa comum & $10^{-6}$ & $10^{6}$ & 7 & 100 \\
\hline $\begin{array}{c}\text { Barulho dos carros } \\
\text { no tráfego pesado }\end{array}$ & $10^{-5}$ & $10^{7}$ & 10 & 120 \\
\hline $\begin{array}{c}\text { Britadeira manual } \\
\text { usada na rua }\end{array}$ & $10^{-2}$ & $10^{10}$ & 12 & 60 \\
\hline $\begin{array}{c}\text { Som que produz } \\
\text { dor e dano }\end{array}$ & 1 & $10^{12}$ & 6 & 70 \\
\hline
\end{tabular}

Fonte: SEE/SP, 2014 p. 35

Após explicar sobre a percepção humana, em relação ao som, e sobre as unidades de medida de nível de intensidade sonora, bel e decibel, sem fornecer suas respectivas fórmulas, a partir das informações da tabela, o Caderno do Aluno (2014) questiona:

a) Um som de intensidade de 90 decibéis é quantas vezes mais intenso que outro de intensidade de 80 decibéis?

b) Quantos decibéis correspondem a uma britadeira defeituosa, que emite som com intensidade $100 \%$ maior do que o normal (tabela)? (Considere $\log 2 \cong 0,3$.)

c) Qual fórmula relaciona o número $\mathbf{n}$ de béis de um som com sua intensidade sonora I ?

d) Qual fórmula relaciona o número $\mathbf{n}$ de decibéis de um som com sua intensidade sonora I? (SEE/SP, 2014, págs. 35 e 36, grifos do autor).

Para responder o item a), pela tabela podemos inferir que 90 decibéis correspondem a $10^{-3} \mathrm{watt} / \mathrm{m}^{2}$, ao passo que 80 decibéis correspondem a $10^{-4} \mathrm{watt} / \mathrm{m}^{2}$. Com base na pergunta, devemos fazer: $\frac{10^{-3}}{10^{-4}}=10$, que é o número correspondente a quantas vezes o som de 90 decibéis é mais intenso a outro de 80 decibéis. 
No item b), temos que, pela tabela, o som emitido por uma britadeira normal é de 10 béis, que corresponde a intensidade de $10^{10}$ vezes maior do que o som fracamente audível. Segundo a informação dada pelo exercício, a britadeira defeituosa tem intensidade de som $2.10^{10}$ vezes maior do que o som fracamente audível.

Para saber a quantos béis tal intensidade corresponde, escrevemos tal número como uma potência de 10 :

$$
\begin{aligned}
2 \cdot 10^{10}=10^{n} & \Leftrightarrow n=\log 2 \cdot 10^{10}=\log 2+\log 10^{10} \cong \\
& \cong 0,3+10=10,3 \text { béis. }
\end{aligned}
$$

Por fim, podemos deduzir pela tabela que o número obtido, em béis, deve ser multiplicado por 10, a fim de que tenhamos a resposta em decibéis. Logo, o nível de intensidade sonora de uma britadeira defeituosa corresponde a 103 decibéis.

Para responder o item c), a partir das informações da tabela, calculamos o número $\mathrm{n}$ de béis, expressando a razão entre a intensidade $I$ e a intensidade do som fracamente audível por meio de uma potência de 10:

$$
\frac{I}{10^{-12}}=10^{n} \Leftrightarrow n=\log \frac{I}{10^{-12}} \text { (n em béis). }
$$

Segue que $n=10 \cdot \log \frac{I}{10^{-12}}$ relaciona o número $n$ de decibéis de um som com sua intensidade sonora $I$, o que responde o item d).

Esta abordagem do Caderno do Aluno (2014) mostra didaticamente como é possível construir a função $n=10 \cdot \log \frac{I}{10^{-12}}$, a fim de que o aluno possa atribuir significado ao uso da função logarítmica e dos logaritmos nos cálculos associados ao nível de intensidade sonora.

\subsubsection{Música}

No livro didático de Furtado e Rosso Jr. (2011), o capítulo Função Logarítmica é introduzido por um texto que apresenta uma noção básica sobre a aplicação dos logaritmos na música.

Furtado e Rosso Jr (2011) explicam que Pitágoras, 500 anos antes de Cristo, estudava os sons que eram obtidos ao fazer vibrar uma corda. Dividindo sucessivamente a corda em 3 
partes, 4 partes, 5 partes etc, ele padronizou uma primeira escala musical, que para alguns é formada por 5 notas, ao passo que para outros é formada por 7 (dó, ré, mi, fá, sol, lá, si). Porém, na época de Pitágoras, as notas musicais não tinham nome, pois eram representadas apenas por letras.

Segundo Furtado e Rosso Jr. (2011), ele determinou as relações matemáticas que havia entre elas, em que a frequência de vibração caracteriza cada nota musical, assim como as notas obtidas, à maneira pitagórica, geradas por relações aritméticas, produzem, a cada oitava $^{7}$, não as mesmas notas da primeira, mas outras sutilmente desiguais. Essa diferença faz com que cada novo conjunto de notas seja diferente do primeiro, o que permite representar a escala pitagórica por meio de uma espiral, conforme a figura 12:

Figura 12 - Esquema representativo da escala pitagórica

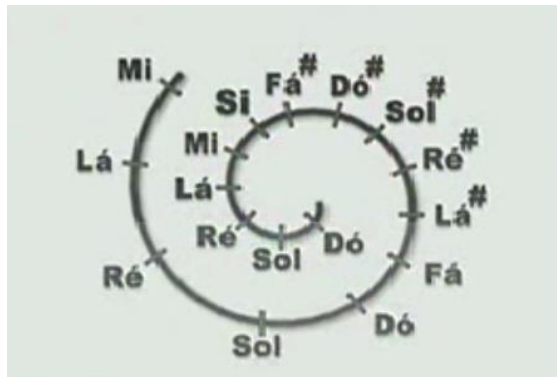

Fonte: http://tvescola.mec.gov.br/tve/video/musicadasesferas

Posteriormente, conforme Furtado e Rosso Jr (2011), na época do compositor alemão Johann Sebastian Bach (1685-1750), surgiu a escala musical na qual o intervalo entre uma nota e outra, de modo diferente da escala formulada por Pitágoras, era dividido entre 12 notas (dó, dó sustenido, ré, ré sustenido, mi, fá, fá sustenido, sol, sol sustenido, lá, lá sustenido, si) com o auxílio dos logaritmos. Nesta escala, denominada temperada ou cromática, as 12 notas estão associadas a logaritmos de base 2 .

Ao adotar o temperamento, obtemos uma escala circular, logo, a espiral fechava e, por mais que o compositor "passeasse" pelas 88 teclas de um cravo, por exemplo, ou posteriormente de um piano, o tom ficava preservado, ao mesmo tempo em que ganhava possibilidades de nuances emotivas quase inesgotáveis. A figura 13 ilustra um esquema representativo da escala temperada ou cromática:

\footnotetext{
${ }^{7}$ Oitava é o nome dado ao intervalo entre duas frequências, cuja razão intervalar é 2.
} 
Figura 13 - Esquema representativo da escala temperada ou cromática

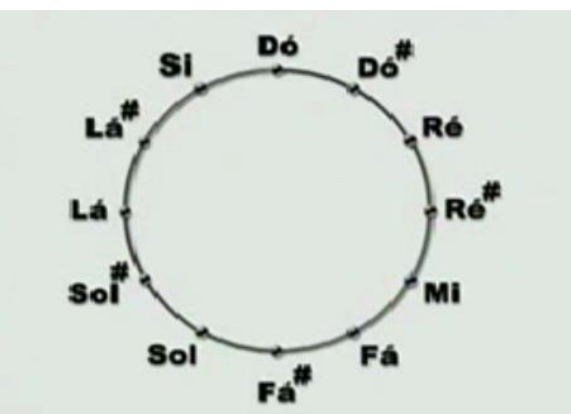

Fonte: http://tvescola.mec.gov.br/tve/video/musicadasesferas

A relação entre logaritmos e música não é aprofundada por Furtado e Rosso Jr. (2011) no decorrer do capítulo Função Logarítmica, porém, esse tipo de introdução serve como motivação ao leitor, ao perceber, por exemplo, que, por meio dos logaritmos, há relação entre a escala musical e a Matemática, o que possibilita uma oportunidade para o aluno estabelecer relações interdisciplinares, cuja abordagem ultrapassa a barreira da educação formal e chega à categoria de atividade cultural.

\subsubsection{Resfriamento de um corpo}

$\mathrm{O}$ resfriamento de um corpo consiste em colocar um objeto aquecido em um meio mais frio, cuja massa seja suficientemente grande, de tal forma que sua temperatura não se altere por causa do objeto aquecido, isto é, a temperatura do meio continuará constante independentemente do objeto ter sido colocado neste meio ou não.

O resfriamento de um corpo obedece à Lei de resfriamento de Newton, que, de acordo com as condições acima, a diferença de temperatura $f$, entre o objeto e o meio que o contém, decresce respeitando uma taxa proporcional à diferença entre as temperaturas.

Conforme Lima (2009), de maneira semelhante à estudada para a lei de desintegração radioativa, podemos mostrar que a lei de resfriamento se expressa por:

$$
f(t)=f_{0} \cdot e^{-k t}
$$

Em que $f_{0}$ é a diferença de temperatura, entre o objeto e o meio que o contém, no instante $t=0, f(t)$ é a diferença de temperatura, entre o objeto e o meio que o contém, num instante $t$ qualquer e $k$ é uma constante que depende do material que constitui o objeto. 
Segundo Lima (2009), a Lei de resfriamento tem validade para expoentes positivos, ou seja, para aquecimento de um corpo colocado em um meio mais quente.

No livro didático de Furtado e Rosso Jr. (2011), há um exercício proposto que trata do resfriamento de um objeto, a partir de uma função exponencial que relaciona a temperatura do objeto com o tempo.

Segundo Newton, a temperatura de um objeto em um meio com temperatura constante (ambiente) é dada por:

$$
T(t)=T_{\text {ambiente }}+c \cdot 10^{k t}
$$

com $t$ em minutos, $k$ e $c$ constantes reais. Sabendo que a temperatura inicial $(t=0)$ do objeto é $80{ }^{\circ} \mathrm{C}$, a do ambiente é $20^{\circ} \mathrm{C}$ e que após 10 minutos a temperatura do objeto é $60{ }^{\circ} \mathrm{C}$, obtenha o valor da constante $k$. Use $\log 2=0,3 \mathrm{e}$ $\log 3=0,48$ (FURTADO e ROSSO JR., 2011, p. 296).

Pelo enunciado temos:

$$
\begin{gathered}
T(0)=20+c=80 \Rightarrow c=60 \Rightarrow \\
\Rightarrow T(10)=20+60 \cdot 10^{10 k}=60 \Rightarrow 60 \cdot 10^{10 k}=40 \Rightarrow \\
\Rightarrow 10^{10 k}=\frac{2}{3} \Leftrightarrow 10 k=\log \frac{2}{3}=\log 2-\log 3=0,3-0,48 \Rightarrow \\
\Rightarrow 10 k=-0,18 \Rightarrow k=-0,018 .
\end{gathered}
$$

Esse tipo de exercício mostra uma adaptação da fórmula que descrevemos anteriormente $\left(f(t)=f_{0} \cdot e^{-k t}\right)$. De fato, interpretando o enunciado, temos:

$$
f(t)=T(t)-T_{\text {ambiente }}, f_{0}=c .
$$

Além disso, substituindo o valor obtido de $k$, em $e^{-k}$ e em $10^{k}$, com o auxílio de calculadora, podemos verificar que:

$$
e^{-(-0,018)}-10^{-0,018}=e^{0,018}-10^{-0,018} \cong 0,06 .
$$

Isso significa que $e^{0,018}$ e $10^{-0,018}$ são relativamente próximos, o que mostra a semelhança entre as funções $f(t)=f_{0} \cdot e^{-k t}$ e $T(t)=T_{\text {ambiente }}+c \cdot 10^{k t}$.

Sem mencionar a Lei de resfriamento de Newton, o ENEM (2016, p. 24) mostra uma questão na qual se aplica o uso dos logaritmos para o cálculo do resfriamento de uma liga metálica. "Uma liga metálica sai do forno a uma temperatura de $3000{ }^{\circ} \mathrm{C}$ e diminui $1 \%$ de sua temperatura a cada 30 min. Use 0,477 como aproximação para $\log _{10} 3$ e 1,041 como 
aproximação para $\log _{10}(11)$ ". A pergunta se refere a qual o tempo necessário, em hora, para que a liga atinja $30^{\circ} \mathrm{C}$, após sua saída do forno.

Denotando $g(t)$ como a função que relaciona a temperatura da liga metálica com o tempo, dadas as condições do enunciado podemos deduzir que:

$$
g(t)=3000 \cdot 0,99^{2 t}
$$

Para determinarmos qual o tempo, em hora, que a liga atinge $30^{\circ} \mathrm{C}$, devemos fazer:

$$
\begin{gathered}
3000 \cdot 0,99^{2 t}=30 \Leftrightarrow 0,99^{2 t}=10^{-2} \Rightarrow \log 0,99^{2 t}=\log 10^{-2} \Rightarrow \\
\Rightarrow 2 t \cdot \log 0,99=-2 \Rightarrow t \cdot\left(\log 99 \cdot 10^{-2}\right)=-1 \Rightarrow \\
\Rightarrow t \cdot\left(\log 3+\log 3+\log 11+\log 10^{-2}\right)=-1 \Rightarrow \\
\Rightarrow t \cdot(0,477+0,477+1,041-2)=-1 \Rightarrow-0,005 t=-1 \Rightarrow t=200 \text { anos. }
\end{gathered}
$$

A partir da interface com a Física, esta questão exige uma interpretação do enunciado para identificar a função exponencial $g(t)=3000.0,99^{2 t}$, bem como requer o uso de propriedades de logaritmo. Isso mostra a importância que é dada pelo ENEM em identificar representações algébricas que expressem a relação entre grandezas, o que torna fundamental o uso dos logaritmos e da função exponencial.

\subsubsection{Engenharia}

Conforme Bazzo e Pereira (2006), o engenheiro é um agente transformador da natureza, que usa seus conhecimentos técnicos para desenvolver e aperfeiçoar mecanismos, produtos, estruturas e processos, a fim de atender as demandas da sociedade.

Engenharia Mecânica, Mecatrônica, Civil, Química, Elétrica, Ambiental, dentre outras, são áreas do saber com leis demonstradas matematicamente. Logo, cabe ao engenheiro estudá-las, compreendê-las e aplicá-las de modo correto, seguro e responsável.

Embarcar num veículo em movimento, que já tem uma trajetória antiga e consolidada, que funciona como um sistema bem-estruturado, com personagens ocupando suas posições nos assentos, não é tão fácil quanto parece. Filmes de aventura, desenhos animados e jogos raramente espelham algum realismo nas suas fantasiosas cenas de heróis e bandidos saltando de um veículo em movimento para outro. Mas na vida real às vezes nem alcançamos o veículo. Quando conseguimos isso, temos dificuldade de nos equilibrarmos na sua carenagem, ou dentro dele. Quando muito, chegamos e mal entendemos as regras do jogo, de onde vem o veículo, como ele funciona, para onde vai, quem ou o que o comanda, onde está o 
manual de operação dos equipamentos de bordo. Enfim, temos de, com rapidez, embarcar, nos desembaraçar dos rituais de chegada, pegar o "jeito da coisa", entender a linguagem utilizada lá dentro, as relações de forças e começar a colher os frutos da viagem, ou quem sabe até contribuir para corrigir o trajeto em curso (BAZZO e PEREIRA, 2006, p.11).

A partir desta perspectiva, destacamos uma questão do ENEM (2015), na qual ilustra um exemplo de um engenheiro que projetou as bordas superiores dos vidros da porta dianteira de um automóvel conforme a curva determinada pela função logarítmica $y=\log (x)$, de acordo com a figura 14:

Figura 14 - Logaritmos no ENEM (2015)

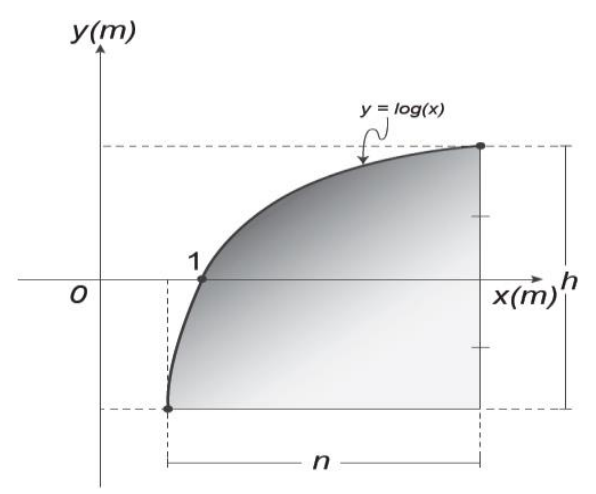

Fonte: Brasil, 2015, p. 24

A forma do vidro foi concebida de modo que o eixo $x$ sempre divida ao meio a altura $h$ do vidro e a base do vidro seja paralela ao eixo $x$. Obedecendo a essas condições, o engenheiro determinou uma expressão que fornece a altura $h$ do vidro em função da medida $n$ de sua base, em metros (BRASIL, 2015, p. 24).

A questão pede para descobrir qual é a expressão determinada pelo engenheiro. Interpretando o enunciado, podemos obter a figura 15 , que é útil na resolução do problema:

Figura 15 - Resolução de questão do ENEM (2015)

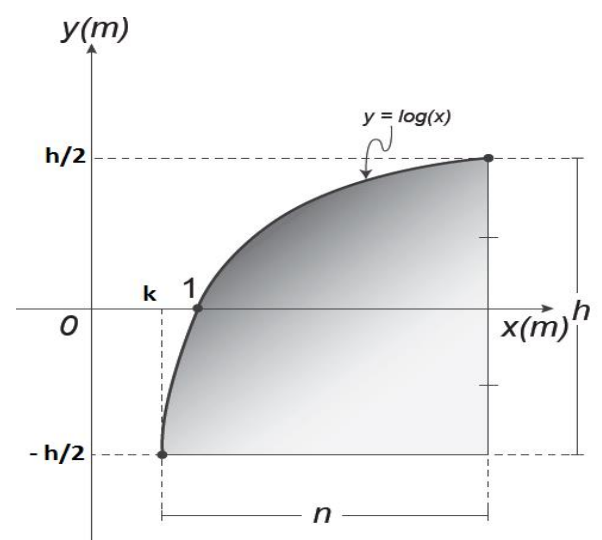

Fonte: Adaptado de Brasil, 2015, p. 24 
A partir da figura 15, podemos resolver o problema do seguinte modo:

$$
\begin{gathered}
\text { I) }\left\{\begin{array} { c } 
{ \operatorname { l o g } ( k + n ) = \frac { h } { 2 } } \\
{ \operatorname { l o g } k = - \frac { h } { 2 } }
\end{array} \Leftrightarrow \left\{\begin{array}{c}
h=2 \cdot \log (k+n) \\
h=-2 \cdot \log k
\end{array} \Rightarrow\right.\right. \\
\Rightarrow 2 \cdot \log (k+n)=-2 \cdot \log k \Leftrightarrow \log (k+n)=-\log k \Leftrightarrow \log (k+n)+\log k=0 \Leftrightarrow \\
\Leftrightarrow \log [(k+n) \cdot k]=0 \Leftrightarrow(k+n) \cdot k=1 \Leftrightarrow k^{2}+n k-1=0 \Rightarrow \\
\Rightarrow k=\frac{-n+\sqrt{n^{2}+4}}{2}, \operatorname{pois}>0 \\
I I) h=2 \cdot \log (k+n)=2 \cdot \log \left(\frac{-n+\sqrt{n^{2}+4}}{2}+n\right) \Rightarrow \\
\Rightarrow h=2 \cdot \log \left(\frac{n+\sqrt{n^{2}+4}}{2}\right)
\end{gathered}
$$

Com esse tipo de questão, o ENEM (2015) ilustra uma de aplicação da Matemática na Engenharia, por meio do uso da função logarítmica, de propriedades de logaritmo e também da resolução de equação do $2^{\circ}$ grau, caracterizando não só o emprego da linguagem matemática em outras áreas do conhecimento, mas também a inter-relação de temas inseridos na mesma disciplina.

A análise das aplicações no contexto da Matemática Escolar evidencia que o logaritmo e a função logarítmica são ferramentas matemáticas que podem propiciar práticas interdisciplinares, que são ressaltadas pelos PCN's (2000), integrando-as na formação dos professores, buscando destacar os significados da linguagem matemática, nas diversas áreas do saber que a utilizam.

Vale a pena lembrar que, lado a lado com uma demarcação disciplinar, é preciso desenvolver uma articulação interdisciplinar, de forma a conduzir organicamente o aprendizado pretendido. A interdisciplinaridade tem uma variedade de sentidos e de dimensões que podem se confundir, mas são todos importantes (BRASIL, 2000, p.8).

Conforme os PCN's (2000), esse caráter interdisciplinar não anula o caráter disciplinar do conhecimento científico, mas sim estimula o estudo da inter-relação entre os fenômenos, o que é primordial para a maior parte das tecnologias, a fim de compreender, por exemplo, 
problemas ambientais, bem como o desenvolvimento de uma visão articulada do ser humano, como construtor e transformador do meio em que vive.

Embora a orientação pedagógica de trabalho com os logaritmos presente na atual Proposta Curricular do Estado de São Paulo tenha resgatado a concepção aritmética dos logaritmos, inclusive por meio das aplicações, esta orientação não é a que tem prevalecido nos livros didáticos brasileiros surgidos a partir da segunda metade da década de 90 até os dias de hoje, o que é possível verificar nos livros de Paiva (1999), Dante (1999) e Almeida et al (2004), por exemplo.

Com isso, apresentamos na próxima seção duas abordagens atuais nas quais predominam a concepção algébrico-funcional, porém, há uma tentativa de resgatar a concepção aritmética, por meio da história dos logaritmos.

\subsection{A concepção aritmética e algébrico-funcional em abordagens atuais}

Primeiramente vejamos o Caderno do Aluno da $1^{\text {a }}$ série do Ensino Médio (2014), fornecido aos alunos da Rede Estadual de Ensino do Estado de São Paulo. Atualmente, o Programa Curricular do Estado de São Paulo situa os logaritmos e a função logarítmica como sub-tópicos de Função Exponencial e Logarítmica, cuja abordagem está presente depois de temas como Progressões Geométricas e Aritméticas, bem como Funções do $1^{\circ}$ grau e $2^{\circ}$ grau. A figura 16 mostra os logaritmos e a função logarítmica inseridos no $3^{\circ}$ bimestre da $1^{\mathrm{a}}$ série do Ensino Médio, segundo o Currículo do Estado de São Paulo (2011):

Figura 16 - Logaritmos e função logarítmica no Currículo do Estado de São Paulo

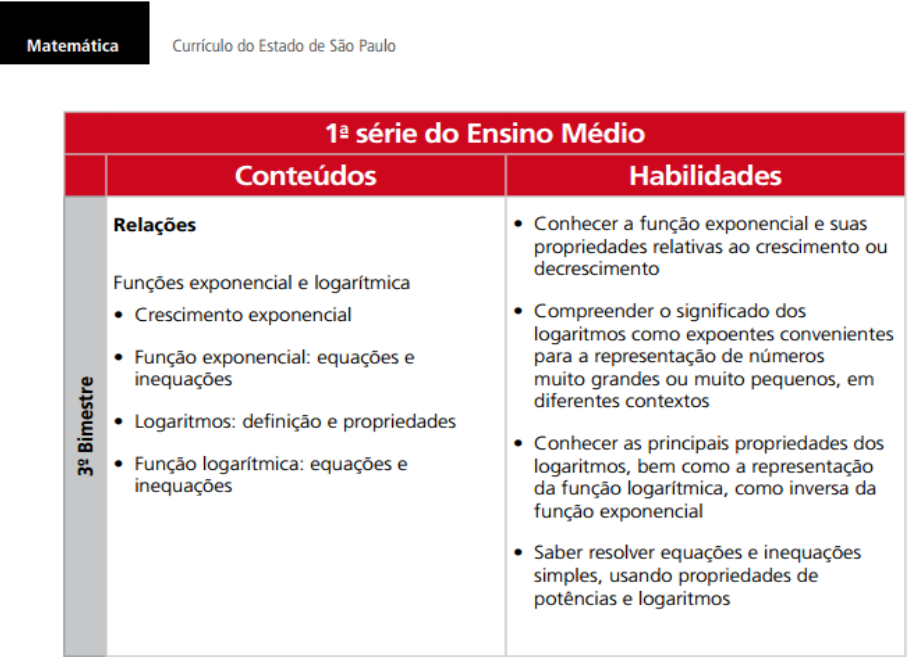

Fonte: SEE/SP, 2011 p. 66 
No Caderno do Aluno (2014), os logaritmos são introduzidos por meio de um breve esboço histórico, destacando a importância do tema no século XVII e nos dias atuais.

A despeito de seu enorme sucesso no século XVII, hoje, em pleno século XXI, os
logaritmos são mais importantes do que o foram no momento de sua criação. Já não
precisamos mais deles para simplificar os cálculos, mas seu significado a força de
sua linguagem tornaram-se fundamentais para a expressão e a compreensão de
fenômenos em diferentes contextos, alguns deles surgidos em pleno século XX: nas
medidas da intensidade sonora, da energia destruidora dos terremotos, do índice de
acidez de um líquido, da rapidez com que uma substância radioativa se desintegra
etc. Sem dúvida, hoje, mais do que antes, aprender logaritmos é fundamental
(SEE/SP, 2014 p. 17).

Mesmo afirmando que hoje não precisamos dos logaritmos para simplificar cálculos, no Caderno do Aluno (2014) há uma preocupação em mostrar ao leitor, por meio da história dos logaritmos, a ideia deste tema sob a concepção de facilitador de cálculos, associando-os inicialmente à concepção aritmética.

Para isso, no início da Situação de Aprendizagem 2, que aborda os logaritmos, é dada a expressão $E=\sqrt[5]{\frac{381,5 \cdot(20,87)^{3} \cdot(4182)^{4}}{(7,935)^{2}}}$. Com a finalidade de mostrar ao aluno como Henry Briggs (1561-1630) ou John Napier (1550-1617) calculariam o número $E$ sem calculadora, o Caderno do Aluno (2014) mostra que a ideia subjacente para resolver esta situação era a seguinte:

- é possível escrever qualquer número positivo $\mathbf{N}$ como uma potência de 10 : $N=10^{n}$

- assim procedendo, o cálculo de uma multiplicação se transforma no cálculo de uma adição (dos expoentes); o cálculo de uma divisão se transforma no cálculo de uma subtração (dos expoentes); o cálculo de uma raiz se transforma no cálculo de uma divisão (do expoente do radicando pelo índice do radical), e assim por diante (SEE/SP, 2014 p. 18, grifos do autor).

A partir dessa ideia, o Caderno do Aluno (2014) mostra que podemos escrever $381,5=10^{a}, \quad 20,87=10^{b}, 4182=10^{c}$ e $7,935=10^{d}$, de tal forma que, usando propriedades de potência, afirmamos que $E=10^{\frac{(a+3 b+4 c-2 d)}{5}}$.

A chave da questão é a representação de qualquer número positivo $N$ como $\mathbf{1 0}^{n}$, o que é fácil quando se tem $N$ igual a 10,100,1000, 10000 etc., mas já não parece tão simples para valores de $N$ como 2, 17, $\sqrt{537}, 30,200$ ou 1932,5, por exemplo.

Não é simples, mas é possível, e esse é o grande mérito dos matemáticos que investiram nesse terreno: a possibilidade de escrever $N$ como $\mathbf{1 0}^{n}$ é equivalente à afirmação de que é possível calcular o valor da potência $\mathbf{1 0}^{x}$ para qualquer número real $\boldsymbol{x}$, e não apenas para os valores inteiros de $\boldsymbol{x}$ (SEE/SP, 2014 p. 18, grifos do autor).

Com isso, os logaritmos são definidos como expoente de uma potência de 10, mas a palavra "base" somente é usada depois do desenvolvimento de alguns exemplos e exercícios, 
quando, então, é apresentada a definição usual de logaritmos, sob a concepção algébricofuncional.

Já vimos que é possível escrever cada número positivo $N$ como uma potência de 10: se $N=\mathbf{1 0}^{n}$, então $n=\log N$.

$\mathrm{Na}$ verdade, pode-se escrever cada número positivo $N$ como uma potência de uma base $\boldsymbol{a}(a>0$ e $a \neq 1)$ que não necessita ser igual a 10 .

De modo geral, se $\boldsymbol{N}=\boldsymbol{a}^{\boldsymbol{n}}$, então dizemos que $\boldsymbol{n}$ é o logaritmo de $\boldsymbol{N}$ na base $\boldsymbol{a}$ e escrevemos: $\boldsymbol{n}=\log _{\boldsymbol{a}} \boldsymbol{N}$ (SEE/SP, 2014 p. 23, grifos do autor).

Depois da conceitualização do tema logaritmos, considerando sua definição e algumas propriedades, o Caderno do Aluno (2014) aborda a função logarítmica a partir de sua associação à função exponencial.

$\mathrm{Na}$ figura 17, notamos que a função logarítmica é identificada por meio de representação gráfica e de sua definição algébrica, caracterizada como inversa da função exponencial.

Figura 17 - A função logarítmica no Caderno do aluno

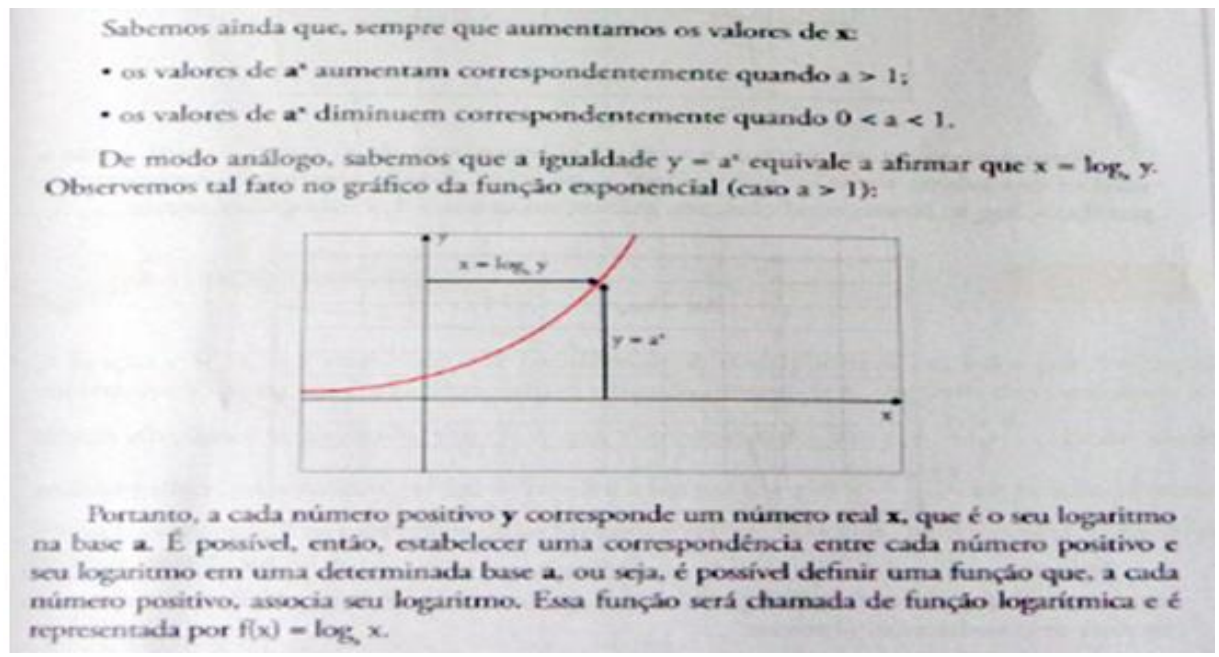

Fonte: SEE/SP, 2014 p. 37

O estudo dos valores de $a$, para os quais $a^{x}$ aumenta ou diminui, permite associar essa ideia, posteriormente, ao estudo do crescimento e decrescimento da função logarítmica, por meio da construção de gráficos.

A fim de aprofundar o estudo dos logaritmos e da função logarítmica, o Caderno do Aluno (2014) mostra a associação desses conteúdos ao uso de software, calculadora, problemas de juros compostos, bem como às aplicações em outras disciplinas, incluindo a utilização da escala Richter, o potencial hidrogeniônico e a intensidade sonora, o que difere esta abordagem, por exemplo, da coleção de Barbosa, Netto e Rocha (1968), na qual a função 
logarítmica não era associada a nenhuma aplicação que os autores propunham, como problemas de Matemática Financeira.

Dado este breve resumo sobre os logaritmos e a função logarítmica no Caderno do Aluno (2014), vejamos um livro didático atual, Conexões com a Matemática 1 (2013), organizado pela Editora Moderna, no qual se evidencia a predominância da concepção algébrico-funcional desde o início da abordagem dos logaritmos, mas também se percebe uma retomada da concepção aritmética no final do capítulo. Neste livro, os logaritmos e a função logarítmica são abordados num mesmo capítulo, intitulado Função Logarítmica.

Antes de definir os logaritmos, é apresentado um exemplo de estudo biológico da multiplicação de uma célula por divisões sucessivas, em que é dada uma tabela (Tabela 4) cujo número $n$ de células está em função da quantidade $t$ de dias.

Tabela 4 - Introdução aos logaritmos

\begin{tabular}{|c|c|c|c|c|c|}
\hline Tempo (t) & 0 & 1 & 2 & 3 & 4 \\
\hline $\begin{array}{c}\text { Número de } \\
\text { células (n) }\end{array}$ & 1 & 2 & 4 & 8 & 16 \\
\hline
\end{tabular}

Fonte: Conexões com a Matemática 1, 2013, p.182

Com isso, é explicado que $n=2^{t}$ é a lei de formação da função que modela essa situação e que, a partir dessa lei, pode ser calculado, por exemplo, quantos dias serão necessários para obtermos 16.384 células.

$n=2^{t} \Rightarrow 16.384=2^{t} \Rightarrow t=14$

Portanto, serão necessários 14 dias para que o número de células seja 16.384 .

$\mathrm{O}$ valor de t é 14 , pois $2^{14}=16.384$. Dizemos que 14 é o logaritmo de 16.384 na base 2 (Conexões com a Matemática 1, 2013, p. 182, grifos do autor).

Os logaritmos são definidos, então, como expoentes, sem que haja alguma associação com a ideia apresentada pelo Caderno do Aluno (2014), na qual os logaritmos são introduzidos como facilitadores de cálculos: "Dados os números reais positivos $a$ e $b$, com $a \neq 1$, o logaritmo de $\boldsymbol{b}$ na base $\boldsymbol{a}$ é o número real $x$ tal que $a^{x}=b$. Ou seja: $\log _{a} b=x \Leftrightarrow$ $\Leftrightarrow a^{x}=b$. O número $b$ é conhecido por logaritmando" (Conexões com a Matemática 1, 2013, p.183, grifos do autor).

Após abordar a definição de logaritmos, as consequências da definição e as propriedades, como a do produto, do quociente e da mudança de base, é apresentada a função 
logarítmica. Com isso, há uma retomada da situação utilizada na introdução do conceito da definição de logaritmos.

Como vimos no início deste capítulo, considerando células que se multiplicam por divisões sucessivas, originando, diariamente, duas células, é possível determinar o número $n$ de células em função da quantidade $t$ de dias por meio da equação $n=2^{t}$. Aplicando o que foi visto sobre logaritmo, é possível escrever uma igualdade que possa ser utilizada para determinar a quantidade $t$ de dias necessários para que se obtenha $n$ células:

$$
n=2^{t} \Rightarrow t=\log _{2} n \text { (Conexões com a Matemática 1, 2013, p. 191). }
$$

Assim, nota-se que a quantidade $t$ de dias é determinada em função da quantidade $n$ de células, o que leva a formalizar a definição de função logarítmica: "Uma função $\mathbb{R}_{+}^{*} \rightarrow \mathbb{R}$ chama-se função logarítmica quando existe um número real $a$, com $a>0$ e $a \neq 1$, tal que $f(x)=\log _{a} x$ para todo $x \in \mathbb{R}_{+}^{*}$ " (Conexões com a Matemática 1, 2013, p. 191, grifos do autor).

Notamos aqui a preocupação de contextualizar a ideia de função logarítmica, por meio de um problema interdisciplinar que ajuda no entendimento da definição. Após a abordagem de sua representação gráfica, bem como de seu crescimento e decrescimento, mostra-se a relação entre a função logarítmica e a função exponencial, conforme a figura 18:

Figura 18 - Relação entre a função logarítmica e a exponencial de Conexões com a

\section{Matemátical}

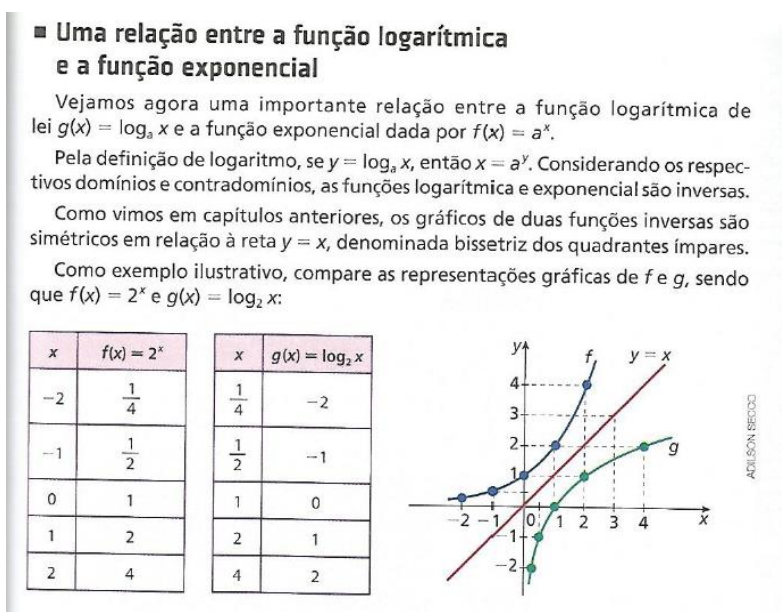

Fonte: Conexões com a Matemática 1, 2013, p.193

Após explorar alguns exemplos e exercícios que buscam retomar conceitos, como cálculo de logaritmo, identificação de uma função logarítmica, análise e construção de gráfico de uma função logarítmica, resolução de situações-problemas que envolvem logaritmos e resolução de equações, sistemas e inequações logarítmicas, há uma seção, denominada 
Modelagem de função logarítmica, que mostra um problema resolvido e comentado, cuja ideia é aplicar o uso do logaritmo para estimar a produção de uma indústria em determinado ano, como mostra a figura 19:

Figura 19 - Aplicações dos logaritmos de Conexões com a Matemática 1

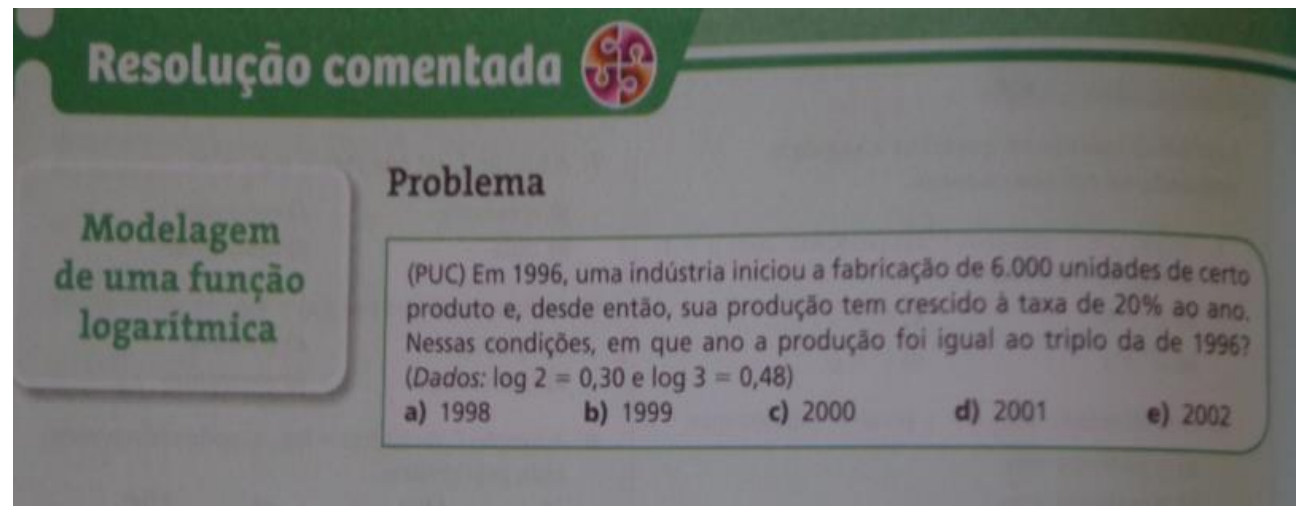

Fonte: Conexões com a Matemática 1, 2013, p.204

No final do capítulo, a história dos logaritmos é apresentada resumidamente, a partir das citações de John Napier, Jost Burgi e Michael Stilfel e da associação entre números sequenciados aritmeticamente e geometricamente, cuja abordagem pode ser verificada principalmente nos livros do final do século XIX e início do século XX, como pudemos ver em Ottoni (1886) e Viana (1910).

Com isso, é dado um exemplo da propriedade do logaritmo de um produto, por meio de uma tabela, ressaltando que Napier e Burgi ampliaram o uso destas tabelas para diversas bases.

A sistematização da teoria dos logaritmos é atribuída a dois matemáticos: o escocês John Napier (1550-1617) e o suíço Jost Burgi (1552-1632).

Antes de Napier e de Burgi, outro matemático, o alemão Michael Stifel (14871567), publicou a obra Arithmetica integra, que continha observações sobre uma relação entre duas sequências numéricas:

Sequência A: $1,2,3,4,5,6,7,8,9, \ldots$.

Sequência B: $2,4,8,16,32,64,128,256,512, \ldots$

Observe que o número 32 na sequência $B$ corresponde ao 5 na sequência $A$; e o número $16 \mathrm{em} \mathrm{B}$ corresponde ao $4 \mathrm{em}$ A. Somando esses dois valores da sequência A, obteríamos $5+4=9$, e o 9 em A corresponde a 512 em B, que é o resultado da multiplicação $32 \cdot 16$.

Propriedade semelhante pode ser obtida com a subtração de dois números em A.

Note que uma utilidade prática dessa ferramenta matemática é a transformação de multiplicações e de divisões em adições e subtrações, respectivamente, que em geral são cálculos mais simples de fazer. Observe ainda que a sequência A contém expoentes das potências de 2 indicadas na sequência $B: 2^{1}, 2^{2}, 2^{3}, 2^{4}, 2^{5}, \ldots$ (Conexões com Matemática 1, 2013, p. 205, grifos do autor).

A partir dessa ideia, é mencionado que os números da sequência A são os logaritmos dos números correspondentes na sequência $\mathrm{B}$, na base 2 , o que caracteriza uma certa retomada 
da concepção aritmética, pois nesta abordagem há a associação dos logaritmos à teoria das progressões.

Notamos assim, que de modo geral, tanto o Caderno do Aluno (2014) como a coleção Conexões com a Matemática 1 (2013) seguem a mesma ordem de abordagem no que se refere aos logaritmos e à função logarítmica. Primeiramente, os logaritmos são apresentados, por meio da contextualização histórica, no caso o Caderno do Aluno (2014), e através de problema do estudo biológico da multiplicação de uma célula por divisões sucessivas, no caso a coleção Conexões com a Matemática 1 (2013). Posteriormente, é conceitualizada a definição de logaritmos, são apresentadas as propriedades e, por fim, é abordada formalmente a função logarítmica.

No Caderno do Aluno (2014), a história dos logaritmos faz parte do desenvolvimento do estudo do tema, no que se refere à simplificação de cálculos aritméticos, o que caracteriza uma retomada da concepção aritmética dos logaritmos, pois, até então, eles não são estabelecidos inicialmente numa equação ou numa função. Embora, posteriormente, seja apresentada a definição usual dos logaritmos como expoentes, sob a concepção algébricofuncional.

Esta maneira de abordar a história dos logaritmos está de acordo com os PCN's+ Ensino Médio (2002), no que se refere à contextualização sócio-cultural:

Compreender o desenvolvimento histórico da tecnologia associada a campos diversos da Matemática, reconhecendo sua presença e implicações no mundo cotidiano, nas relações sociais de cada época, nas transformações e na criação de novas necessidades, nas condições de vida. Por exemplo, ao se perceber a origem do uso dos logaritmos ou das razões trigonométricas como resultado do avanço tecnológico do período das grandes navegações do século 16, pode-se conceber a Matemática como instrumento para a solução de problemas práticos e que se desenvolve para muito além deles, ganhando a dimensão de ideias gerais para novas aplicações fora do contexto que deu origem a elas (BRASIL, 2002, págs. 117 e 118).

Na coleção Conexões com a Matemática 1 (2013), notamos que é exposto um breve resumo histórico no final do capítulo, resgatando a concepção aritmética, por meio da associação dos logaritmos à teoria das progressões, mas não explorando essa ideia no desenvolvimento da abordagem. Além disso, desde sua definição neste livro, os logaritmos são caracterizados como expoentes, sejam numa função ou equação exponencial.

Tanto no Caderno do Aluno (2014) como na coleção Conexões com a Matemática 1 (2013), o tratamento da função logarítmica é dado depois do tema logaritmos, isso mostra 
uma mudança que pode ser verificada a partir da década de 1980 , em relação ao que se estabelecera após a reforma Francisco Campos, em 1931.

As abordagens analisadas são exemplos de que, atualmente, há uma predominância da concepção algébrico-funcional, porém, existe uma tentativa de resgatar a concepção aritmética, a partir da história dos logaritmos. Isso evidencia a inserção do logaritmo e da função logarítmica nos dias de hoje pelo modo como estes conteúdos são apontados pelos PCN's+ Ensino Médio (2002), nos quais o logaritmo deve ser compreendido como instrumento para resolver problemas práticos, mas que também se desenvolve para outras aplicações que estão além do contexto de sua origem.

Apresentamos uma síntese (Tabela 5) dos principais períodos mencionados neste capítulo, considerando suas respectivas observações relativas à inserção dos logaritmos e da função logarítmica como conteúdos da Matemática Escolar brasileira, a partir do tratamento dado, principalmente, pelos livros didáticos.

Tabela 5 - Síntese da inserção dos logaritmos e da função logarítmica na Matemática Escolar brasileira

(continua)

\begin{tabular}{|c|l|}
\hline Período & \multicolumn{1}{|c|}{ Fatos importantes e observações } \\
\hline 1850 até 1912 & $\begin{array}{l}\text { Teoria dos Logaritmos quase sempre presente apenas } \\
\text { no campo da Aritmética; logaritmos associados à teoria } \\
\text { das Progressões. }\end{array}$ \\
\hline \multirow{2}{*}{1893 até 1912} & $\begin{array}{l}\text { Reforma da Educação Brasileira, proposta por } \\
\text { Benjamin Constant, em 1890. Logaritmos aparecem } \\
\text { tanto no campo da Aritmética como no campo da } \\
\text { Álgebra. Nesse período, na década de 1890, Aarão } \\
\text { Reis já abordava a função logarítmica, porém, ele a } \\
\text { denominava como formação logarítmica. }\end{array}$ \\
\hline 1915 & $\begin{array}{l}\text { Os programas oficiais situam os logaritmos } \\
\text { exclusivamente no terreno da Álgebra. }\end{array}$ \\
\hline 1929 & $\begin{array}{l}\text { Introdução do tópico Função Exponencial nos } \\
\text { programas oficiais. }\end{array}$ \\
\hline \multirow{2}{*}{1931} & $\begin{array}{l}\text { Reforma Francisco Campos. Por influência do alemão } \\
\text { Félix Klein, o tópico Função Logarítmica é vinculado à } \\
\text { Função Exponencial. }\end{array}$ \\
\hline \multirow{2}{*}{1936} & $\begin{array}{l}\text { Portaria Ministerial de 17 de março de 1936 - } \\
\text { Programas Propostos para o Curso Complementar. O } \\
\text { estudo das funçóes exponencial e logarítmica é } \\
\text { associado ao Cálculo Diferencial e Integral e à } \\
\text { Geometria Analítica; a concepção algébrico-funcional } \\
\text { dos logaritmos é focada na função logarítmica como } \\
\text { inversa da função exponencial, o que permanece até } \\
\text { hoje. }\end{array}$ \\
\hline
\end{tabular}


Tabela 6 - Síntese da inserção dos logaritmos e da função logarítmica na Matemática Escolar brasileira

(conclusão)

\begin{tabular}{|c|c|}
\hline Período & Fatos importantes e observações \\
\hline $2^{\mathrm{a}}$ metade da década de 1960 & $\begin{array}{l}\text { Movimento da Matemática Moderna. A concepção } \\
\text { algébrico- funcional do logaritmo passa a ser tratada } \\
\text { com mais formalismo; a função exponencial e } \\
\text { logarítmica não mais aparecem associadas à teoria das } \\
\text { progressões e nem com noções de Geometria Analítica } \\
\text { e Cálculo Diferencial e Integral. }\end{array}$ \\
\hline Década de 1980 & $\begin{array}{l}\text { Críticas ao Movimento da Matemática Moderna; } \\
\text { configuração de novas tendências na Educação } \\
\text { Matemática Brasileira. Nos programas oficiais, os } \\
\text { logaritmos aparecem como um sub-tópico da função } \\
\text { exponencial; a função logarítmica é apresentada depois } \\
\text { da teoria dos logaritmos; a concepção algébrico- } \\
\text { funcional de logaritmo como função inversa da função } \\
\text { exponencial continua dominante, assim como } \\
\text { permanece a desvinculação do tema logaritmos da } \\
\text { teoria das progressões e do ensino de Cálculo } \\
\text { Diferencial e Integral. }\end{array}$ \\
\hline Década de 1990 até os dias de hoje & $\begin{array}{l}\text { O estudo dos logaritmos e da função logarítmica é } \\
\text { vinculado às aplicações. Há exemplos de abordagens } \\
\text { que tentam resgatar a concepção aritmética, por meio } \\
\text { da história dos logaritmos, mas predomina a concepção } \\
\text { algébrico-funcional. }\end{array}$ \\
\hline
\end{tabular}

Fonte: Elaborado pelo autor 


\section{CONSIDERAÇÕES FINAIS}

Os resultados desta pesquisa indicam que, no século XIX, os logaritmos eram tratados pelos livros didáticos quase sempre somente no campo da Aritmética, por meio da associação à teoria das Progressões. Porém, a concepção algébrico-funcional do logaritmo também passou a estar presente na Matemática Escolar brasileira a partir do final do século XIX, depois da Reforma da Educação Brasileira proposta por Benjamin Constant, no Decreto ${ }^{\circ}$ 981 de 8 de novembro de 1890.

A partir de então, os logaritmos apareceram oficialmente tanto nos livros de Álgebra como nos livros de Aritmética. Assim, podemos verificar que Reis [189-?] já tratava da função logarítmica, denominando-a como a formação logarítmica, a inversa da formação exponencial.

Depois dos programas oficiais situarem os logaritmos exclusivamente no campo da Álgebra, em 1915, verificamos que, por exemplo, Perez y Marin (1923) já definia explicitamente a função logarítmica como inversa da exponencial, a partir do que ele se referia como definição algébrica do logaritmo.

A partir de então, verificamos algumas abordagens da função logarítmica que, de modo geral, não vinculavam seu uso às aplicações. Isso começou a mudar com as críticas ao Movimento da Matemática Moderna e com a configuração de novas tendências na Educação Matemática brasileira.

Antes da década de 1980, vimos que alguns autores tratavam a Teoria dos Logaritmos, desde suas propriedades até as tábuas de logaritmos, depois da conceitualização da função logarítmica.

Isso mostra a importância do ensino da função logarítmica em períodos anteriores à década de 1980, mas não evidencia seus aspectos utilitários, pois a aplicabilidade dos logaritmos, até este momento, não exigia o conhecimento de conceitos relacionados à função logarítmica, e sim de propriedades de logaritmos, a fim de explorar o uso das tábuas e a conceitualização de característica e mantissa.

Atualmente, nos livros didáticos brasileiros, é muito rara a abordagem em que são utilizadas as tábuas, pois, com o advento das calculadoras e dos computadores, o uso dos logaritmos não ficou restrito somente à ideia de facilitadores de cálculos. 
Hoje verificamos que os livros didáticos, de modo geral, definem os logaritmos, como expoentes, segundo a concepção algébrico-funcional, apresentam as consequências da definição e exploram as propriedades, por meio de exemplos e exercícios.

Após esta abordagem, a função logarítmica é definida como inversa da exponencial, são apresentadas suas principais características e é explorada sua representação gráfica. Os autores atuais geralmente apresentam uma série de problemas interdisciplinares que enfatizam a aplicabilidade da função logarítmica em diversas áreas do conhecimento, como na economia, física, biologia e química.

Em 1614, quando Napier publicou sua obra Mirifici Logarithmorum Canonis Descriptio, sua intenção era facilitar os cálculos extensos provenientes da Astronomia, Navegação e Comércio. Com as contribuições de Gregorius de Saint Vicent, Euler, Leibniz, Newton, Fermat, dentre outros, o logaritmo não é mais concebido somente no campo aritmético, mas passa a também fazer parte da Álgebra, pois aparece como expoente de uma equação ou como função inversa da exponencial, o que caracteriza a concepção algébricofuncional dos logaritmos.

Relacionando isso com o histórico dos logaritmos e da função logarítmica na Matemática Escolar, esta concepção algébrico-funcional ganhou força com a Reforma Francisco Campos, na década de 1930, que teve influência do matemático alemão Félix Klein. A partir da década de 1960, passou a ser tratada de modo mais formalizado e, mesmo com as críticas ao Movimento da Matemática Moderna e as novas tendências da Educação Matemática, atualmente se mostra dominante.

Contudo, a diferença é que no momento atual os logaritmos e a função logarítmica se inserem no contexto da Matemática Escolar com ênfase nas aplicações. Além disso, é possível encontrar exemplos de abordagens recentes que, mesmo com a predominância da concepção algébrico-funcional, tentam resgatar a concepção aritmética, por meio da história dos logaritmos, como a coleção Conexões com a Matemática 1 (2013) e o Caderno do Aluno (2014).

Isso mostra que essas produções didáticas atuais estão de acordo com as orientações dos PCN's+ Ensino Médio (2002), nas quais a percepção da origem do uso dos logaritmos pode conceber a Matemática para a solução de problemas práticos e desenvolver aplicações em outras áreas do conhecimento. 
A partir da perspectiva histórica dos logaritmos na Matemática, verificamos que a definição de logaritmos estava, originalmente, associada à Geometria e, concomitantemente, os logaritmos eram uma ferramenta da Aritmética, pois foram concebidos com a finalidade de facilitar cálculos extensos. Posteriormente, com o desenvolvimento da função logarítmica, percebe-se o logaritmo inserido também no Cálculo Diferencial e Integral.

Em relação à Matemática Escolar brasileira, notamos que, por um determinado período, os logaritmos transitaram tanto na Aritmética, quando o logaritmo era associado à teoria das progressões, como na Álgebra, quando os logaritmos apareceram como expoente numa equação ou como função.

Com isso, acreditamos que este trabalho contribui para a formação do professor, evidenciando o potencial didático dos logaritmos e da função logarítmica como ferramentas matemáticas que transitam em diversos campos, como Geometria, Aritmética, Álgebra e Cálculo, tanto pela perspectiva histórica da Matemática, como também pela análise da inserção de tais conteúdos na Matemática Escolar, por meio dos livros didáticos.

Esta pesquisa caracteriza, portanto, o logaritmo e a função logarítmica como temas que permitem conexões entre diversos conceitos matemáticos e entre diferentes formas de pensamento matemático, o que mostra a relevância cultural dos temas, a partir de suas aplicações e de sua importância histórica no desenvolvimento da Matemática.

Vimos que a invenção dos logaritmos foi de grande importância para o avanço da tecnologia, dando mais rapidez aos cálculos utilizados a partir do século XVI. Porém, suas aplicações tomaram rumos diversos, expandindo dessa forma suas áreas de atuação.

Apesar das calculadoras e computadores terem tornado os logaritmos obsoletos para cálculo, mostramos que seu estudo é muito importante, pois está relacionado a leis matemáticas que descrevem alguns fenômenos naturais, por meio da função logarítmica e de sua inversa, a exponencial, que estão associadas a grandezas cuja taxa de variação a cada instante, é proporcional ao seu valor naquele instante. Exemplos de aplicações desse tipo são:

- Capital empregado a juros compostos.

- Dinâmica de uma população de seres vivos.

- Radioatividade de uma substância. 
Por meio das aplicações e da História da Matemática, notamos que os logaritmos não abrangem somente a visão disciplinar, mas também outros fatores importantes que contribuem para o progresso científico e o avanço tecnológico. Logo, os logaritmos não consistem apenas no modo como são abordados no Ensino Médio. Seu valor aplicativo ultrapassa a forma conceitual e teórica fundamentada pela memorização e resoluções de exercícios repetitivos encontrados em alguns livros didáticos de Matemática.

Assim, acreditamos que, por meio do estudo histórico dos logaritmos e da função logarítmica, abordado no Capítulo 3, bem como pelo estudo das aplicações mencionadas na seção 4.3, este trabalho pode servir como material de apoio ao professor de Matemática do Ensino Médio, no sentido de complementar e ampliar a abordagem dos logaritmos e da função logarítmica no ensino.

Isso mostra que esta pesquisa não se trata apenas de uma investigação em História da Educação Matemática no Brasil, mas também pode ser útil para mostrar as relações entre História da Matemática, História da Educação Matemática e Educação Matemática, uma vez que aponta, ao professor, articulações entre saberes que não se estabelecem de modo simples e estão presentes na Matemática Escolar, como as concepções algébrico-funcional e aritmética, a inserção do logaritmo como função na Matemática e o uso das aplicações.

Dependendo do que o leitor necessita, há muitas maneiras de ler este trabalho. No caso do professor de Matemática do Ensino Médio, ele pode utilizar os exemplos de aplicações para enriquecer as abordagens sobre logaritmos e função logarítmica. Ao futuro professor, este trabalho pode evidenciar as adaptações ou resistências das produções didáticas em relação aos documentos oficiais e correntes pedagógicas de cada época, indicando as permanências e mudanças observadas nos programas curriculares ao longo dos anos.

De modo geral, este trabalho pode servir como fonte de pesquisa a uma prática docente que visa articular o conhecimento histórico da Matemática numa perspectiva interdisciplinar, levando em consideração o tratamento do logaritmo e da função logarítmica em livros didáticos e os aspectos utilitários associados a esses conteúdos na atualidade.

Segundo as Orientações Curriculares para o Ensino Médio (2006), o trabalho interdisciplinar é uma das formas de integrar os conhecimentos inseridos no currículo do Ensino Médio, o que é um desafio para os professores, mas que pode propiciar a contextualização e a integração dos saberes aos alunos. 
Portanto, enfatizamos que o conhecimento dos logaritmos e da função logarítmica não deve ser tratado apenas como conhecimento de inumeráveis regras e técnicas algébricas, ao contrário, é necessária a busca pela compreensão dos conceitos envolvidos e nas suas diversas interpretações, considerando o modo pelo qual esses conteúdos se inserem na Matemática Escolar e reconhecendo suas aplicabilidades em outras áreas do conhecimento. 


\section{REFERÊNCIAS}

ALMEIDA, Fernando Furquim de; CASTANHO, João B; CASTRUCCI, Benedito; CATUNDA, Omar; FARAH, Edison; Matemática Segunda Série - Curso Colegial Clássico e Científico . Série Colegial. $2^{\text {a }}$ edição. vol. 19. São Paulo, Rio de Janeiro, Belo Horizonte, Salvador, Recife, Curitiba, Porto Alegre: Editora do Brasil S/A, 1949.

ALMEIDA, Nilze de; DEGENSZAJN, David; DOLCE, Osvaldo; IEZZI, Gelson; PÉRIGO,

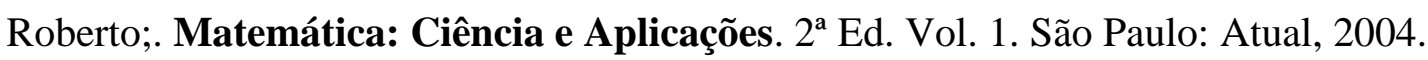

ALONSO, Mônica Machado; ERCOLIN, Eliza Helena; LEME, Fabrício Augusto Aguiar; PINTO, Tânia Cristina dos Guedes; RODRIGUES, Norberto; SÓRIO, Walter Fernandes. Livros Didáticos como fonte de pesquisa para a História da Educação Matemática. Revista Don Domênico. Guarujá - SP: $6^{\mathbf{a}}$ edição - set. 2012. Disponível em: <http://faculdadedondomenico.edu.br/novo/revista_don/artigos6edicao/11ed6.pdf.> Acesso em: 07 jul. 2016.

AMBRÓSIO, Maria Beatriz; MAGALHÃES, Otávio Luciano Camargo Sales; MORALES, Cíntia; PEDRASSOLI, Reginaldo. Uma história da Educação Matemática no Brasil através dos livros didáticos de Matemática dos Anos Finais do Ensino Fundamental, 2003. Disponível em: http://www.mat.ufmg.br/ead/acervo/livros/historia\%20do\%20 ensino\%20da\%20matematica.pdf. Acesso em: 02 dez. 2015.

BARBOSA, Ruy Madsen; NETTO, Scipione Di Pierro; ROCHA, Luiz Mauro. Matemática Curso Colegial Moderno. $2^{\mathrm{a}}$ edição. Vol. 1 - $1^{\mathrm{a}}$ série colegial. São Paulo: Instituto Brasileiro de Edições Pedagógicas, 1967.

BARBOSA, Ruy Madsen; NETTO, Scipione Di Pierro; ROCHA, Luiz Mauro;. Matemática Curso Colegial Moderno. Vol. $2-2^{a}$ série colegial. São Paulo: Instituto Brasileiro de Edições Pedagógicas, 1968.

BAZZO, Walter Antônio; PEREIRA, Luiz Teixeira do Vale. Introdução à engenharia: conceitos, ferramentas e comportamentos. Florianópolis: Editora da Universidade Federal de São Carlos, 2006.

BITTENCOURT, Circe Maria Fernandes. Em foco: história, produção e memória do livro didático. Apresentação. Educação e Pesquisa. V. 30, n.3. São Paulo: FE/USP, 2004. 
BITTENCOURT, Circe Maria Fernandes. Livro didático e saber escolar (1810 - 1910). Belo Horizonte: Autêntica Editora, 2008.

BOngIOVAnNi, Vincenzo. Currículo do sistema Currículo Lattes. Brasília, 03 de dez. 2014. Disponível em:

<http://buscatextual.cnpq.br/buscatextual/visualizacv.do?id=K4771179P3>. Acesso em: 27 de nov. 2016

BONGIOVANNI, Vincenzo; FILHO, Roberto Benedicto Aguiar; NEVES, Vera Lúcia Oliveira das; SILVA, Benedito Cardoso da; TEIXEIRA, José Carlo; Aulas Práticas de Matemática $-\mathbf{2}^{\mathbf{0}}$ grau. Vol. 1. São Paulo: Editora Ática, 1988.

BORTOLI, Adriana de. Uma análise dos livros de André Perez y Marin: Um momento da História da Matemática Escolar Brasileira no início do século XX. Universidade Estadual Paulista "Júlio de Mesquita Filho" - Instituto de Geociências e Ciências Exatas: Rio Claro SP, 2016. Disponível em:

$<$ http://repositorio.unesp.br/bitstream/handle/11449/138873/bortoli_a_dr_rcla.pdf?sequence= 3>. Acesso em: 24 de nov. 2016.

BOYER, Carl. B. História da matemática. Revista por Uta C. Merzbach; Tradução Elza F. Gomide - $2^{\text {a }}$ Ed. São Paulo: Editora Edgard Blucher, 1996.

BRASIL. Decreto 981 de 8/11/1890. Disponível em: <http://www2.camara.leg.br/ legin/fed/decret/1824-1899/decreto-981-8-novembro-1890-515376-publicacaooriginal-1pe.html>. Acesso em 17 de jul. de 2016.

BRASIL. Decreto n$^{\circ} 19890$ de 18 de abril de 1931. Organização do Ensino Secundário. Disponível em: < http://www2.camara.leg.br/legin/fed/decret/1930-1939/decreto-19890-18abril-1931-504631-publicacaooriginal-141245-pe.html>. Acesso em 20 de Nov. de 2015.

BRASIL. Ministério da Educação. Instituto Nacional de Estudos e Pesquisas Educacionais (INEP). Edital no 10, de 14 Abril de 2016 - Exame Nacional do Ensino Médio (ENEM). Brasília, 2016.

Disponível em: <http://download.inep.gov.br/educacao_basica/enem/edital/2016/edital _enem_2016.pdf>. Acesso em: 14 de nov. 2016. 
BRASIL. Ministério da Educação. Instituto Nacional de Estudos e Pesquisas Educacionais (INEP). Exame Nacional do Ensino Médio (ENEM) - Prova de Redação e de Linguagens, Códigos e suas Tecnologias, Matemática e suas Tecnologias. Caderno Azul. Brasília, 2011.

BRASIL. Ministério da Educação. Instituto Nacional de Estudos e Pesquisas Educacionais (INEP). Exame Nacional do Ensino Médio (ENEM) - Prova de Redação e de Linguagens, Códigos e suas Tecnologias, Matemática e suas Tecnologias. Caderno Azul. Brasília, 2013.

BRASIL. Ministério da Educação. Instituto Nacional de Estudos e Pesquisas Educacionais (INEP). Exame Nacional do Ensino Médio (ENEM) - Prova de Redação e de Linguagens, Códigos e suas Tecnologias, Matemática e suas Tecnologias. Caderno Azul. Brasília, 2015.

BRASIL. Ministério da Educação. Instituto Nacional de Estudos e Pesquisas Educacionais (INEP). Exame Nacional do Ensino Médio (ENEM) - Prova de Redação e de Linguagens, Códigos e suas Tecnologias, Matemática e suas Tecnologias. Caderno Azul. Brasília, 2016.

BRASIL. Ministério da Educação. Secretaria de Educação Básica. Orientações Curriculares para o Ensino Médio - Ciências da Natureza, Matemática e suas Tecnologias. Brasília, 2006.

BRASIL. Ministério da Educação. Secretaria de Educação Básica. Parâmetros Curriculares Nacionais Ensino Médio - Ciências da Natureza, Matemática e suas Tecnologias. Brasília, 2000.

BRASIL. Ministério da Educação. Secretaria de Educação Básica. Parâmetros Curriculares Nacionais+ Ensino Médio: Orientações Educacionais Complementares aos Parâmetros Curriculares Nacionais - Ciências da Natureza, Matemática e suas Tecnologias. Brasília, 2002.

BRASIL. Portaria Ministerial de 17 de março de 1936. Sobre Programa proposto para o Curso Complementar. Disponível em: < http://www.jusbrasil.com.br/diarios/2018851/pg-5secao-1-diario-oficial-da-uniao-dou-de-17-03-1936>. Acesso em 13 de Nov. de 2015.

BRITTO, Luciana Patrocínio de. Scipione di Pierro Netto e sua proposta para o ensino da Geometria na Coleção Curso Colegial Moderno. Pontifícia Universidade Católica de São Paulo - PUC/SP. São Paulo, 2008. Disponível em: 
< http://www.dominiopublico.gov.br/download/texto/cp065494.pdf>. Acesso em: 30 de nov. 2016.

CARVAlHO, Thales Mello. Matemática para os Cursos Clássico e Científico. $1^{\mathrm{o}}$ ano. $12^{\mathrm{a}}$ Ed. Companhia Editora Nacional: São Paulo, 1957.

CHERVEL, A. História das disciplinas escolares: reflexões sobre um campo de pesquisa. Teoria \& Educação, Porto Alegre, RS, n.2, 1990.

CHOPPIN, Alain. História dos livros e das edições didáticas: sobre o estado da arte. Revista: Educação e Pesquisa. São Paulo, v. 30, n.3, p.549-566, set/dez.2004.

CLARET, Martin. Dicionário Filosófico - Voltaire. São Paulo: Martin Claret, 2002.

Conexões com a Matemática 1. São Paulo: Moderna, 2013.

CORRÊA, Rosa Lydia Teixeira. O livro escolar como fonte de pesquisa em História da Educação. In: Cadernos Cedes, ano XIX, nº 52, p.11 - 24, Campinas, 2000.

CUNHA, Haroldo Lisbôa da; NETTO, Cesar Dacorso; PEIXOTO, Roberto; ROXO, Euclides. Matemática $2^{\circ}$ Ciclo $-1^{\text {a }}$ série. v.2. Rio de Janeiro, São Paulo, Belo Horizonte: Livraria Francisco Alves, 1944.

CUNHA, Haroldo Lisbôa da; NETTO, Cesar Dacorso; PEIXOTO, Roberto; ROXO, Euclides. Matemática $2^{\circ}$ Ciclo $-2^{a}$ série. v.2. Rio de Janeiro, São Paulo, Belo Horizonte: Livraria Francisco Alves, 1944.

CUNHA, Haroldo Lisbôa da; NETTO, Cesar Dacorso; PEIXOTO, Roberto; ROXO, Euclides. Matemática $2^{\circ}$ Ciclo $-3^{\text {a }}$ série. v.2. Rio de Janeiro, São Paulo, Belo Horizonte: Livraria Francisco Alves, 1944.

CUNHA, Haroldo Lisbôa da; NETTO, Cesar Dacorso; PEIXOTO, Roberto; ROXO, Euclides. Matemática $2^{\circ}$ Ciclo $-\mathbf{1}^{\mathbf{a}}$ série. v.2. Rio de Janeiro, São Paulo, Belo Horizonte: Livraria Francisco Alves, 1959.

CUNHA, Haroldo Lisbôa da; NETTO, Cesar Dacorso; PEIXOTO, Roberto; ROXO, Euclides. Matemática $2^{\circ}$ Ciclo $-2^{a}$ série. v.2. Rio de Janeiro, São Paulo, Belo Horizonte: Livraria Francisco Alves, 1959. 
CUNHA, Haroldo Lisbôa da; NETTO, Cesar Dacorso; PEIXOTO, Roberto; ROXO, Euclides. Matemática $2^{\circ}$ Ciclo $-3^{a}$ série. v.2. Rio de Janeiro, São Paulo, Belo Horizonte: Livraria Francisco Alves, 1959.

DANTE, Luiz Roberto. Matemática: Contexto e Aplicações. $1^{a}$ Ed. vol1. São Paulo: Ática, 1999.

DANTE, Luiz Roberto. Matemática: Contexto e Aplicações. $4^{\mathrm{a}}$ ed. vol1. São Paulo: Editora Ática, 2007.

DEGENSZAJN, David; DOLCE, Osvaldo; IEZZI, Gelson; PÉRIGO, Roberto. Matemática: volume único. $4^{\mathrm{a}}$ ed. São Paulo: Atual, 2007.

DUARTE, Aparecida Rodrigues Silva. Matemática e Educação Matemática: a dinâmica de suas relações ao tempo do Movimento da Matemática Moderna no Brasil. Pontifícia Universidade Católica: São Paulo, 2007. Disponível em:

<http://www.educadores.diaadia.pr.gov.br/arquivos/File/2010/artigos_teses/MATEMATICA/ Tese_Duarte.pdf>. Acesso em: 25 de nov. 2006.

DUARTE, Aparecida Rodrigues S.; OLIVEIRA, Maria Cristina A. de; PINTO, Neuza Bertoni. A relação conhecimento matemático versus conhecimento pedagógico na formação do professor de Matemática: um estudo histórico. Zetetiké - FE - Unicamp - v. 18, nº 33, jan./jun. 2010. Disponível em:

<http://ojs.fe.unicamp.br/ged/zetetike/article/viewFile/2801/2465>. Acesso em: 26 de nov. 2016.

EDWARDS, Charles Henry. The historical Development of the Calculus. New York: Springer Verlag, 1979.

EULER, Léornard. Introductio in analysin infinitorum, 1748. Traduzido para o francês por J. B. Labey.

FURTADO, Patrícia; ROSSO JR. Antônio Carlos. Matemática: uma ciência para a vida, 1. São Paulo: Editora Harbra, 2011.

GÓES, Célia Contin; Netto, Scipione di Pierro. Matemática na Escola Renovada (1 ${ }^{\mathbf{a}}$ série do $2^{\mathbf{o}}$ grau). $3^{\text {a }}$ Ed. São Paulo: Editora Saraiva, 1973. 
GOMES, Maria Laura Magalhães. História do Ensino de Matemática: uma introdução, 2012. Disponível em: <http://www.mat.ufmg.br/ead/acervo/livros/historia\%20do\%20ensino\% 20da\%20matematica.pdf>. Acesso em: 27 nov. 2015.

GUSSI, João Carlos. O Ensino de Matemática no Brasil: Análise dos Programas de Ensino do Colégio Pedro II (1837 a 1931). Universidade Metodista de Piracicaba Faculdade de Ciências Humanas - Programa de Pós-Graduação em Educação. Piracicaba-SP, 2011. Disponível em: <https://www.unimep.br/phpg/bibdig/pdfs/docs/27092011_105018_ tesepdf.pdf>. Acesso em: 17 de jul. 2016.

IMENES, Luis Márcio Pereira; JAKUBOVIC José; TROTTA, Fernando. Matemática Aplicada 1 - 2º Grau. São Paulo: Editora Moderna, 1979.

KATZ, Victor J. A history of mathematics: an introduction. $2^{\text {nd }}$ ed. United States of America: Addison-Wesley Educational Publishers, 1998.

KLEIN, Félix. Matemática Elemental desde um ponto de vista superior. vol. 1. Traduzido para o espanhol por Roberto Araújo. Nuevas Gráficas S.A: Madrid, [19--?].

KUHN, Thomas. A estrutura das revoluções científicas. Tradução: Beatriz Vianna Boeira e Nelson Boeira. São Paulo: 5a edição. Editora Perspectiva S/A, 1998.

LAJOLO, Marisa. Livro didático: um (quase) manual de usuário. Em Aberto, $\mathrm{n}^{\circ}$ 69, ano 16. p. 3 - 9, 1996. Disponível em: <http://www.dominiopublico.gov.br/download/texto/ me001398.pdf>. Acesso em 07 jul. 2016.

LANCILOTTI, Samira Saad Pulchério; LUIZ, Elaine Cristina. "Elementos de Álgebra" de Cristiano Benedito Ottoni: Análise de um instrumento didático do século XIX. Revista HISTEDBR On-line, Campinas, nº 60, p.21-37, dez 2014 - ISSN: 1676-2584. Disponível em: <http://periodicos.sbu.unicamp.br/ojs/index.php/histedbr/article/view/8640546/8105>. Acesso em: 02 de jan. 2017.

LEITE, Neila M. Gualberto; MAGALHÃES, Maycon Luiz A. Equações Diferenciais Aplicadas à Dinâmica Populacional. Anais do Congresso de Matemática Aplicada e Computacional - CMAC Nordeste, p. 351-353. ISSN: 2317-3297. Natal - RN, 2012. Disponível em: <http://www.sbmac.org.br/cmacs/cmac-ne/2012/trabalhos/PDF/294.pdf>. Acesso em: 02 de jan. 2017. 
LIMA, Elon Lages. Logaritmos. $4^{\mathrm{a}}$ ed. Rio de Janeiro: Sociedade Brasileira de Matemática, 2009.

LORENZ, Karl Michael; VECHIA, Ariclê. Os livros didáticos de matemática na escola secundária brasileira no século XIX. História da Educação. ASPHE/FaE/UFPel, Pelotas, n. 15, p. 53-72, 2004. Disponível em: <www.seer.ufrgs.br/asphe/article/download/30280/pdf〉. Acesso em: 24 de nov. 2016.

MAOR, Eli. e: A história de um número. $4^{\text {a }}$ Ed. Rio de Janeiro: Record, 2008.

MIORIM, Maria Ângela; MIGUEL, Antônio. Os logaritmos na cultura escolar brasileira. Natal: SBHMat, 2002.

MOTOKI, Márcia Eiko. Aplicações da Função Logarítmica em sala de aula no Ensino Médio: Uma proposta de solução de problemas pela transposição para a linguagem matemática. Universidade Estadual Paulista "Júlio de Mesquita Filho". Instituto de Biociências, Letras e Ciências Exatas. Presidente Prudente, 2016. Disponível em: $<$ http://repositorio.unesp.br/bitstream/handle/11449/134301/motoki_me_me_prud.pdf?sequen ce=3>. Acesso em: 30 de out. 2016.

MUNAKATA, Kazumi. Livro didático: produção e leituras. In: ABREU, Márcia. Leitura, História e História da Leitura. São Paulo: Mercado de Letras, 1999.

OSSENBACH, Gabriela; SORMOZA, Miguel. Los Manuales Escolares como fuente para la Historia de la Educación en América Latina. Madrid: UNED ediciones, 2001.

OTTONI, C.B. Elementos de Algebra. $4^{\text {a }}$ Ed. Rio de Janeiro: Laemmert e Nicolau AlvesEditores, 1879.

OTTONI, C.B. Elementos de Arithmetica. $7^{\text {a }}$ Ed. Rio de Janeiro: Laemmert e C., LivreirosEditores, 1886.

PAIVA. Manoel. Matemática. Vol. único. 1ª Ed. São Paulo: Moderna, 1999.

PEREZ y MARIN, André. Elementos de álgebra. $5^{\text {a }}$ Ed. Campinas: Escolas Profissionaes do Lyceu Coração de Jesus, 1923. 
PINHEIRO, Bruno de Sena. Logaritmos: uma apresentação contextualizada para Educação Básica. Universidade Estadual do Ceará, Centro de Ciências e Tecnologia. Fortaleza, 2013. Disponível em:

<http://bit.profmat-sbm.org.br/xmlui/bitstream/handle/123456789/982/2011_00671_ BRUNO_DE_SENA_PINHEIRO.pdf?sequence=1>. Acesso em: 30 de out. 2016.

REIS, Aarão. Curso de Matemática II - Álgebra. Volume 2. $2^{\mathrm{a}}$ Ed. Rio de Janeiro: Livraria Garnier, [189-?].

REIS, Aarão. REIS, Lucano. Curso Elementar de Mathemática - Arithmetica. $2^{\mathrm{a}}$ Ed. Rio de Janeiro: F. Alves e Cia, 1892.

RIBEIRO, Denise Franco Capello; VALENTE Wagner Rodrigues. A Matemática dos Cursos Clássico e Científico da Reforma Gustavo Capanema e os livros didáticos. Programa de Estudos Pós-Graduados. Pontifícia Universidade Católica. São Paulo, 2007. Disponível em:

<http://www.pucpr.br/eventos/educere/educere2007/anaisEvento/arquivos/CI-211-14.pdf>. Acesso em: 25 de nov. 2016.

ROBALlO, Murilo Sérgio. Aplicações de funções exponenciais e logarítmicas. Universidade de Brasília -Instituto de Ciências Exatas-Departamento de Matemática. Brasília, 2014. Disponível em:

<http://repositorio.unb.br/bitstream/10482/17315/1/2014_MuriloSergioRoballo.pdf>. Acesso em: 30 de out. 2016.

ROQUE, Tatiana. História da Matemática: uma visão crítica, desfazendo mitos e lendas. Rio de Janeiro: Zahar, 2012.

SCHUBRING, Gert. Análise histórica do livro didático de matemática: notas de aula. Tradução: Maria Laura Magalhães Gomes. Campinas: Autores Associados, 2003

SEE/SP. Secretaria de Estado da Educação de São Paulo. Currículo do Estado de São Paulo: Matemática e suas tecnologias - Ensino Fundamental Ciclo II e Ensino Médio. $1^{\text {a }}$ ed., 2011.

SEE/SP. Secretaria de Estado da Educação de São Paulo. Proposta Curricular. Caderno do Aluno - 1 ${ }^{\text {a }}$ série Ensino Médio Matemática. Vol 2. São Paulo: IMESP, 2014. 
SILVA, Circe Mary S. da. A faculdade de Filosofia, Ciências e Letras da USP e a formação de professores de Matemática. Anais da $23^{a}$ Reunião Anual da ANPED. Caxambu, 2000.

SILVA, Circe Mary S. da. Livro aberto: uma análise histórica. Revista do Programa de Pós-Graduação em Educação Matemática da Universidade Federal de Mato Grosso do Sul, v. 8, Número Temático, p. 378 - 395, 2015.

SILVA, Givanildo Farias da. A reorganização da Matemática Escolar do Colégio em tempos do Movimento da Matemática Moderna. Pontifícia Universidade Católica de São Paulo - PUC: São Paulo, 2008. Disponível em:

< http://livros01.livrosgratis.com.br/cp079343.pdf>. Acesso em: 27 de nov. 2016.

SILVA, Ivo Pereira da. Matemática Escolar da década de 1970: esquecimento, abandono, gestação ou nascimento? Universidade Federal de Mato Grosso - Instituto de Educação Programa de Pós-Graduação em Educação: Cuiabá, 2009. Disponível em:

<http://www.dominiopublico.gov.br/download/texto/cp087557.pdf>. Acesso em: 30 de nov. 2016.

SOARES, Diogo Oliveira. Logaritmos: Napier versus Dante .São Paulo: IFSP, 2012. Disponível em: <https://ifspmatematica.files.wordpress.com/2015/07/tcc_diogo.pdf.> Acesso em: 10 out. 2015.

VALENTE, Wagner Rodrigues. A matemática escolar: epistemologia e história. Revista Educação em Questão - v. 23 - n. 9, p. 16 - 30, maio/ago 2005. Disponível em:

<https://periodicos.ufrn.br/educacaoemquestao/article/view/8340>. Acesso em: 05 dez. 2016.

VALENTE, Wagner Rodrigues. Considerações sobre a Matemática Escolar numa abordagem histórica. Cadernos de História da Educação - nº. 3, p. 77-82, jan./dez. 2004. Disponível em: <http://www.seer.ufu.br/index.php/che/article/viewFile/363/354>. Acesso em: 05 dez. 2016.

VALENTE, Wagner Rodrigues. Livro didático e educação matemática: uma história inseparável. Zetetiké - Cempem - FE - Unicamp - v. 16 - n. 30, p. 139 - 162, jul./dez. 2008. Disponível em: http://ojs.fe.unicamp.br/ged/zetetike/article/viewFile/2518/2277. Acesso em: 06 jul. 2016. 
VALENTE, Wagner Rodrigures. Uma História da Matemática Escolar no Brasil, 1730 1930. São Paulo: Annablume: FAPESP, 1999.

VIANA, José Luiz João. Elementos de Arithmetica. 13ª edição. Rio de Janeiro, São Paulo, Bello Horizonte: Livraria Francisco Alves, 1910.

ZILL, Dennis G. Equações diferenciais com aplicações em modelagem. Tradução Cyro de Carvalho Patarra e Heitor Honda Federico. $2^{\mathrm{a}}$ ed. São Paulo: Cengage Learning, 2011. 